Portland State University

PDXScholar

Summer 8-13-2013

\title{
Substituent Effects on Reactivity and Allergenicity of Benzoquinone
}

Wilbes Mbiya

Portland State University

Follow this and additional works at: https://pdxscholar.library.pdx.edu/open_access_etds

Part of the Chemistry Commons

Let us know how access to this document benefits you.

Recommended Citation

Mbiya, Wilbes, "Substituent Effects on Reactivity and Allergenicity of Benzoquinone" (2013). Dissertations and Theses. Paper 1406.

https://doi.org/10.15760/etd.1406

This Dissertation is brought to you for free and open access. It has been accepted for inclusion in Dissertations and Theses by an authorized administrator of PDXScholar. Please contact us if we can make this document more accessible: pdxscholar@pdx.edu. 
Substituent Effects on Reactivity and Allergenicity of Benzoquinone

by

Wilbes Mbiya

A dissertation submitted in partial fulfillment of the requirements for the degree of

\author{
Doctor of Philosophy \\ in \\ Chemistry
}

Dissertation Committee:

Reuben H. Simoyi, Chair

Paul D. Siegel

Itai Chipinda

Andrea M. Goforth

Bradley A. Buckley

Robert M. Strongin

Shankar Rananavare

Portland State University

2013 
(C) 2013 Wilbes Mbiya 


\begin{abstract}
Benzoquinone $(\mathrm{BQ})$ is an extremely potent electrophilic contact allergen that haptenates endogenous proteins through Michael addition (MA). It is also hypothesized that BQ may haptenate proteins via free radical formation. The objective of this study was to assess the inductive effects (activating and deactivating) of substituents on BQ reactivity and the mechanistic pathway of covalent binding to nucleophilic thiols. The BQ binding by Cys34 on human serum albumin was studied, and for reactivity studies, nitrobenzenethiol (NBT) was used as a surrogate for protein binding of the BQ and benzoquinone derivatives (BQD). Stopped flow techniques were used to determine pseudo-first order rate constants (k) of methyl-, t-butyl-, and chlorine-substituted BQD reactions with NBT, whereas electron pair resonance (EPR) studies were performed to investigate the possible free radical mediated binding mechanism of BQD.

Characterization of adducts was performed using mass spectrometry (MS) and nuclear magnetic resonance spectroscopy (NMR). The rate constant values demonstrated the chlorine substituted (activated) BQD to be more reactive toward NBT, than the methyl and t-butyl-substituted (deactivated) BQD, and this correlated with the respective EPR intensities. The EPR signal, however, was quenched in the presence of NBT suggesting MA as the dominant reaction pathway. MS and NMR results confirmed adduct formation to be a result of MA of NBT onto the BQ ring with vinylic substitution also occurring for chlorine-substituted derivatives. The binding positions on BQ and NBT/BQD stoichiometric ratios were affected by whether the inductive effects of the substituents on
\end{abstract}


the ring were positive or negative. The reactivity of $\mathrm{BQ}$ and $\mathrm{BQD}$ is discussed in terms of the potential relationship to allergenic potency. Hammett and Taft (HT) constants were then used to estimate the influence of these substituents on chemical reactivity. HT values demonstrated chlorine substituted BQD to be more reactive than methyl substituted BQD. BQ and BQD dermal allergenicity, as evaluated in the murine local lymph node assay, (LLNA) was consistent with that predicted by reactivity and HT parameters. These results demonstrate the effect of substituents on $B Q$ reactivity and dermal allergic sensitization, and suggest the potential utility of chemical reactivity data and HT values for electrophilic allergen identification and potency ranking. 


\section{DEDICATION}

This thesis is dedicated to my treasure:

My Lord and Savior Jesus Christ 


\section{ACKNOWLEDGEMENTS}

First and foremost I would like to thank my graduate advisor Prof. Reuben H. Simoyi and my two co-advisors and mentors, Dr. Paul D. Siegel and Dr. Itai Chipinda, for their guidance and invaluable support throughout my studies at Portland State University. Your comments were fruitful, stimulating and enriching.

I would like to thank the members of my dissertation committee: Drs. Bradley A. Buckley, Shankar B. Rananavare, Robert M. Strongin and Andrea M. Goforth for all of their contributions toward the completion of my Ph.D work and requirements. I say a big thank you to the faculty, staff and members of the PSU Chemistry Department for the support I got during studies.

I would also like to express my sincere gratitude to the department for the uninterrupted financial support, to the National Science and Foundation (Grant Number CHE 1056311) and to the NIEHS/NIOSH Inter Agency Agreement (Y1-ES-0001) support in part, all through the years of my study. I finally say a big thank you to Simoyi research group (SRG) members present and past for their advice and support.

To my "best friend” and son Ariel MacWilbes Mbiya, I joined your company when writing my dissertation. My profound gratitude goes to my parents (Ephta Mbiya and Tsitsi Mbiya) and my sisters (Primrose, Linda and Judith) for their trust and for believing in my success. 
Finally and above all, I give all the glory and honor to my Lord and Savior; the King of Kings and the Lord of Lords, Jesus Christ. 


\section{TABLE OF CONTENTS}

ABSTRACT TEDICATION

CHAPTER ONE: INTRODUCTION AND RATIONALE …….................................. 1

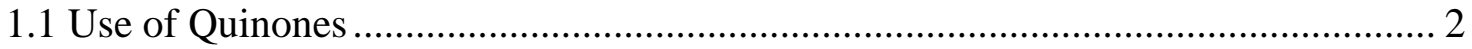

1.2 Development of Allergic Contact Dermatitis....................................................... 3

1.3 Develop Non-animal Based Assays .................................................................. 5

1.4 Reaction Mechanisms of Protein Binding......................................................... 7

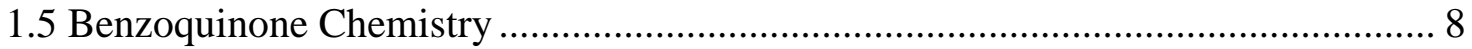

1.5.1 Michael Addition Reactions ..................................................................... 10

1.5.2 Free Radicals in Biology ....................................................................... 12

1.5.3 Conjugation via MA versus Free Radical Mechanism .................................... 12

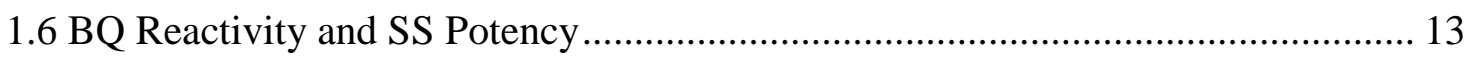

CHAPTER TWO: INSTRUMENTATION, MATERIALS AND METHODS ........ 16

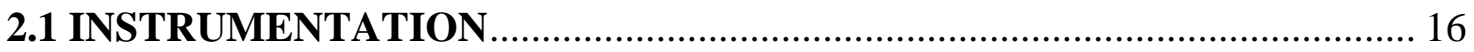

2.1.1 Conventional UV/Vis Spectrophotometry...................................................... 16

2.1.2 Stopped Flow Spectrophotometry ………………………………………..... 16

2.1.3 Nuclear Magnetic Resonance Spectrometry (NMR) Spectroscopy ................. 18

2.1.4 Electron Paramagnetic Resonance (EPR) Spectroscopy ................................... 21

2.1.5 Electrospray-Ionization Mass Spectrometry (ESI-MS) .................................... 23

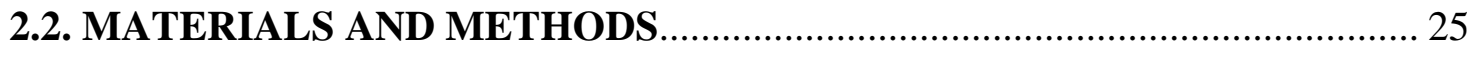

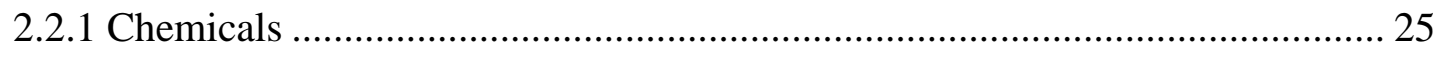




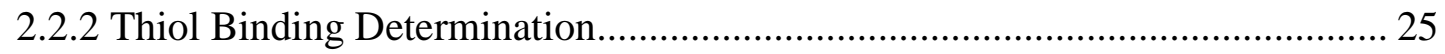

2.2.3 Preparation of Reduced Thiols ................................................................... 27

2.2.4 Extent of BQ Binding to Cys34 in HSA....................................................... 27

2.2.5 Extent of BQ Binding to Primary Amines in HSA ……….............................. 28

2.2.6 Whole Human Fresh Blood Collection and Serum Separation ........................ 28

2.2.7 BQ and BQD Binding Kinetic Studies ........................................................ 29

2.2.8 Sample preparations and solvents used in Electron Paramagnetic Resonance

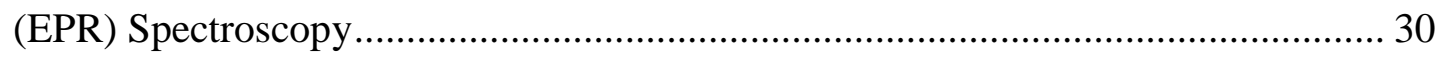

2.2.9 Sample Purification Methods for Samples used for Mass Spectroscopy and Nuclear Magnetic Resonance ……………………........................................ 30

2.2.10 Approach for QSAR Analysis ................................................................... 31

2.2.11 Local lymph node assay ............................................................................ 32

2.2.12 Statistical Analysis ................................................................................. 34

CHAPTER THREE: REACTIVITY AND FREE RADICAL FORMATION......... 35

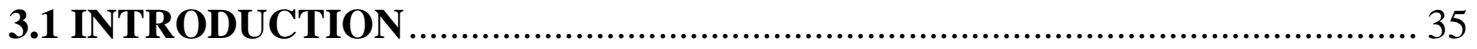

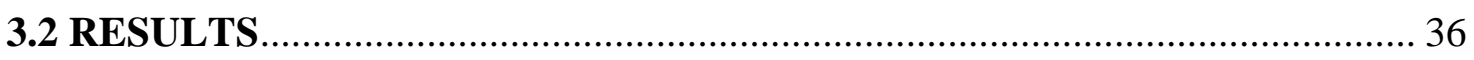

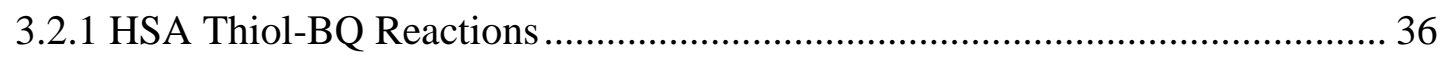

3.2.2 BQ reactivity to Primary Amines in HSA …………………………………... 37

3.2.3 Serum Thiol - BQ Reactivity .................................................................... 38

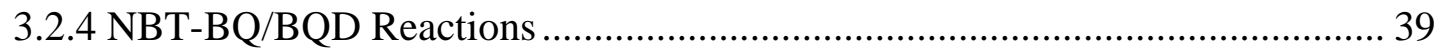

3.2.5 Benzoquinone Derivatives and Free Radical Formation .................................. 47

3.2.6 The Effect of $\mathrm{pH}$ on Radical formation ......................................................... 49

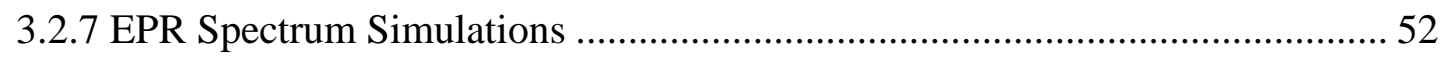

3.2.8 NBT Effect on SQ Radical Formation ………………................................. 53

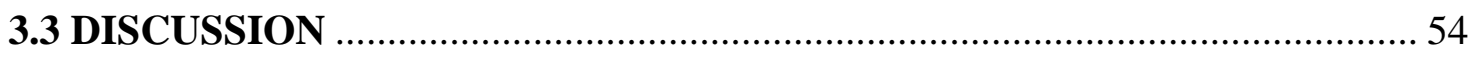

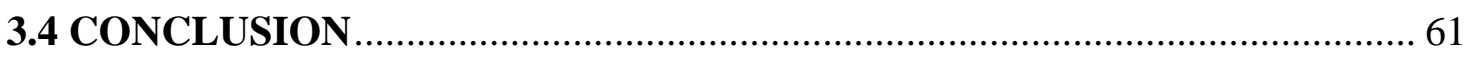

\section{CHAPTER FOUR: CHARACTERISATION OF ADDUCTS AND REACTION}

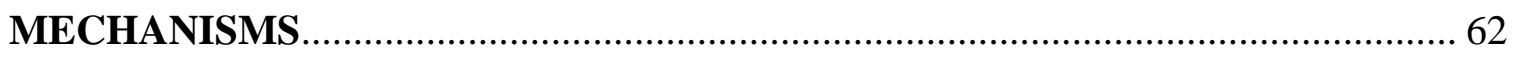




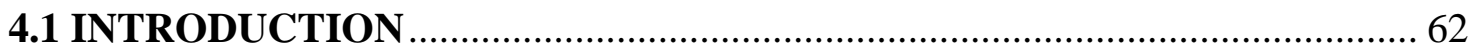

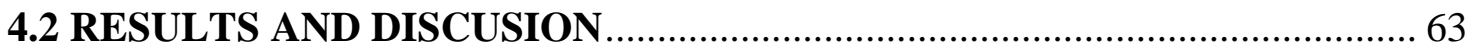

4.2.1 Characterization of BQD-NBT Adducts ............................................................ 64

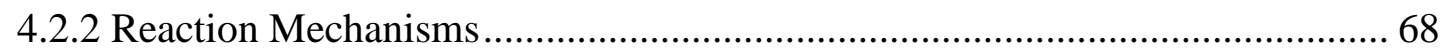

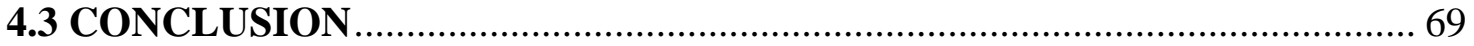

CHAPTER FIVE: LOCAL LYMPH NODE ASSAY AND QUALITATIVE

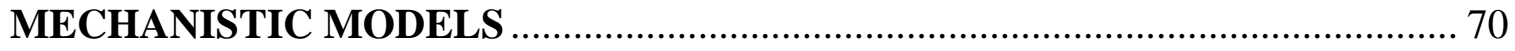

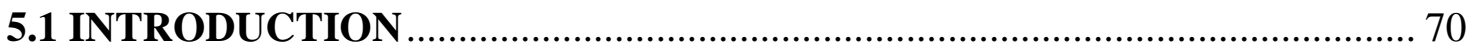

5.1.1 Local Lymph Node Assay …………………………..................................... 70

5.2 RESULTS

5.2.1 LLNA: Allegenicity Assessment ................................................................... 72

5.2.2 Correlation Analysis of Reactivity Data with LLNA EC3 Values................... 77

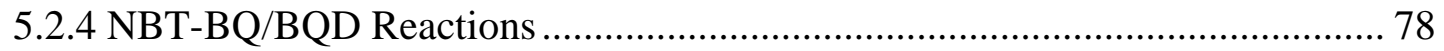

5.2.5 Prediction of EC3 Values from Reactivity Data ………................................ 79

5.2.6 Quantitative Mechanistic Modeling (QMM) ................................................. 80

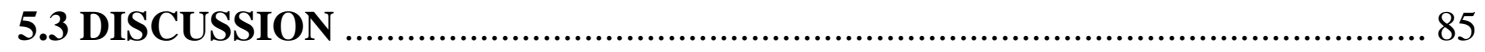

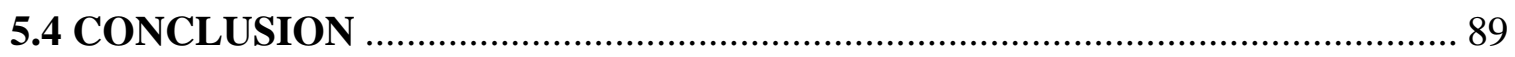

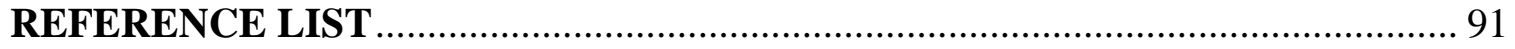




\section{LIST OF TABLES}

Table 1.1: Common Mechanistic Domains ( $\mathrm{Nu}$ is nucleophile and $\mathrm{Pr}$ is for protein)...... 8

Table 3.1: Rate Constants Derived from the Initial Rate Methods for NBT-BQ/BQD

Reactions. 46

Table 3.2: Rate Constants and Half Lives for BQ and BQD at $\mathrm{pH} 7.4$ and 5.5............. 47

Table 3.3: Summary of Peak shift and g-factor Values................................................ 49

Table 5.1: Potency rating of skin sensitizers................................................... 71

Table 5.2: Predicted EC3 Values from Reactivity Data ......................................... 78

Table 5.3: Substituent Constants, $\sigma$ - and $\sigma^{*}$ Used to Calculate Values in Table 5.3 ...... 80

Table 5.4: Calculated $\Sigma \sigma$ - and $\sigma^{*}$ Values Used to Plot Figures 5.5 and 5.6................. 80 


\section{LIST OF FIGURES}

Figure 1.1: Sensitization and elicitation phases of ACD ............................................ 5

Figure 1.2: Shows the uneven distribution of $\pi$-electrons. ......................................... 9

Figure 1.3: Alkylation(by R)and redox cycling of quinone, generating adducts and ROS.

Figure 1.4: Examples of Michael acceptor compounds.......................................... 11

Figure 1.5: Benzoquinone and methyl or t-tert-butyl substituted benzoquinone derivatives and Chlorine substituted benzoquinone derivatives used in this study... 14

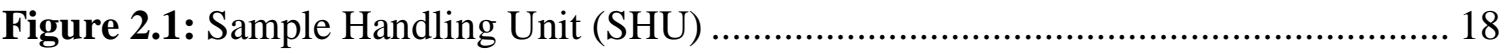

Figure 2.2: Zeeman splitting of the two spin Eigenstates of an electron in an external magnetic field.

Figure 2. 3: Schematic representation of the electrospray ionization(ESI) process....... 23

Figure 3.1: Measurement of BQ binding to HSA Cys34 by loss of DTNB reactivity. . 37

Figure 3.2: Measurement of BQ binding to Serum thiol by loss of DTNB reactivity..... 38

Figure 3.3: Reaction of MBQ with NBT in 50\% acetonitrile in a $\mathrm{pH} 7.4 \ldots \ldots \ldots \ldots \ldots \ldots . . . . . . . . .40$

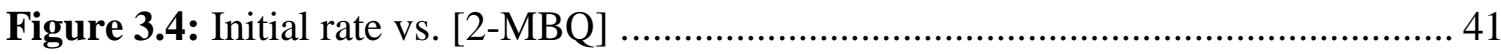

Figure 3.5: Reaction of 2-CBQ with NBT in 50\% acetonitrile in a $\mathrm{pH} 7.4 \ldots \ldots \ldots \ldots \ldots \ldots . . . . . . . .42$

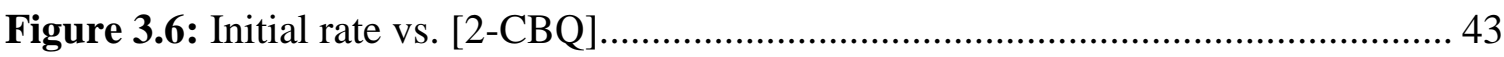

Figure 3.7: Effects of chlorine substitution on BQ on EPR signal intensity .................. 48

Figure 3.8: The relationship between EPR signal intensity and rate constants .............. 50 
Figure 3.9: Schematic routes which lead to DMPO-SQ and DMPO-OH EPR active

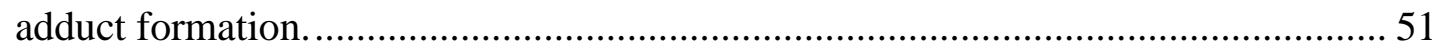

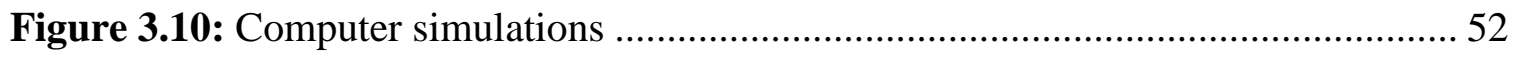

Figure 3.11: Plot of depletion of DMPO-SQ signal versus [NBT] .............................. 54

Figure 4.1: Negative ESI-MS spectra of p-nitrobenzenethiol adduct(s) formation with

CBQ. 65

Figure 4.2: Negative ESI-MS spectra of p-nitrobenzenethiol adduct(s) formation with MBQ.

Figure 5.1: Murine local lymph node assay (LLNA) for BQ and its derivatives (a): BQ,

2-CBQ, 2,5-DCBQ and 2,6-DCBQ,

Figure 5.2:Murine local lymph node assay (LLNA) for BQ and its derivatives :2-MBQ,

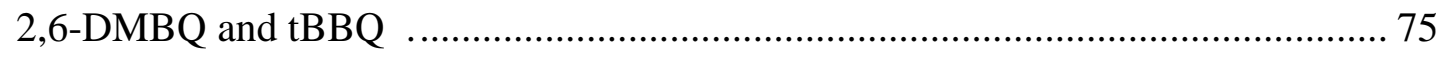

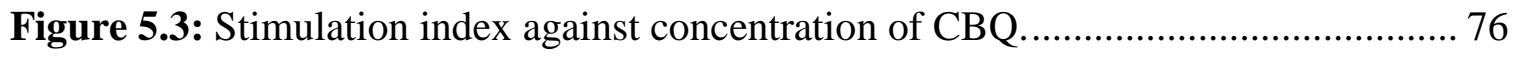

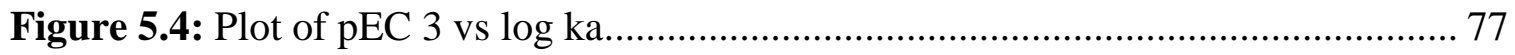

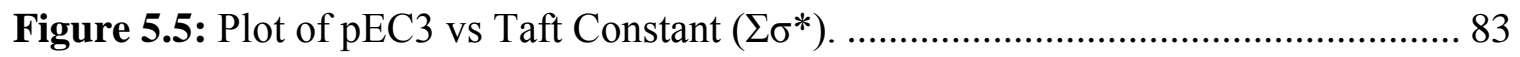

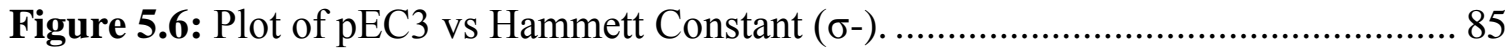




\section{LIST OF SCHEMES}

Scheme 4.1: Reaction mechanisms for electron withdrawing and electron donating

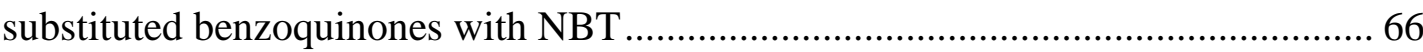

Scheme 4.2: The proposed MA reaction between MBQ and p-nitrobenzenethiol ......... 68

Scheme 4.3: The proposed reaction between CBQ and p-nitrobenzenethiol.................. 68

Scheme 5.1: Michael addition reaction mechanism for methyl/tert-butyl substituted benzoquinone derivatives with thiol containing proteins .................................. 82

Scheme 5.2: Nucleophilic vinylic substitution reaction mechanism for chlorine substituted benzoquinone derivatives with thiol containing proteins 82 


\section{LIST OF ABBREVIATIONS}

2,5-DCBQ

2,5-DMBQ

2,6-DCBQ

2-CBQ

2-MBQ

2-tBBQ

ACD

BQ

BQD

DI

DPM

DTH

DTNB

DTT

EC3

EDG

EPR

EWG

HSA

ICD

LCAOMO 2,5-dichloro-p-benzoquinone

2,5-dimethyl-p-benzoquinone

2,6-dichloro-p-benzoquinone

2-chloro-benzoquinone

2-methyl-p-benzoquinone

2-tertbutyl benzoquinone

allergic contact dermatitis

1,4-benzoquinone ( $\mathrm{p}$-benzoquinone)

benzoquinone derivatives

di-imine

disintegrations per minute

delayed-type hypersensitivity

5,5'-dithiobis-(2-nitrobenzoic acid)

Dithiothreitol

effective concentration inducing a 3 fold stimulation index over

vehicle control

electron donating group

electron paramagnetic resonance

electron withdrawing group

human serum albumin

irritant contact dermatitis

linear combination of atomic orbital -molecular orbital 


$\begin{array}{ll}\text { LLNA } & \text { local lymph node assay } \\ \text { MA } & \text { Michael Acceptor } \\ \text { MHC II } & \text { Major histocompatibility complex 2 } \\ \text { NBT } & \text { 4-nitrobenzenethiol } \\ \text { NEM } & \text { N-ethylmaleimide } \\ \text { PBS } & \text { phosphate buffered saline } \\ \text { PPD } & \text { para-phenylenediamine } \\ \text { SQ } & \text { semiquinone } \\ \text { SS } & \text { skin sensitization }\end{array}$




\section{CHAPTER ONE}

\section{INTRODUCTION AND RATIONALE}

Allergic contact dermatitis (ACD) is caused by a wide range of chemicals after prolonged or repeated contact with the skin. Dermal exposure to chemicals can either be intentional (drugs and cosmetics), or unintentional (environmental pollutants and occupational exposure) resulting in $\mathrm{ACD}$ and other skin disorders which include irritant contact dermatitis (ICD) and in some cases immediate (Type I) allergic reactions (urticarial reactions). In developed countries, $15-20 \%$ of the population is allergic to one or more chemicals in their environment. ${ }^{1}$ Contact allergies are relevant in $20-50 \%$ of recognized occupational contact dermatitis cases and it is estimated that ACD accounts for $7 \%$ of all occupation related diseases. ${ }^{2,3}$ Several hundreds of chemicals have been shown to possess the ability to induce skin sensitization and ACD remains an important occupational and environmental health problem. ${ }^{4}$ There is no cure for ACD, and the pharmacological treatment still only targets the symptoms (e.g., anti-inflammatory corticosteroids). As an acquired disease, ACD is episodic and only avoidance of the offending agent can prevent elicitation of an ACD reaction. ${ }^{5}$ Over 13 million workers in the US are believed to be at risk from exposure to chemicals that are potential skin sensitizers and the level of compensation due to occupational contact dermatitis has been estimated to be greater than $\$ 1$ billion/yr. ${ }^{6}$ The main causes of ACD in the USA are the members of the Rhus genus (poison ivy, poison oak, and poison sumac), 
paraphenylenediamine, nickel, rubber compounds and ethylenediamine hydrochloride..$^{3,5}$ Quinones and quinone derivatives are another large group of chemicals that are widely used and amongst the most common contact allergens. ACD can develop anywhere on the body depending on exposure, but the hands are the sites most commonly exposed to chemicals and are thus most affected.

\subsection{Use of Quinones}

The use of quinone has traditionally been limited to dye production. More recently the utility of quinones has increased and become widespread. Quinones have been reportedly used as analytical reagents, ${ }^{7}$ polymer modifiers, ${ }^{8}$ photoresistors, ${ }^{9}$ and catalysts. ${ }^{10}$ In agriculture they are being used as herbicides, fungicides, and plant-growth regulators. BQ and BQD are broadly used in tanning, dyes, production of chemicals (e.g., hydrogen peroxide), cosmetics and nonprescription forms of skin lightening cosmetics. ${ }^{11-}$

${ }^{13} \mathrm{BQ}$ is also used in hydroquinone production and as an intermediate in the production of a variety of substances, including rubber accelerators and oxidizing agents. ${ }^{14-16}$ To date, pharmaceutical applications of quinones have developed enormously, not only with the discovery of the vitamin $\mathrm{K}$ group, but also as the basic subunit which has found prominent applications in drugs such as antibiotics, ${ }^{11}$ antitumor compounds, ${ }^{17,18}$ and as antimalarial agents. ${ }^{19}$

Quinones are also used extensively in temporary tattoo and hair dyes. The use of temporary tattoos and hair dyeing has become more fashionable, not only among adult women but also among adult men, teenagers, and children. ${ }^{20}$ Adverse skin reactions to 
hair dyes also were reported in about $5 \%$ of individuals who have ever used hair dye and many of the hair dyes contain potent haptens such as para-phenylenediamine (PPD) and related substances. ${ }^{21}$ PPD is believed to be a pro-electrophilic sensitizer (prohapten) which can be oxidized either abiotically or enzymatically to a di-imine (DI), the nitrogen analogue of BQ, which can either act as a Michael acceptor electrophile or undergo hydrolysis to form BQ. Some BQDs, such as 2-tert-butyl-1,4-benzoquinone, are commercially available for use in cosmetics and as insect feeding deterrents on plants. ${ }^{22}$ Quinones are a large class of compounds endowed with rich and fascinating chemistry. ${ }^{23}$ Environmentally, quinones are conserved among living organisms ${ }^{2}$ as they are found in arthropods, bacteria and plants. Quinones also play a pivotal role in biological functions, such as oxidative phosphorylation and electron transfer. Their role as electron transfer agents in primary metabolic processes like photosynthesis and respiration is vital to life. Quinones and quinine derivatives are most widely used as chemical defensive agents by arthropods, millipedes, beetles, arachnids and termites. Due to their industrial utility and natural abundance, it is most likely that the commercial use of quinones is going to persist and become more prominent. A larger percent of the world population will be thus exposed to BQ and BQD due to this widespread use of BQ and its products from homes to agriculture to industries.

\subsection{Development of Allergic Contact Dermatitis}

Development of ACD occurs in two steps (Figure 1.1); the first phase, termed induction or sensitization phase, occurs during the initial exposure to the offending chemical. Upon chemical absorption into the skin, this induction phase involves protein haptenation 
(reactivity), antigen presentation and development of antigen-specific T cells in draining lymph nodes. The second phase, termed elicitation, occurs with re-exposure to the chemical allergen (hapten) resulting in migration of activated antigen-specific $\mathrm{T}$ cells to the site of exposure. Macrophages are recruited to the site of secondary contact, where interactions between T-cells and antigen-presenting cells can take place directly in the epidermis, thus initiating the inflammatory process, as shown in the elicitation stage in Figure 1.1. The allergic reaction is manifested as skin inflammation, edema and eczema. In both phases of $\mathrm{ACD}$, the reaction of a low molecular weight chemical (<5000 Da) with epidermal protein/s resulting in an immunogenic adduct is the molecular initiating event (MIE) leading to immunological induction and elicitation of the allergic pathology.

As such, the chemicals are too small to cause an immune response thus the need to haptenate endogenous proteins or peptides of the skin epidermis. ${ }^{25}$ Lipophilicity $(\log P$ 2) to enable the chemical to pass through the skin epidermis ${ }^{26}$ is a helpful aspect distinguishing skin sensitizers from non-sensitizers. ACD is regarded as a delayed hypersensitivity reaction (type IV hypersensitivity), because the mechanism requires 2472 hours from exposure to full development, where development is mediated by antigenspecific T-lymphocytes. ${ }^{26}$ A number of reviews have discussed the pathogenesis of ACD in greater detail. ${ }^{27-29}$ 


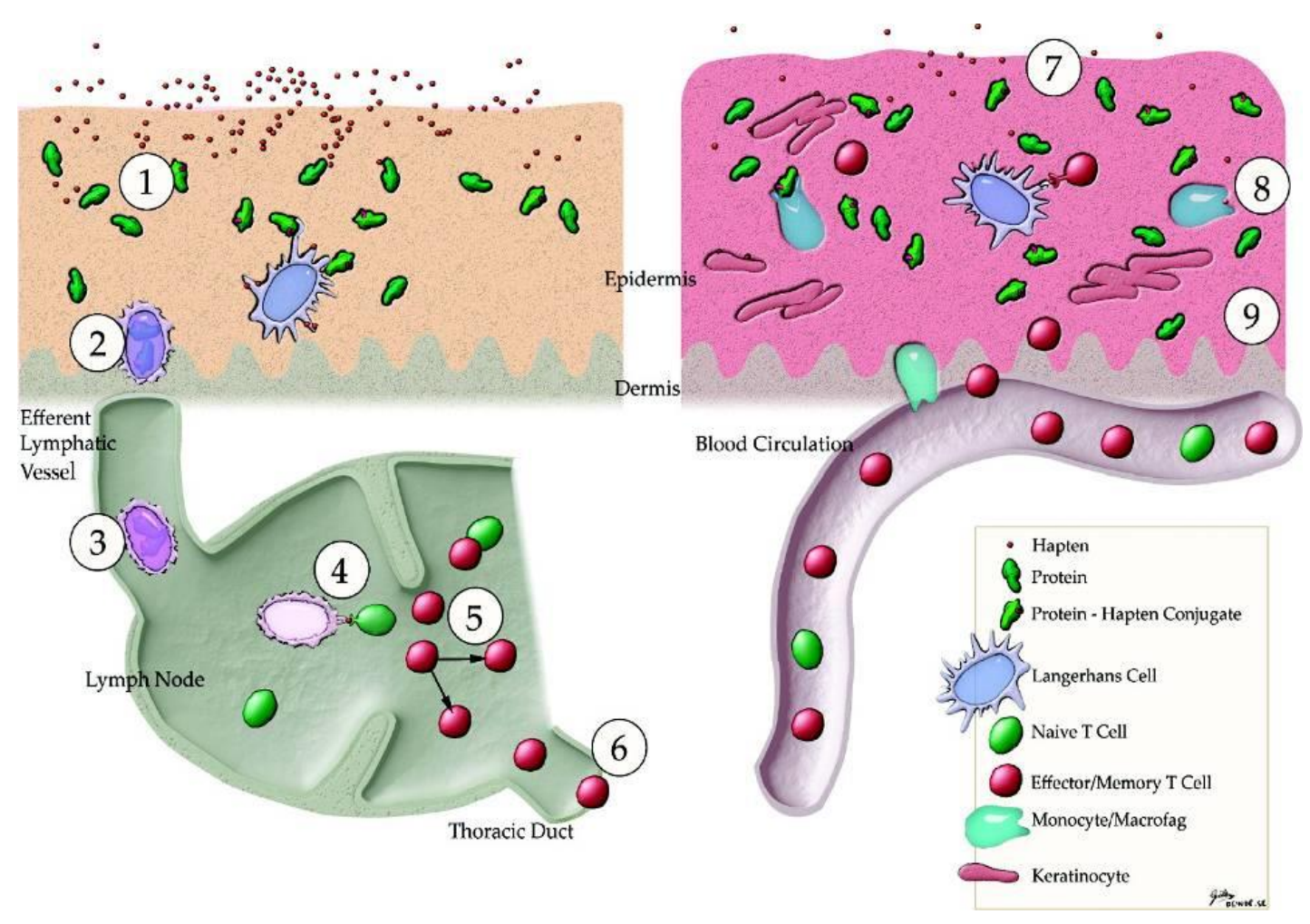

Figure 1.1: (Adapted from Basketter, et al. 2000) ${ }^{24}$ Sensitization and elicitation phases of ACD. (1) Binding of haptens to epidermal proteins and other macromolecules. (2) Internalization of hapten-modified protein by Langerhans cells (LC)s. (3) Hapteninduced activation of LCs that migrate to the lymphatic system and process haptenprotein complexes as they mature into dendritic cells $(D C)$ s. (4) Presentation of the hapten-protein complex (antigen) by DCs to naive T-cells. (5) Proliferation of antigen specific T-cells resulting in formation of memory T-cells. (6) Antigen-specific memory Tcells leave the lymph node and enter the circulation. (7) Re-exposure to the hapten. (8) Release of cytokines and chemokines attracting cells to the skin from the circulation. (9) Inflammatory response within 24-72 hours with resultant symptoms of ACD.

\subsection{Develop Non-animal Based Assays}

It is very important that the safety of all chemicals encountered in occupational settings and as ingredients in consumer products be tested with respect to skin sensitization. Existing animal based assays such as the LLNA, ${ }^{30}$ which is based on the 
proliferation of lymph node cells in the induction phase or the mouse ear swelling test $\left(\mathrm{MEST}^{30}\right.$ and the Guinea Pig Maximization Test (GPMT) ${ }^{31}$ which is based on the observation of the allergic responses in the elicitation phase of $\mathrm{ACD}$, are widely used to screen for allergenic chemicals. Recent mandates in the US and Europe, under which committees such as the Interagency Coordinating Committee for the Validation of Alternative Methods (ICCVAM) $)^{32}$ and the European Centre for Validation of Alternative Methods (ECVAM) ${ }^{33}$ respectively, function, have increased emphasis on the development of non-animal methods for skin sensitization testing. Elsewhere, the Canadian Domestic Substance List, the European Union's Registration, Evaluation, Authorisation and Restriction of Chemicals (REACH) and Cosmetics regulations, the Japanese Chemical Substance Control Law are other legislations that have necessitated the need for alternative methods that are anchored on robust science. ${ }^{34}$ In vitro cellular assays ${ }^{35-37}$ and peptide binding assays ${ }^{38}$ have been reported as potential replacements for animal based assays. The human Cell Line Activation Test (h-CLAT) and the Direct Peptide Reactivity Assay (DPRA) are notable examples of non-animal based assays that have been nominated to ICCVAM and ECVAM, and are undergoing validation before they can be adopted as alternative methods. ${ }^{39}$ Other reactivity assays utilizing cysteine, lysine, glutathione, and several model peptides have been developed and efforts are underway to validate them as alternative in chemico methods for screening skin sensitizers. ${ }^{40-42}$ Despite the headway that some of the current alternative assays have made in providing data that can be utilized to screen sensitizing chemicals with sufficient confidence there are challenges that these current methods have not been able to address including an in-depth understanding of the chemistry behind the reactivity assays. This 
expertise is required to produce qualitative and quantitative data and also for determination of appropriate solvent systems for reactivity assessment. All aspects of reactivity such as selectivity (i.e., toward a particular amino acid target), reaction rate and the stability of the conjugate need to be considered in developing in chemico assays as it is often difficult to determine which aspect is relevant for in vivo potency. While most chemicals with reactive electrophilic centers will form covalent adducts with proteins, mechanistic pathways are different for different chemicals and this may determine the type and strength of adduct formed. The major limitation of the existing models in predicting or screening is their failure to predict the effects that substituents may have on the parent hapten. Do inductive effects result in lack of/decreased or increased skin sensitization potency of the derivative? Can these effects be included in developing an alternative model that can accurately predict potency as shown in the LLNA? The current alternative methods also lack the distinctive categorization of chemicals into their respective mechanistic domains.

\subsection{Reaction Mechanisms of Protein Binding}

Mechanistic domains are functional reaction groups that are targeted as alerting pointers to a chemical's possible reaction with a protein and thus allow classification of chemicals based on their reaction chemistry. There are about 50 specific reactive protein binding mechanisms, ${ }^{43}$ which can be clustered under the general mechanisms shown in Table 1.1, illustrating the common mechanistic domains and the electrophilic centers amenable to nucleophilic attack. More extensive analysis of mechanistic domains, their subcategories and 'special cases (domain not clearly defined or $>1$ domain for a single 
chemical)' have been discussed in recent reviews ${ }^{40,44,45}$ and need to be utilized in categorization of test chemicals.

Table 1.1: Common Mechanistic Domains (Nu is nucleophile and Pr is for protein)

\begin{tabular}{|c|c|c|c|c|}
\hline \multicolumn{5}{|c|}{ Mechanistic Domain } \\
\hline $\begin{array}{l}\text { Michael } \\
\text { Acceptors }\end{array}$ & $\begin{array}{l}\text { Acylating } \\
\text { Agents }\end{array}$ & $\begin{array}{l}\text { Schiff Base } \\
\text { Formers }\end{array}$ & $\begin{array}{l}\mathrm{S}_{\mathrm{N}} \mathrm{Ar} \\
\text { Electrophiles }\end{array}$ & $\begin{array}{l}\mathrm{S}_{\mathrm{N}} 1 / \mathrm{S}_{\mathrm{N}} 2 \\
\text { Electrophiles }\end{array}$ \\
\hline $\begin{array}{l}\mathrm{X} \\
\text { withdrawing } \\
\text { group. }\end{array}$ & $\begin{array}{l}\mathrm{Z} \\
\mathrm{X}=\text { electron } \\
\text { withdrawing } \\
\text { and a good } \\
\text { leaving group. }\end{array}$ & $\begin{array}{l}\text { Attacking } \\
\text { nucleophile is } \\
\text { an amine }\left(\mathrm{NH}_{2}-\right. \\
\text { ) group. }\end{array}$ & $\begin{array}{l}\ldots \mathrm{Y}_{2}, \mathrm{Y}_{1} \\
\mathrm{X}=\text { usually a } \\
\text { halogen or } \\
\text { pseudohalogen. } \\
\mathrm{Y}_{1}, \mathrm{Y}_{2}=\text { electron } \\
\text { withdrawing group. }\end{array}$ & 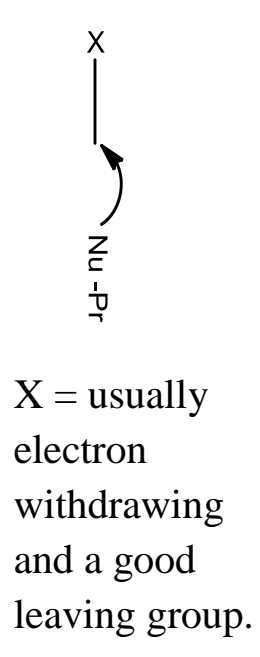 \\
\hline
\end{tabular}

\subsection{Benzoquinone Chemistry}

BQ (which was first synthesized in 1838$)^{46}$ and BQD present an attractive model to study in terms of nucleophile reactivity and the contribution of substituents on the ring to $\mathrm{BQ}$ reactivity and potency. Quinones are conjugated cyclic diketones rather than aromatic compounds. Linear Combination Atomic Orbital-Molecular Orbital (LCAO$\mathrm{MO}$ ) calculations for BQ have shown that the distribution of $\pi$-electron density is very uneven, as depicted in Figure 1.2. 


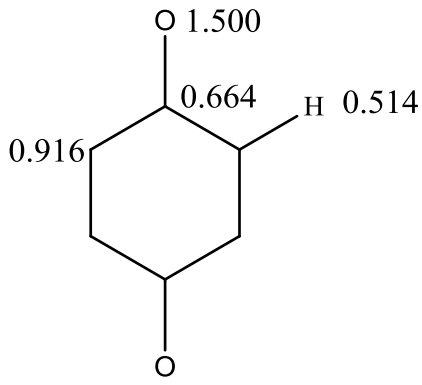

Figure 1.2: Shows the uneven distribution of $\pi$-electrons.

The wide variation in the electron density distribution of quinones explains the broad spectrum of reactivity of this class of compound. In fact, quinones participate in an enormous number of homolytic and heterolytic reactions. ${ }^{47}$ In heterolytic reactions, quinones which are potent oxidizing agents are proposed to be Michael acceptors (MA) and are stabilized by conjugation. Depending on the quinone and the site of reduction, reduction can either re-aromatize the compound or break the conjugation. They can also undergo enzymatic (i.e., P450/P450 reductase) and nonenzymatic redox cycling with their corresponding semiquinone radical and as a result generate superoxide anion radicals (Figure 1.3). ${ }^{48}$

Covalent binding of BQ and BQD species to cellular nucleophiles cause damage. For example, they react readily with sulfur nucleophiles, such as glutathione (GSH) or cysteine residues on proteins, leading to depletion of cellular GSH/thiol levels and/or protein alkylation. In addition, some quinones can react with nucleophilic amino groups on proteins or DNA. ${ }^{48}$ The reactions of BQ and BQD with proteins lead to the formation of covalent bonds with bond energies ranging from 200 to $420 \mathrm{~kJ} / \mathrm{mol}$. ${ }^{44}$ Chemically, the 
skin can best be described as a nucleophilic environment, rich in water and lipids with electron-rich nucleophilic functional groups present on the proteins.

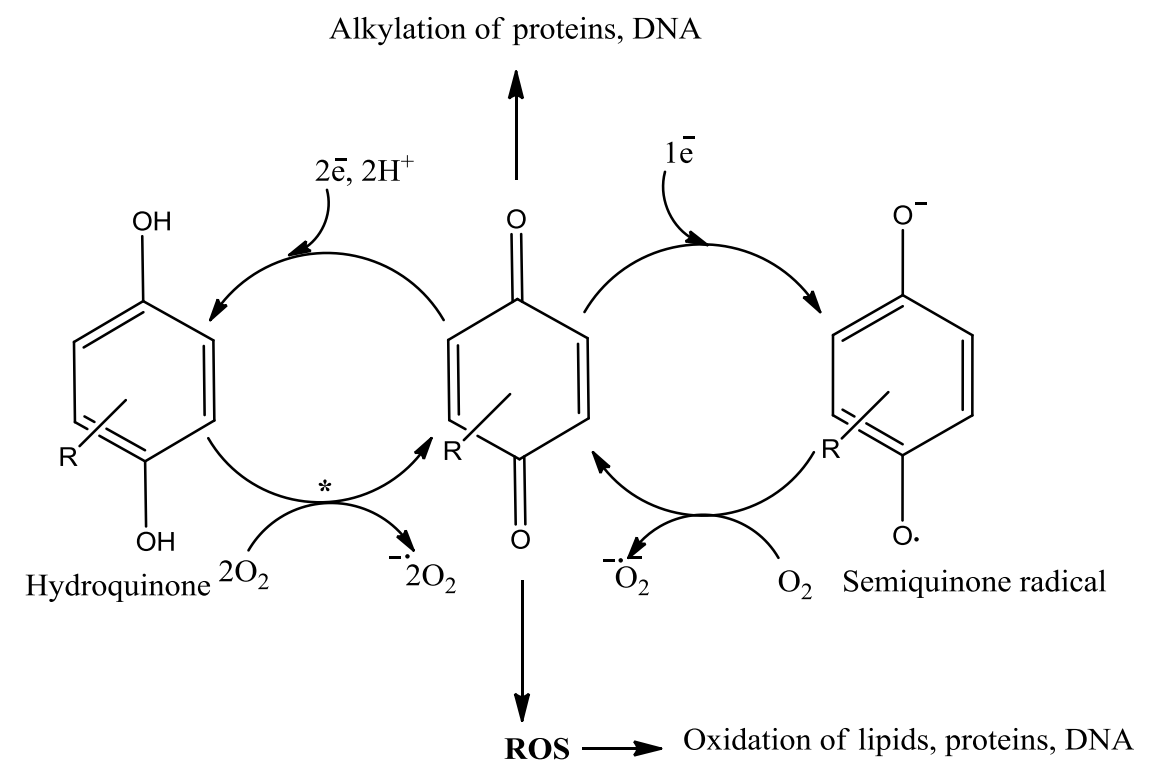

Figure 1.3: Alkylation(by $R$ ) and redox cycling of quinone, generating adducts and ROS. Asterisk indicates that this reaction only occurs for quinones with autoxidase. ${ }^{48}$

\subsubsection{Michael Addition Reactions}

Among the molecular mechanisms that lead to the molecular initiating events of protein alteration is Michael addition, which results in the formation of covalent adducts at a soft electro(nucleo)philic centers without expulsion of leaving groups from the molecules. Electrophiles acting in this manner are typically organic materials that contain olefinic $\pi$-bonds polarized by a neighboring electron-withdrawing substituent. Electro(nucleo)philic interactions of Michael acceptors include the addition of an -SH 
group to the $\beta-$ carbon atom $(\beta-\mathrm{C}$ atom) of a carbon-carbon double $(\mathrm{C}=\mathrm{C})$ or triple $(\mathrm{C} \equiv \mathrm{C})$ bond. Having a polarized $\mathrm{R}$ group and an unsaturated configuration results in a relatively diffuse and polarizable electron density of the olefinic $\pi$-bond, placing Michael acceptors among the softest electrophiles. ${ }^{49}$ Benzoquinone (BQ) is thus chemically reactive as a Michael acceptor electrophile. Identification characteristics of a Michael acceptor include a double or triple bond with an electron-withdrawing substituent $\mathrm{X}$, such as - $\mathrm{CHO}$, $\mathrm{COR},-\mathrm{CO}_{2} \mathrm{R},-\mathrm{CN},-\mathrm{SO}_{2} \mathrm{R}$, or $-\mathrm{NO}_{2},{ }^{50}$ where $\mathrm{R}$ is a hydrocarbon as shown by examples in Figure 1.4.

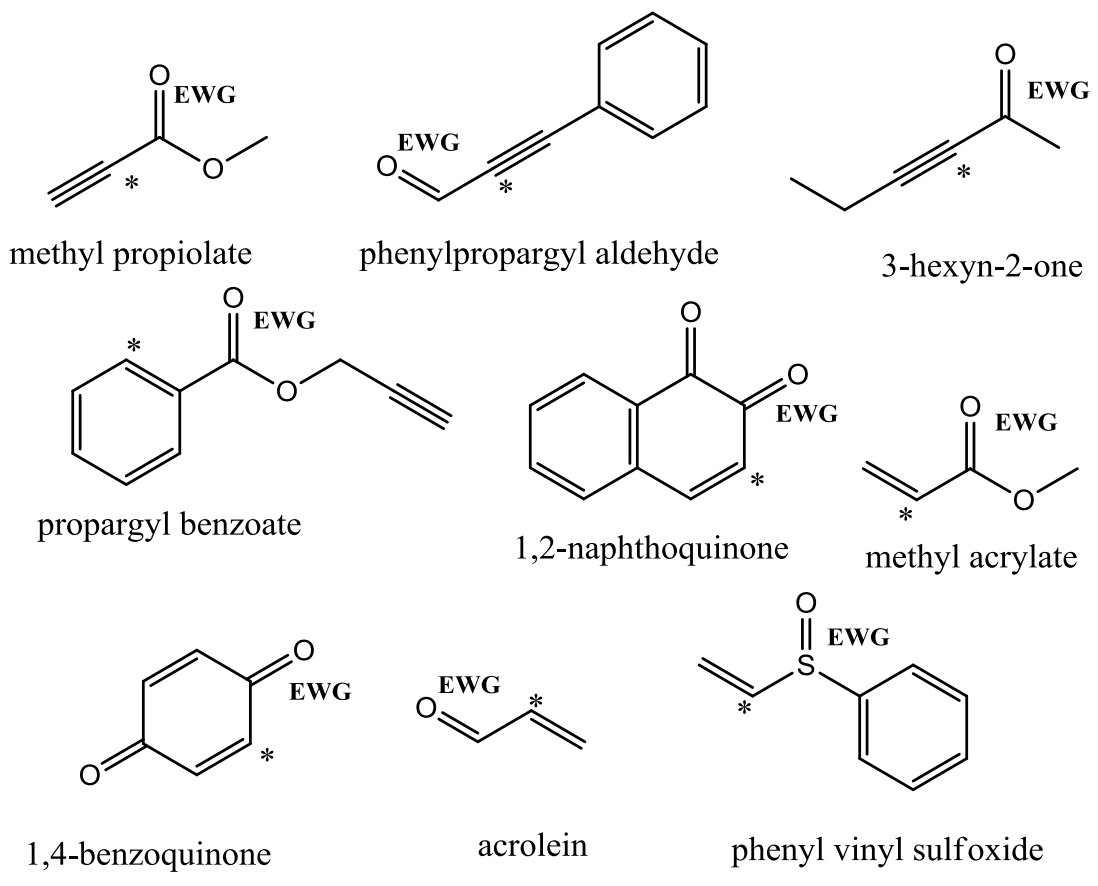

Figure 1.4: Examples of Michael acceptor compounds. 


\subsubsection{Free Radicals in Biology}

Free radicals are reactive atoms, ions or molecules that have an odd number of electrons in one of their orbitals and have the ability of independent existence. ${ }^{50}$ The presence of unpaired electrons makes radicals readily react with a wide range of molecules in a way as to fill their half empty orbitals with electrons. ${ }^{51}$ The mechanism of free radical production is an endless chain, which produces many free radicals that are responsible for oxidative stress in the biological systems.

It has long been known that electron acceptors such as quinine(Q) and its derivatives are reduced in the presence of an electron donor like hydroxide ion $\left(\mathrm{OH}^{-}\right)$to yield the corresponding one-electron reduced radical species and semiquinone radical $\left(\mathrm{SQ}^{\bullet}\right)^{52}$ anions. The semiquinone radicals are strong reducing agents in aqueous solution at physiological pHs and reduce dissolved oxygen to form superoxide and other biologically active reactive oxygen species (ROS) ${ }^{53}$ In relation to ACD, free radical mechanism may be one of the mechanisms through which contact allergens bind proteins even though evidence implicating free radical formation in ACD is scant.

\subsubsection{Conjugation via MA versus Free Radical Mechanism}

The hyperfine coupling constant, $A n$, is directly proportional to the probability of finding the unpaired electron at the nucleus, $n$. Hyperfine couplings observed in EPR spectra of the radical anion of a molecule are also related to the site of reaction of nucleophiles on the neutral molecule. When the unpaired electron is in a conjugated $\pi$ 
molecular orbital consisting of aromatic carbons or hetero atoms, the McConnell equation (equation 1.1) predicts the ${ }^{1} \mathrm{H}$ hyperfine coupling constant, $A_{\mathrm{H}}$ :

$$
A_{H}=Q \rho
$$

where $\mathrm{Q}$ is $25+5 \mathrm{G}$ for carbon, and $\rho$ is the unpaired $\pi$-electron density at the aromatic carbon nucleus to which the $\mathrm{H}$ atom is bonded. This means that the hyperfine couplings are related to the spin densities at a given site through the McConnell equation. ${ }^{54}$ The singly occupied orbital of the radical anion is the lowest unoccupied molecular orbital (LUMO) of the neutral molecule. Thus, the site of largest hyperfine coupling in the radical anion is also the site of attack of a nucleophile on the neutral molecule. This means that there is a relationship between MA and radical anions, ${ }^{55}$ and the studies herein investigate this link.

\subsection{BQ Reactivity and SS Potency}

The use of in vivo methods to screen allergenic chemicals requires a large number of animals. Thus, the goal of these reactivity studies is to enable screening of chemicals for skin sensitizing potential without or with minimal use of animals. Epidermal absorption of a chemical and its subsequent reactivity is influenced by physicochemical parameters, such as octanol-water partition co-efficients and substituent effects.

Measuring reactivity rates is a direct way of quantifying the contribution of physicochemical parameters, which could otherwise be estimated mathematically from the known mechanism of action, applying established principles of chemistry. ${ }^{56}$ In this study, the derived reactivity constants were correlated with skin sensitization potency, 
quantified by the murine LLNA data on BQ and BQD electrophiles. Another set of predicted EC3 values from a quantitative mechanistic model (QMM) was based on the Hammett $\left(\sigma^{-}\right)$values for the activating and deactivating groups and the Taft $\left(\sigma^{*}\right)$ values for the leaving group. These values were integrated into the QMM equations for Michael acceptors to predict the EC3 values for the BQD. Thus the other aim in this study is to gather further evidence regarding the role of reaction chemistry in determining skin sensitization potency, by developing a targeted QMM for LLNA data on BQD which are in MA domain.

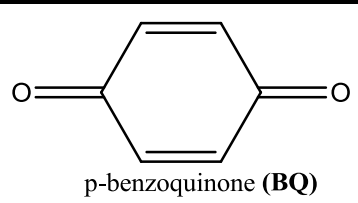

(2)

\section{Electron Donating Substituents}<smiles>CC1=CC(=O)C=CC1=O</smiles>

2-methylbenzoquinone (MBQ)

(3)

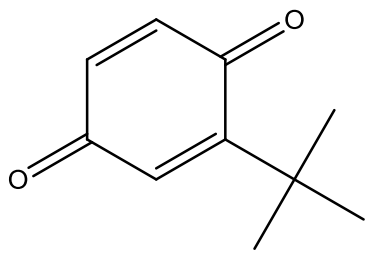

2-tertbutylbenzoquinone (tBBQ)

(4)

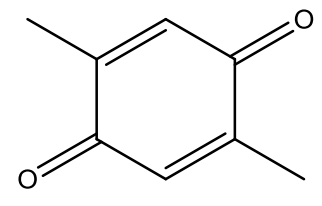

2,5-dimethylbenzoquinone (DMBQ)

(8)

\section{Electron Withdrawing Substituents}<smiles>O=C1C=CC(=O)C(Cl)=C1</smiles>

2-chlorobenzoquinone (CBQ)

(5)<smiles>O=C1C=C(Cl)C(=O)C=C1Cl</smiles>

2,5-dichlorobenzoquinone (2,5-DCBQ)

(6)

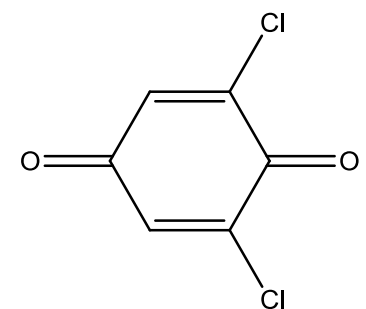

2,6-dichlorobenzoquinone (2,6-DCBQ)

(7)

Figure 1.5: Benzoquinone and methyl or t-tert-butyl substituted benzoquinone derivatives and Chlorine substituted benzoquinone derivatives used in this study. 
In order to analyze how chemical reactivity and sensitizing capability depend on the structure of the contact allergen BQ, a series of structural derivatives of BQ (Figure 1.5) was used. Their reactivity was evaluated via experiments with a thiol (NBT) and changes in absorbance due to depletion of thiol were monitored. To investigate if the sensitizing potency of these analogues is related to their reactivity an animal model (LLNA) was used.

The goal of this project was to investigate and determine the inductive effects of substituents on benzoquinone reactivity and subsequent skin sensitizing potency. The inductive effects on BQD were used to develop a chemical reactivity based predictive model for skin sensitization, which was evaluated using the murine local lymph node assay (LLNA), a well accepted assay for allergen identification. The aims of this thesis were; (i) to determine the potential reaction mechanisms and the relative rate constants of $\mathrm{BQ}$ and $\mathrm{BQD}$ binding to NBT as a surrogate for protein haptenation and (ii) to perform LLNA for BQ and BQD to test the predictive power of the reactivity data and the potential utility of the reactivity approach as an alternative method for identification of skin sensitizers and potency assessment. The reactivity constants determined in (i) were used to predict the LLNA EC3 (threshold dose) values for the BQD. Using BQ as a positive control, the LLNA for six BQD ( 3 with electron withdrawing groups +3 with electron donating groups) was performed and the determined EC3 values compared with the predicted EC3 values from a previously published reactivity assay. ${ }^{57}$ Finally the BQD were ranked according to their skin sensitization potency was performed. 


\section{CHAPTER TWO}

\section{INSTRUMENTATION, MATERIALS AND METHODS}

\subsection{INSTRUMENTATION}

\subsubsection{Conventional UV/Vis Spectrophotometry}

Reactions which occur in minutes were measured using either a Perkin Elmer Lambda 25 UV/Vis spectrophotometer or a Beckman DU800 both featuring a doublebeam, total reflection system within the range 200 to $800 \mathrm{~nm}$. For instruments, holographic grating was used as the monochromator and two radiation sources, a deuterium lamp (UV) and a halogen lamp (visible range) were used in sequence as the polychromator light sources. The Perkin Elmer spectrophotometer was interfaced to a Pentium III computer and uses the UV WinLab Software for data collection and analyses while the Beckman spectrophotometer is interfaced to an IBM PC computer and used the DU Series 800 Software. Path length of the cuvette was $1 \mathrm{~cm}$. The Beckman spectrometer gave the option of using either a single cell holder or a multi-cell holder (maximum of 6), depending on the experiment. Constant temperature was maintained by use of a circulating water bath attached to the cell holders.

\subsubsection{Stopped Flow Spectrophotometry}

All rapid reactions (with time scales as short as 2-10 seconds) were measured using the stopped-flow technique, which can follow reactions with time scales as short as 
milliseconds. The Hi-Tech Scientific SF61 - DX2 Double mixing stopped-flow spectrophotometer was used for the acquisition of absorbance data. The instrument was interfaced to a Pentium III computer via a $413 \mathrm{kHz} 16$ bit A/D converter to enable the conversion of data to digital form. A high efficiency mixer mix small volumes of solutions, which were driven into it from high performance syringes. Small volumes of solutions are driven from high performance syringes through high efficiency mixer(s). The sample handling unit (Figure 2.1) facilitates both the single mixing of two reagents, using only one of the drives, and double mixing of three reactants by a push-push mode of operation. Double mixing mode enables transient species formed by mixing reactants in $\mathrm{A}$ and $\mathrm{B}$ to be subsequently mixed with a third reactant, $\mathrm{C}$, after a delay period. Reactant reservoir D is reserved for the buffer and this will push the premixed solutions A and B (from mixer 1) to a second mixer (mixer 2) where it reacts further with reactant C. The resultant mixture passes through a measurement flow cell and into a stopping syringe where the flow is stopped. Just prior to stopping, a steady state flow is achieved. The solution entering the flow cell is only milliseconds old. The age of this reaction mixture is also known as the dead time of the stopped-flow system. As the solution fills the stopping syringe, the plunger hits a block, causing the flow to be stopped instantaneously. Reactions in which three or more reactants that require separate mixing prior to introduction into the observation chamber are analyzed using the double mixing feature of the SF61- DX2. The kinetics of the reaction can be measured in the cell using the appropriate techniques. ${ }^{58}$ 


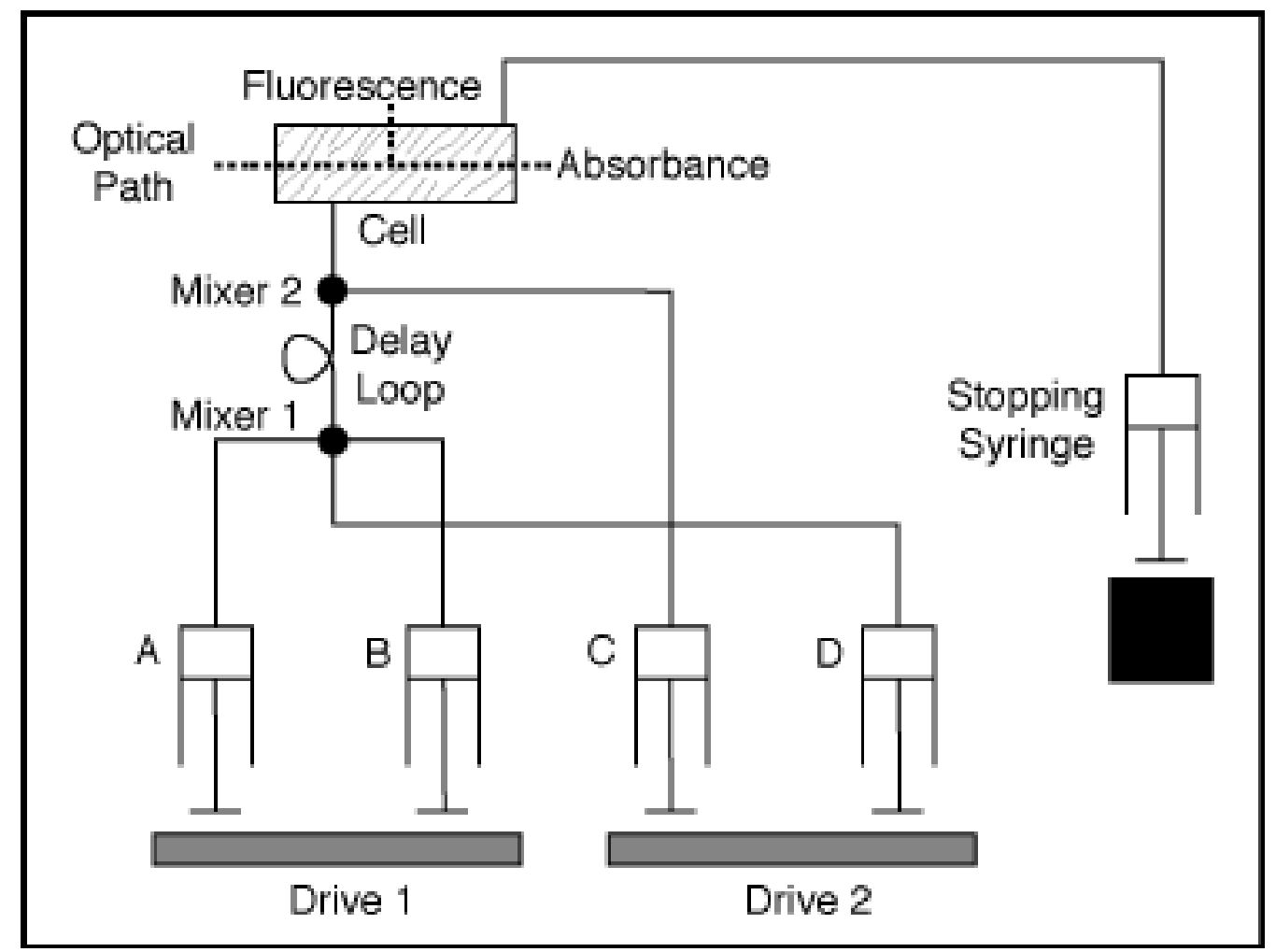

Figure 2.1: Sample Handling Unit (SHU) flow circuit diagram for the SF61-DX2 HiTech KinetAsyst stopped-flow spectrometer. [Courtesy of Hi-Tech Scientific operator's Manual $]^{58}$

\subsubsection{Nuclear Magnetic Resonance Spectrometry (NMR) Spectroscopy}

Structural characterization and verification of products and intermediates were conducted using a Bruker AMX-400 MHz Nuclear Magnetic Resonance (NMR) spectrometer. Each atom possesses a nucleus surrounded by an electron cloud. For the 
hydrogen atom, the nucleus is composed of a single proton which possesses a property called spin. Nuclei such as the hydrogen nucleus, with unpaired spins of protons and neutrons, will possess an overall nuclear spin, thus creating a nuclear magnetic dipole moment, where the inherent magnitude of the dipole is a nuclear property commonly referred to as the dipole moment, $\mu$. Thus, if the nucleus is placed in a magnetic field, the nuclear dipole moment will proceed about the magnetic field. The $\mathrm{z}$ component of the nuclear magnetic moment of the nucleus can either be aligned parallel to the external field (low energy) or can be anti-parallel to the external field (high energy). A particle in the low energy state can be excited to the higher energy state, when it absorbs a photon of frequency $(\gamma)$, where the energy of the photon is the difference in energy between the two states given by

$$
E=h \gamma
$$

The variable $\gamma$ is also known as the Larmor frequency or resonance frequency. ${ }^{59}$ Hence it is the nuclei of atoms that are involved in the absorption process in NMR, unlike in UV/Vis and IR absorption. The signal in NMR spectroscopy is due to the disparities in the energy absorbed by the nuclei as they are excited from the lower energy state to the higher energy state, and the energy emitted by the nuclei as they relax from the higher energy state to the lower energy state. ${ }^{59}$ The intensity of the signal is proportional to the population difference between the two states and the area under a given peak is directly proportional to the number of that type of protons in the molecule. The frequency of electromagnetic radiation necessary for resonance to occur depends on both the strength 
of the external magnetic field, and on the characteristics of the nucleus being studied. ${ }^{59}$ The electron cloud surrounding the nucleus tends to shield it from the full strength of the applied magnetic field. The greater the electron density, the greater the shielding, thus nuclei which are in electron-rich environments will undergo transition at a higher applied field than nuclei in electron-poor environments.

Similarly, nuclei that are adjacent to electronegative atoms, are deshielded and undergo transitions at a lower applied filed. The resulting shift in the NMR signal for the given nuclei is referred to as the chemical shift. ${ }^{59}$ Spin-spin coupling ${ }^{59}$ occurs between chemically inequivalent nuclei that are close enough to each other to exert an influence on each other's effective magnetic field, giving rise to the various splitting patterns observed in an NMR spectrum. Such an effect is observable if the distance between the chemically inequivalent nuclei is less than or equal to three bond lengths. ${ }^{59}$ In some molecules, certain protons may appear to be inequivalent to other protons in a particular rotamer, although they become equivalent if rapid rotation occurs. In some instances, this does not remove the inequivalence and the protons can be interchanged via symmetry operations. This inherent asymmetry may result in observable differences in the chemical shifts. ${ }^{60}{ }^{1} \mathrm{H}-\mathrm{NMR}$ spectra were recorded with a Bruker AMX-400MHz spectrometer using $\mathrm{CDCl}_{3}$ and $\mathrm{D}_{2} \mathrm{O}$ as solvents. Chemical shifts were reported as values in ppm relative to $\mathrm{CHCl}_{3}(7.26)$ in $\mathrm{CDCl}_{3}$ and TMS which was used as an internal standard(0). ${ }^{61}$ 


\subsubsection{Electron Paramagnetic Resonance (EPR) Spectroscopy}

Electron Paramagnetic Resonance (EPR) was discovered in 1944 by E.K. Zavoisky. ${ }^{62}$ The principles of EPR are quite analogous to those of NMR. Thus the electron has an intrinsic magnetic moment $\left(\mu_{\mathrm{e}}=g \beta_{e} S\right)$. Where $g=2.0023, \beta_{e}=$ $\left((e h) /(4 \pi m c)=9.27 \times 10^{-24} \mathrm{~J} \mathrm{~T}^{-1}\right.$ (Bohr magneton, where $e$ is the elementary charge, $h$ is the reduced Planck constant, $m$ is the electron rest mass andc is the speed of light) and $S$ $=(1 / 2)$. The first order Zeeman Effect splits the two $\mathrm{m}_{\mathrm{s}}$ states of the unpaired electrons in a paramagnetic material.

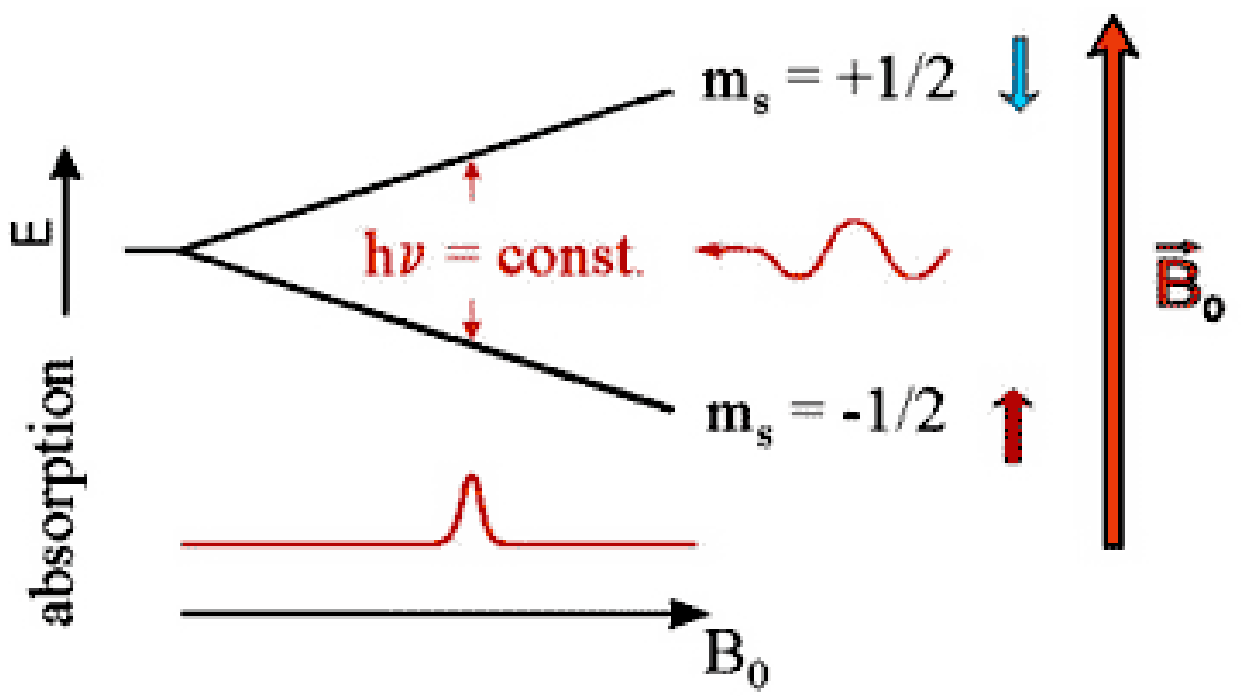

Figure 2.2: Zeeman splitting of the two spin Eigenstates of an electron in an external magnetic field. The classical analogue to bar magnets is indicated on the right. 
In EPR spectroscopy the energy differences, $\Delta \mathrm{E}$, due to interaction of unpaired electrons in the sample with a magnetic field produced by a magnet are studied. Absorption occurs when $\Delta \mathrm{E}$ equals the microwave energy, $\mathrm{h} v$. Equation 2.2 and Figure 2.2 describe the general principle of EPR.

$$
\Delta E=h v=g \beta_{e} H
$$

where $h$ is Planck's constant, $v$ is microwave frequency, $\beta$ is Bohr magneton (a constant related to electron charge and mass), $\mathrm{H}$ is magnetic field at which resonance occurs and $\mathrm{g}$ is a spectroscopic factor, which is a characteristic of a given paramagnetic center. The shape and width of the spectral line as well as the hyperfine (splitting) and area under the absorption curve are other important parameters in EPR spectroscopy. The area which is the double integral of the 1st derivation curve is proportional to the amount of a given paramagnetic center (spin) present in the resonator cavity of the EPR instrument.

EPR spectroscopy was carried out using a Bruker (Fremont, CA) EMX spectrometer equipped with a high-sensitivity cavity and an Aqua-X sample holder. Spectra were obtained at room temperature. Typical EPR parameters were as follows: $100 \mathrm{G}$ sweep width (for the spin trapping experiments with 5,5-dimethyl-1-pyrroline Noxide, (DMPO)); $9.77 \mathrm{GHz}$ microwave frequency; $32 \mathrm{~mW}$ power; $2 \times 10^{5}$ receiver gain; modulation frequency of $86 \mathrm{kHz}$; modulation amplitude of $2 \mathrm{G}$; with the conversion time $5 \mathrm{~ms}$ and time constant being $10 \mathrm{~ms}$ with $200 \mathrm{X}$-scans for each 512 point spectrum. 


\subsubsection{Electrospray-Ionization Mass Spectrometry (ESI-MS)}

Mass spectrometry (MS), is an analytical technique that sorts and measures ionized molecules based on their mass-to-charge ratios. This spectrometric method works on the basic principle of separation of ions of a compound on the basis of their mass-tocharge ratio $(\mathrm{m} / \mathrm{z})$. ESI uses electrical energy to assist the transfer of ions from solution into the gaseous phase before they are subjected to mass spectrometric analysis. Ionic species in solution can thus be analysed by ESI-MS with increased sensitivity. Neutral compounds can also be converted to ionic form in solution or in gaseous phase by protonation or cationisation (e.g., metal cationisation), and hence can be studied by ESIMS.

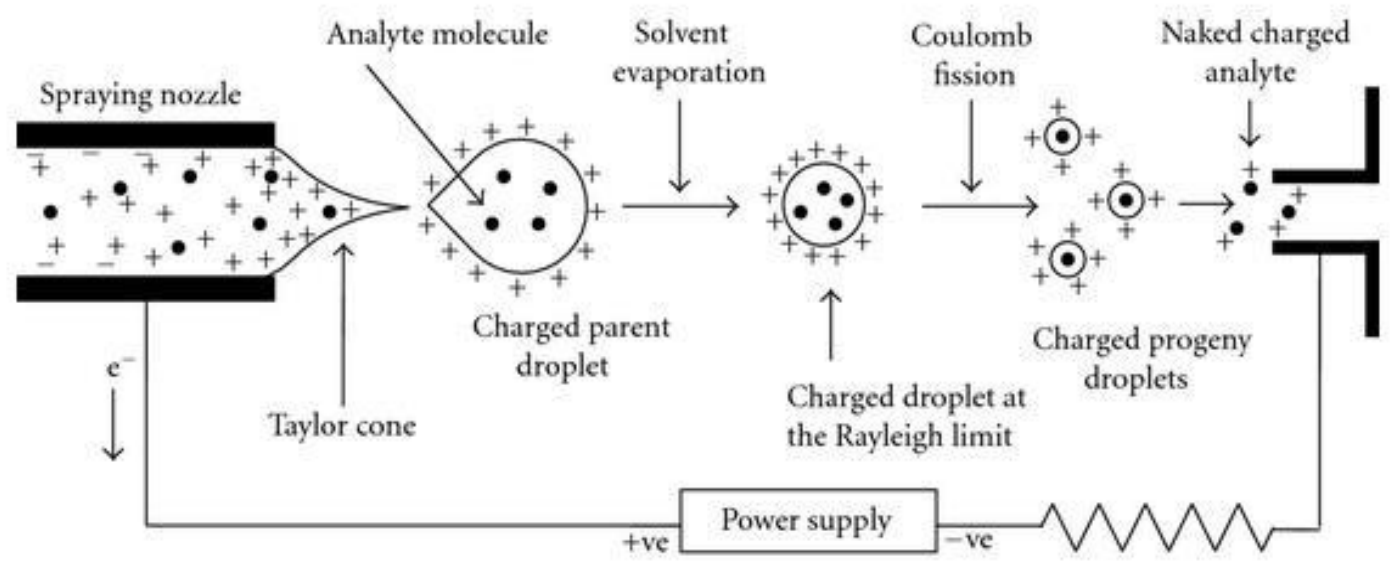

Figure 2.3: Schematic representation of the electrospray ionization(ESI) process. $^{63}$

The transfer of ionic species from solution into the gas phase by ESI involves three steps:

(1) dispersal of a fine spray of charge droplets, followed by (2) solvent evaporation and

(3) ion ejection from the highly charged droplets (Figure 2.3) into the tube, which is 
maintained at a high voltage (e.g., $2.5-6.0 \mathrm{kV}$ ) relative to the wall of the surrounding chamber.

A mist of highly charged droplets with the same polarity as the capillary voltage is generated. The application of a nebulizing gas (e.g. nitrogen), which shears around the eluted sample solution, enhances a higher sample flow rate. The charged droplets, generated at the exit of the electrospray tip, pass down a pressure and potential gradient toward the analyzer region of the mass spectrometer. With the aid of an elevated ESIsource temperature and/or another stream of nitrogen drying gas, the charged droplets are continuously reduced in size by evaporation of the solvent, leading to an increase of surface charge density and a decrease of the droplet radius. Finally, the electric field strength within the charged droplet reaches a critical point at which it is kinetically and energetically possible for ions at the surface of the droplets to be ejected into the gaseous phase. The emitted ions are sampled by a sampling skimmer cone and are then accelerated into the mass analyzer for subsequent analysis of molecular mass and measurement of ion intensity. The mass spectrum is a graphical display of the relative abundance of ion signals against the $\mathrm{m} / \mathrm{z}$ ratios. It is a common practice that the highest signal is taken as $100 \%$ abundance and all the other signals are expressed as a percentage of this. ${ }^{64}$

Mass spectra of products from reaction mixtures were taken on a high-resolution $(\mathrm{m} / \Delta \mathrm{m}=30$ 000) Thermo Scientific LTQ-Orbitrap Discovery mass spectrometer (San Jose, CA) equipped with an electrospray ionization source. All mass spectrometer 
samples were dissolved in $\mathrm{MeOH} / \mathrm{H}_{2} \mathrm{O}$ (1:1) mixture. The ESI-MS source parameters were set as follows: spray voltage of $2.5 \mathrm{kV}$, spray current of $1.96 \mu \mathrm{A}$, sheath gas flow rate of 20, auxiliary gas flow rate of 0.01 , capillary voltage of $-16 \mathrm{~V}$, capillary temperature of $300{ }^{\circ} \mathrm{C}$ and tube lens of $-115 \mathrm{~V}$. Detection was carried out in the negative ionization mode (-ESI) for 2 minutes in mass range $\mathrm{m} / \mathrm{z}$ of $100-1000$. The detection parameters were set up as follows: Analyzer was fourier transform mass spectrometry (FTMS), negative polarity; mass range was normal with resolution of 30000 and scan type was centroid.

\subsection{MATERIALS AND METHODS}

\subsubsection{Chemicals}

All chemicals were purchased from Sigma Chemical Co. (St. Louis, MO) and were used without further purification unless otherwise noted.

\subsubsection{Thiol Binding Determination}

The method reported by Schultz et al. ${ }^{41}$ was used with slight modification. Briefly, Ellman's reagent (5,5'-dithiobis-(2-nitrobenzoic acid; DTNB)) and cysteine (5 $\mathrm{mM}$ ) stock solutions were prepared in a $50 \mathrm{mM}$ ammonium carbonate buffer $\left(\mathrm{NH}_{4}\right)_{2} \mathrm{CO}_{3}$; $\mathrm{pH}$ 7.4) buffer. Cysteine (Cys) standards from 50 to $250 \mu \mathrm{M}$ were reacted with $1 \mathrm{mM}$ DTNB at room temperature in a total volume of $2 \mathrm{~mL}$. Absorbance readings taken at 412 $\mathrm{nm}\left(\boldsymbol{\epsilon}_{412 \mathrm{~nm}}=14,150 \mathrm{M}^{-1} \mathrm{~cm}^{-1}\right)$ after 15 min were plotted against the final cysteine concentration to give the standard curve (Figure 2.4). This calibration curve was used to 
determine Cys and glutathione (GSH) binding to $\mathrm{BQ}$ following reaction of $0.125 \mathrm{mM}$ Cys/GSH with $0.625 \mathrm{mM} \mathrm{BQ}$ for $2 \mathrm{~h}$ with subsequent addition of $0.625 \mathrm{mM}$ DTNB for 15 min. The calibration curve was also used to determine human serum albumin (HSA) reduced sulfhydryl concentration $([\mathrm{SH}] /[\mathrm{HSA}])$ following reaction of $0.8 \mathrm{mg} / \mathrm{mL}(\approx 11.9$ $\mu \mathrm{M})$ HSA with $0.625 \mathrm{mM}$ DTNB for 15 min with subsequent absorbance readings at 412 nm. BQ $(0.625 \mathrm{mM})$ was incubated with $0.8 \mathrm{mg} / \mathrm{mL}(\approx 11.9 \mu \mathrm{M}) \mathrm{HSA}$ for $2 \mathrm{~h}$ with subsequent addition of $0.625 \mathrm{mM}$ DTNB to measure the loss of Cys34 reactivity.

Figure 2.4: Calibration curve of Cysteine (Cys) standards from 0 to $100 \mu \mathrm{M}$ were reacted with $1 \mathrm{mM} D T N B$ at room temperature in a total volume of $2 \mathrm{~mL}$. Absorbance

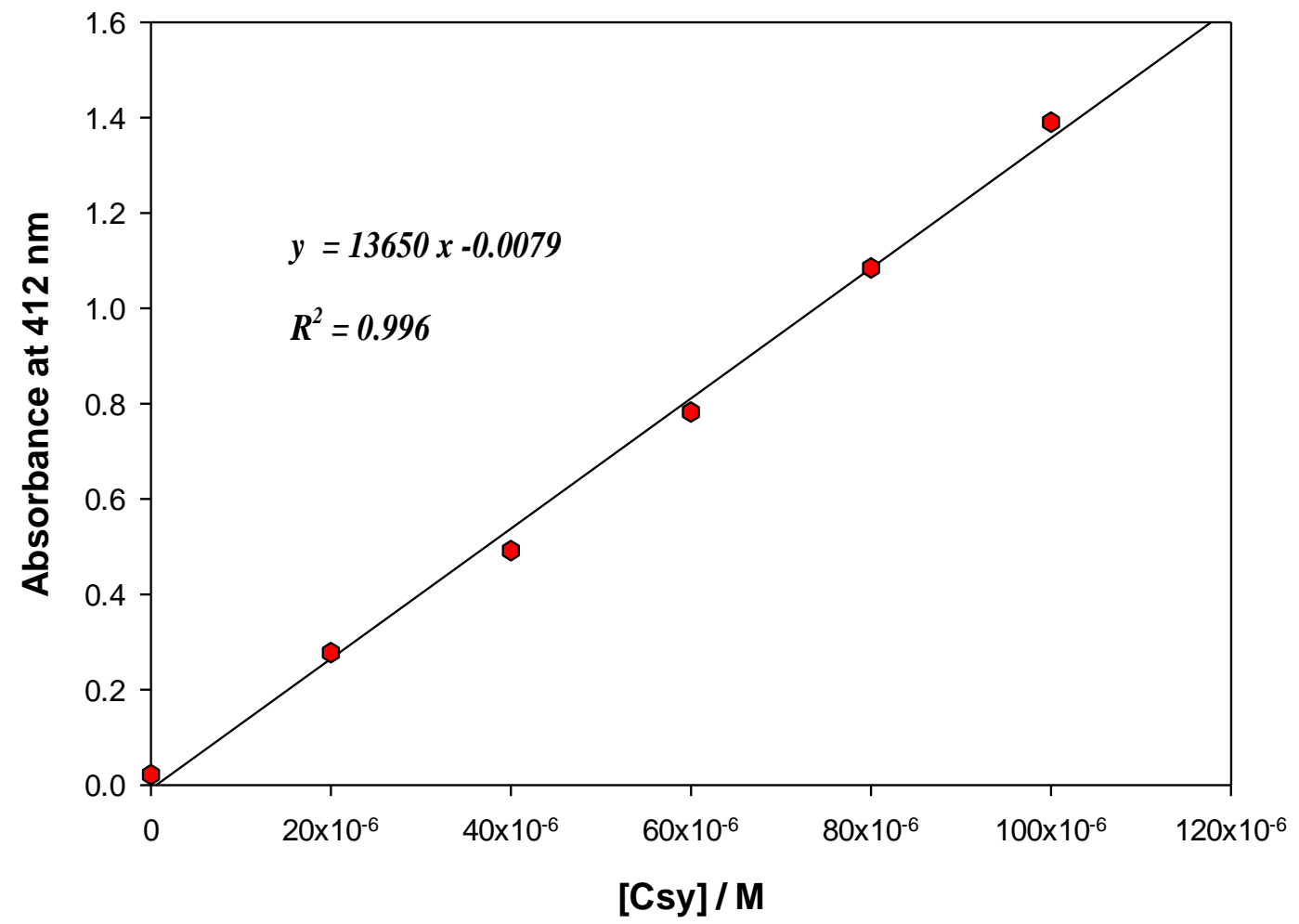

readings taken at $412 \mathrm{~nm}$ after $15 \mathrm{~min}$ were plotted against the final cysteine concentration to give the standard curve. Equation of line: $y=13650 x-0.0079\left(R^{2}=\right.$ 0.996). 


\subsubsection{Preparation of Reduced Thiols}

The reconversion of the Cys34 residue on HSA to the free sulfhydryl form was performed by incubating equal volumes of $4 \mathrm{mg} / \mathrm{mL}$ HSA with $4 \mathrm{mM}$ dithiothreitol (DTT) in $\left(\mathrm{NH}_{4}\right)_{2} \mathrm{CO}_{3}$ buffer $(50 \mathrm{mM})$ at room temperature for $3 \mathrm{~h}$, followed by dialysis (molecular mass cutoff of $3500 \mathrm{Da}$ ) in $2 \mathrm{~L}$ of $50 \mathrm{mM}\left(\mathrm{NH}_{4}\right)_{2} \mathrm{CO}_{3}$ for $48 \mathrm{~h}$ with three buffer changes during that period to ensure complete removal of DTT. The post-dialysis HSA concentrations were determined using the Bradford assay ${ }^{65}$ with human serum albumin (HSA) as the standard protein. HSA thiol concentrations were determined using Ellman's reagent as outlined above and the extent of thiol blocking with BQ was measured with Ellman's reagent and compared with blocking performed with the thiol specific reagent, N-ethylmaleimide (NEM).

\subsubsection{Extent of BQ Binding to Cys34 in HSA}

A stock solution consisting of $4 \mathrm{mg} / \mathrm{mL}$ HSA was prepared in $50 \mathrm{mM}\left(\mathrm{NH}_{4}\right)_{2} \mathrm{CO}_{3}$. Then, $0.8 \mathrm{mg} / \mathrm{mL}(\approx 11.9 \mu \mathrm{M}) \mathrm{HSA}$ was incubated with $250 \mu \mathrm{M}$ BQ for $1 \mathrm{~h}$ on a shaker at $37{ }^{\circ} \mathrm{C}$ followed by dialysis for $48 \mathrm{~h}$. Loss of DTNB reactivity (as described above) was used to determine loss of thiol reactivity as a result of BQ covalent binding. As controls, HSA thiol concentrations were determined for (i) fresh HSA in buffer that was not incubated or dialyzed, (ii) HSA (in the absence of BQ) that had been incubated under the same conditions (as the BQ-treated HSA) and dialyzed, and (iii) HSA which had been reduced by dithiothreitol (DTT) and dialyzed. A comparison of the kinetics of the reaction of DTNB with (i) reduced HSA, (ii) reduced and dialyzed HSA, and (iii) reduced 
HSA incubated with BQ with subsequent dialysis was performed. Human albumin has only one free thiol, Cys34. To ascertain the Cys34 as the BQ-targeted residue, the thiol specific blocking reagent $\mathrm{N}$-ethylmaleimide (NEM) was reacted with reduced HSA (as a positive control) prior to reactions with DTNB. DTT-reduced HSA $(0.8 \mathrm{mg} / \mathrm{mL}, 11.9$ $\mu \mathrm{M})$ was reacted with $250 \mu \mathrm{M}$ NEM for $30 \mathrm{~min}$ in a $\mathrm{pH} 7.4\left(\mathrm{NH}_{4}\right)_{2} \mathrm{CO}_{3}$ buffer at room temperature with subsequent dialysis. Aliquots were taken for $[\mathrm{SH}] /[\mathrm{HSA}]$ determination with DTNB. HSA pretreated with BQ and incubated with DTNB was also subjected to the same analysis.

\subsubsection{Extent of BQ Binding to Primary Amines in HSA}

A stock solution consisting of $0.8 \mathrm{mg} / \mathrm{ml}$ HSA prepared in PBS ( $\mathrm{pH} 7.4$ ) was incubated with $250 \mu \mathrm{M}$ BQ for $1 \mathrm{~h}$ at room temperature followed by dialysis for $48 \mathrm{~h}$ against PBS buffer. The trinitrobenzene sulfonic acid (TNBS) amine specific probe assay was performed on HSA and HSA-BQ conjugates. HSA $(500,400,200,100,50 \mu \mathrm{g} / \mathrm{mL})$ were prepared in PBS buffer (pH 7.4). TNBS (5\% w/v) was diluted 1: 5.48 with $0.1 \mathrm{M}$ borate buffer (pH 9.3). To $500 \mu \mathrm{L}$ of HSA and HSA-BQ, $12.5 \mu \mathrm{L}$ of TNBS was added, mixed well and left to react for 30 minutes and absorbance was measured at $420 \mathrm{~nm}$.

\subsubsection{Whole Human Fresh Blood Collection and Serum Separation}

Whole blood was drawn into $10 \mathrm{~mL}$ BD Vacutainer Serum Separation Tubes containing gel and clot activator transport and inverted four times for the blood to mix with the tube additives. The blood was allowed to sit for $30 \mathrm{~min}$ at room temperature for clotting to occur. Serum was separated by centrifugation of the tubes at $1000 \mathrm{~g}$ for $10 \mathrm{~min}$ 
at $4^{\circ} \mathrm{C}$. The serum was transferred into plastic tubes using glass pasteur pipettes and aliquoted before determination of protein concentration. The aliquoted samples were stored at $-20^{\circ} \mathrm{C}$. The Cys-DTNB calibration curve was used to determine serum total sulfhydryl concentration ([SH $\left.\mathrm{SH}_{\mathrm{T}}\right]$ ) following reaction of $0.1 \mathrm{ml}$ of $0.1 \mathrm{mg} / \mathrm{mL}$ serum protein with $0.4 \mathrm{ml}$ of $0.5 \mathrm{mM}$ DTNB for $15 \mathrm{~min}$ with subsequent absorbance readings at $412 \mathrm{~nm}$. The calibration curve was also used to determine loss of $\left[\mathrm{SH}_{\mathrm{T}}\right]$ and the ratio $\left[\mathrm{SH}_{\mathrm{r}}\right] /\left[\mathrm{SH}_{\mathrm{T}}\right]\left(\mathrm{SH}_{\mathrm{r}}=\right.$ blocked thiol$)$ when serum was incubated with BQ prior to DTNB reactivity. To measure binding of BQ and NEM to high molecular weight thiols dialysis of the serum samples was performed for $48 \mathrm{~h}$ against PBS to remove low molecular weight thiols prior to incubation with $\mathrm{BQ} / \mathrm{NEM}$ and subsequent determination of thiol binding with DTNB. The ratio of blocked thiol post dialysis $\left(\mathrm{SH}_{\mathrm{d}}\right)$ to total thiol of the control post dialysis $\mathrm{SH}_{\mathrm{Td}}\left(=\left[\mathrm{SH}_{\mathrm{d}}\right] /\left[\mathrm{SH}_{\mathrm{Td}}\right]\right)$ was also determined.

\subsubsection{BQ and BQD Binding Kinetic Studies}

Reaction kinetics were measured on a Hitech Scientific (Bradford-on-Avon, UK) SF61DX2 double-mixing stopped-flow spectrophotometer with an F/4 Czerny-Turner MG60 monochromator and a spectra scan control unit. The signal from the spectrophotometer was amplified and digitized via an Omega Engineering DAS-50/1 16bit A/D board interfaced to a computer for storage and data analysis. Reaction progress was followed by monitoring the loss of free thiol on NBT at $412 \mathrm{~nm}$, where it has its highest molar absorptivity coefficient $(\varepsilon)$ as previously described. ${ }^{66}$ 
Test chemicals listed in table 2.1 were dissolved in acetonitrile at concentrations ranging from 0.01 to $10 \mathrm{mM}$. These solutions $(5 \mu \mathrm{L})$ were combined with $5 \mu \mathrm{L}$ of $0.1 \mathrm{mM}$ NBT in phosphate buffer ( $\mathrm{pH}$ 7.4) in a sealed reaction cell with rapid mixing. Absorbance readings were collected after a dead time of $1 \mathrm{~ms}$. Control experiments contained test chemical in acetonitrile/phosphate buffer to determine background absorbance. Five replicates were performed for each chemical at each concentration. The temperature was maintained at $25^{\circ} \mathrm{C}$ in the observation cell with a VWR International (Radnor, PA) circulating water bath.

\subsubsection{Sample preparations and solvents used in Electron Paramagnetic Resonance (EPR) Spectroscopy}

The final concentrations of BQD derivatives were $50 \mu \mathrm{M}$ and DMPO was 100 $\mathrm{mM}$ unless specifically mentioned. Buffer solutions were prepared by adjusting with $5 \mathrm{M}$ sodium hydroxide solution or $1 \mathrm{M}$ hydrochloric acid. The effect of NBT on the generation of free radicals was studied by incubating $0.1 \mathrm{mM}$ NBT with $1 \mathrm{mM}$ BQD + 100 mM DMPO. Spectral simulations of EPR spectra were performed using WinEPR program developed by Bruker and the coefficients of simulated spectra were $>0.96$.

\subsubsection{Sample Purification Methods for Samples used for Mass Spectroscopy and Nuclear Magnetic Resonance}

Reagents were from Sigma Aldrich and used as supplied. The reaction mixture of six-fold molar excess of NBT samples were incubated in phosphate buffer $\mathrm{pH} 7.4$ for 24 hours. The reaction mixture was purified by preparative TLC (10-20\% EtOAc/80-90\% n- 
hexane) for samples of compounds 3-7 to obtain the products in a pure state whilst compound 8 was separated using Teledyne Isco Combflash Rf 200 PSI. After completion, solvents were evaporated using a rotor evaporator, and the products were dissolved in appropriate solvent for spectroscopy analysis.

\subsubsection{Approach for QSAR Analysis}

Hammett and Taft substituent constants were taken from Perrin et al. ${ }^{67}$ The structures are given in Figure 2.5. The reaction sites are indicated by the arrows. For Hammett constants compounds 2-MBQ, 2,5-DMBQ, 2,6-DMBQ, 2-CBQ, 2,5-DCBQ and 2,6-DCBQ were used whilst for Taft constants test compounds BQ, 2-CBQ, 2,5DCBQ and 2,6-DCBQ were used.<smiles>[N-]C1=CC(=O)C=CC1=O</smiles>
(BQ; 0.043)

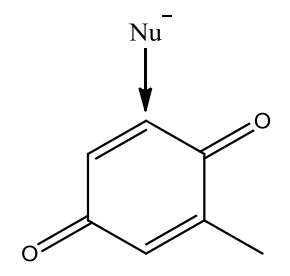

(2) 2-methyl-p-benzoquinone $(2-\mathrm{MBQ} ; 0.238)$<smiles>CC1=CC(=O)C(C)=C([N])C1=O</smiles>

(3) 2,5-dimethyl-p-benzoquinone (2,5-DMBQ ; 0.181)

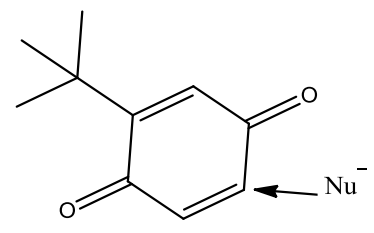

(4) 2-tert-butyl-p-benzoquinone $($ (BBBQ)*
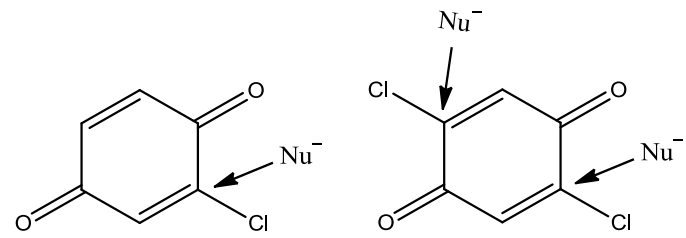

(5) 2-chloro-p-benzoquinone (6) 2,5-dichloro-p-benzoquinone (2-CBQ ; 0.039)

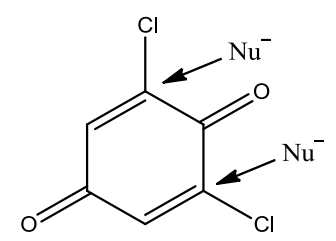

(7) 2,6-dichloro-p-benzoquinone (2,6-DCBQ; 0.028)

* 2-tBBQ produced clinical signs of systemic toxicity including weight loss, lethargy and ruffled fur that gave poor dose-dependent proliferative responses and preventing a reliable EC3 determination.

Figure 2.5: Benzoquinone and its derivatives. The arrows are the sites of nucleophilic attack. 


\subsubsection{Local lymph node assay}

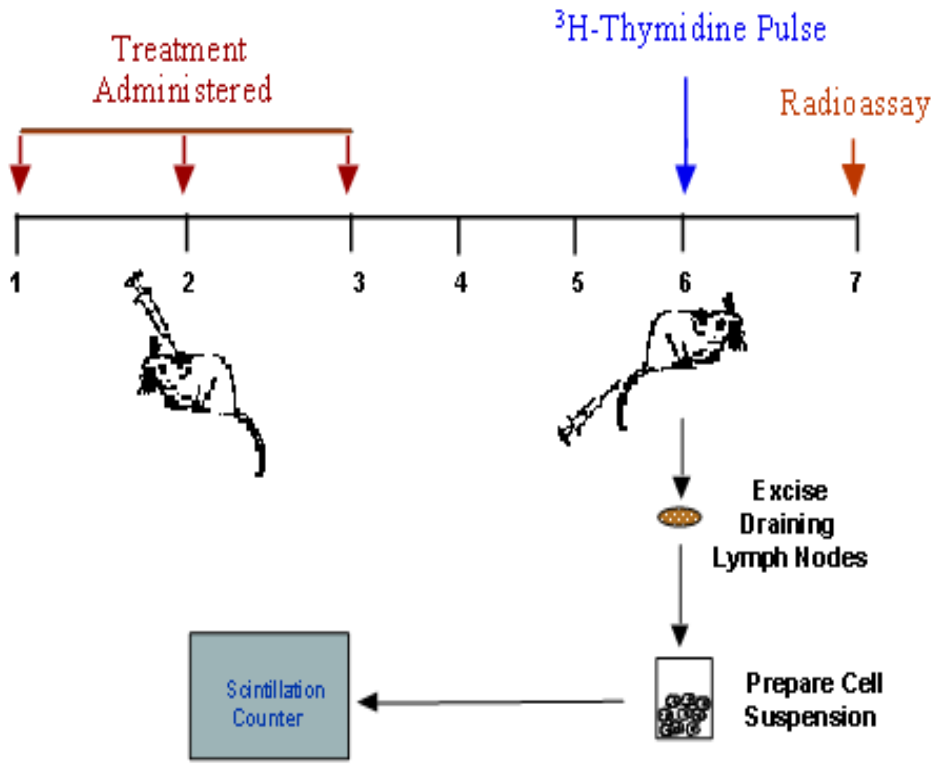

Determine ${ }^{3} \mathrm{H}$ Thymidine Incorporation

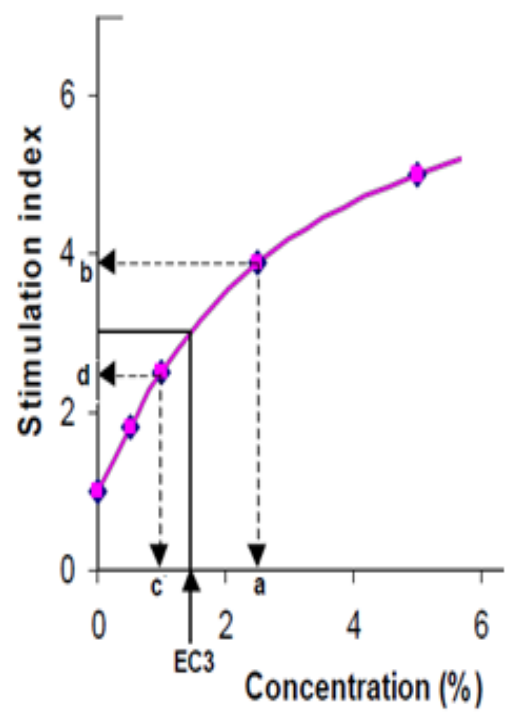

Figure 2.6: Overview of the LLNA and the dose response curve.

The Interagency Coordinating Committee on the Validation of Alternative Methods ( ICCVAM) validated LLNA protocol ${ }^{68}$ (NIOSH Local Lymph Node Assay Procedure (SOP \# ACI00043) was used to determine the EC3 values of BQ and BQD, with the exception that Balb/C mice were used.

Female BALB/c mice were purchased from Taconic (Hudson, NY, USA). Animals were 6-8 weeks old upon arrival and allowed to acclimate for a minimum of 10 days. Animals were housed in the Association for Assessment and Accreditation of Laboratory Animal Care International-accredited animal facility at National Institute for Occupational Safety and Health (NIOSH), Morgantown, WV, USA. Animals were housed under controlled 
environmental conditions in High Efficiency Particulate Act (HEPA)-filtered ventilated polycarbonate cages on autoclaved hardwood beta-chip bedding and provided food and autoclaved tap water ad libitum. All animal procedures were reviewed and approved by the NIOSH Animal Care and Use Committee.

The LLNA test (Figure 2.6) was conducted in three independent blocks, each of which contained solvent controls, assay of $2 \mathrm{BQDQ}$ and BQ as the positive control. After grouping mice into homogenous groups $(n=4)$ based on their weight, mice were dosed with $25 \mu \mathrm{L} /$ ear of a test chemical in acetone olive oil (AOO; 4:1). The negative vehicle control group was dosed with AOO. The vehicle and test chemicals were applied on the dorsum of both ears. Two hundred $\mu \mathrm{L}$ of $20 \mu \mathrm{Ci}{ }^{3} \mathrm{H}-\mathrm{TdR}$ in $0.01 \mathrm{M}$ PBS was injected into the tail vein on day 6 , and after $5 \mathrm{~h}$ the mice were euthanized via $\mathrm{CO}_{2}$ inhalation. Left and right draining auricular lymph nodes were excised and pooled for each animal. Single cell suspensions were made and following overnight protein precipitation using 5\% TCA, samples were counted on a Packard Tri-Carb 2500TR (Meriden, CT) liquid scintillation analyzer with background subtraction. Stimulation indices (SI) were calculated by dividing the mean disintegrations per minute (DPM) per test group by the mean DPM for the vehicle control group. A test chemical is thus considered to be a sensitizer if it has a three-fold SI over that of the vehicle (which is assigned an SI of 1). The concentration responsible for a three-fold stimulation is thus termed the EC3 value of the chemical. ${ }^{35,69,70}$ The EC3 value is usually calculated using a defined dose-response curve and the linear interpolation method (Figure 2.6 insert) published by Basketter, ${ }^{71}$ 


$$
\mathrm{EC} 3=\mathrm{c}+[(3-\mathrm{d}) /(\mathrm{b}-\mathrm{d})] \times(\mathrm{a}-\mathrm{c})
$$

where $\mathrm{a}=$ the lowest concentration giving stimulation $>3 ; \mathrm{b}=$ the actual stimulation index caused by a; $c=$ the concentration with a stimulation index of $<3$; and $d=$ the stimulation index caused by c. The values represent stimulation indexes below and above the 3-fold stimulation index.

In our case the EC3 was estimated by the benchmark approach, by fitting a nonlinear regression model to the data of all individual animals.

\subsubsection{Statistical Analysis}

LLNA: The structure of these experiments was a nested design. Mice were randomly placed into treatment groups, which included solvent control, positive control, + hapten groups. Lymph node cell proliferation was measured as described above. A sample size of four per treatment group provides greater than $95 \%$ power to find a change in lymphocyte proliferative activity of at least $50 \%$, based on a treatment variance of $20 \%$, which iwas based on previous studies. Analysis was performed using the Mixed Procedure on an SAS platform to perform a hierarchical analysis of variance. Results will be considered significant if $\mathrm{p}<0.05$.

The $\log P$ values were calculated from structure using ADMET® (MedChem-Designer) software $^{72}$ and the values are given as mean \pm SD. SigmaPlot (Version 12.0 Systat

Software Inc.) was used for statistical analysis and graphical presentation. ${ }^{73}$ 


\section{CHAPTER THREE}

\section{REACTIVITY AND FREE RADICAL FORMATION}

\subsection{INTRODUCTION}

The interaction of skin sensitizers with proteins, peptides, and model nucleophiles representing cutaneously available proteins has been reported to be predominantly covalent bonding between electrophiles $\left(\mathrm{E}^{+}\right)$and nucleophiles. It is generally agreed that low-molecular mass xenobiotics such as BQD (<500 Da) do not have a sufficient molecular volume, once they have penetrated the stratum corneum into the epidermis, to stimulate a cellular and/or antibody immune response. Therefore, the xenobiotic has to bind to a protein to form a macromolecular immunogen in the form of a hapten-carrier complex, a postulation which has come to be commonly termed the "hapten hypothesis." Reactivity of BQ to thiols (e.g., Cys34 on HSA) and to primary amines (on HSA) was tested. The kinetic spectrophotometric chemoassay for the assessment of skin sensitizers by reactivity toward 4-nitrobenzenethiol (NBT) as a surrogate protein binding was utilized with BQ and BQD. Stopped-flow techniques were used to monitor the depletion of NBT at $412 \mathrm{~nm}$ from which NBT depletion rate constants of reaction were obtained and ranged from seconds to minutes to reach completion. It was previously suggested by Christensson et al. (2006), ${ }^{74}$ that semiquinone radicals may act as a hapten. The relationship between semiquinone radicals and reactivity was examined. Semiquinone radicals were detected using EPR, spectroscopy. EPR spectroscopy is a technique that 
provides unique insight into the redox biochemistry, due to its ability to distinguish and quantify different reactive species, such as SQ radicals, and to provide information on other important parameters of biological systems. ${ }^{75}$

\subsection{RESULTS}

\subsubsection{HSA Thiol-BQ Reactions}

Loss of thiol reactivity of DTNB was observed with both fresh HSA and DTT reduced HSA when they were incubated with BQ before reacting with DTNB. In order to confirm the thiol residue as the target for BQ, the thiol blocking reagent $\mathrm{N}$ ethylmaleimide (NEM) was incubated with DTT-reduced HSA followed by dialysis before addition of DTNB. Figure 3.1 shows that BQ and NEM resulted in $72.3 \pm 2.6 \%$ and $90.4 \pm 2.3 \%$ loss, respectively, of HSA thiol-DTNB reactivity after 5 min at 21:1 molar ratios of BQ:HSA and NEM:HSA. A paired t-test of the thiol losses demonstrated a significant difference $(\mathrm{p}<0.05)$ between BQ and NEM induced thiol loss. Dialysis of both the HSA-BQ and HSA-NEM adducts did not result in recovery of Cys34 reactivity, confirming that both BQ and NEM bind irreversibly to Cys34 on HSA. There was, however, a slight dilution of the protein concentration after dialysis. Preincubation of HSA for 30 min with BQ or NEM with subsequent DTNB reactivity assay resulted in $85.4 \pm 3.7 \%$ and $91.5 \pm 4.2 \%$ thiol loss, respectively (Figure 3.1 ). The thiol reactivity loss between BQ and NEM were not statistically significant $(\mathrm{p}=0.16)$ after $30 \mathrm{~min}$. 


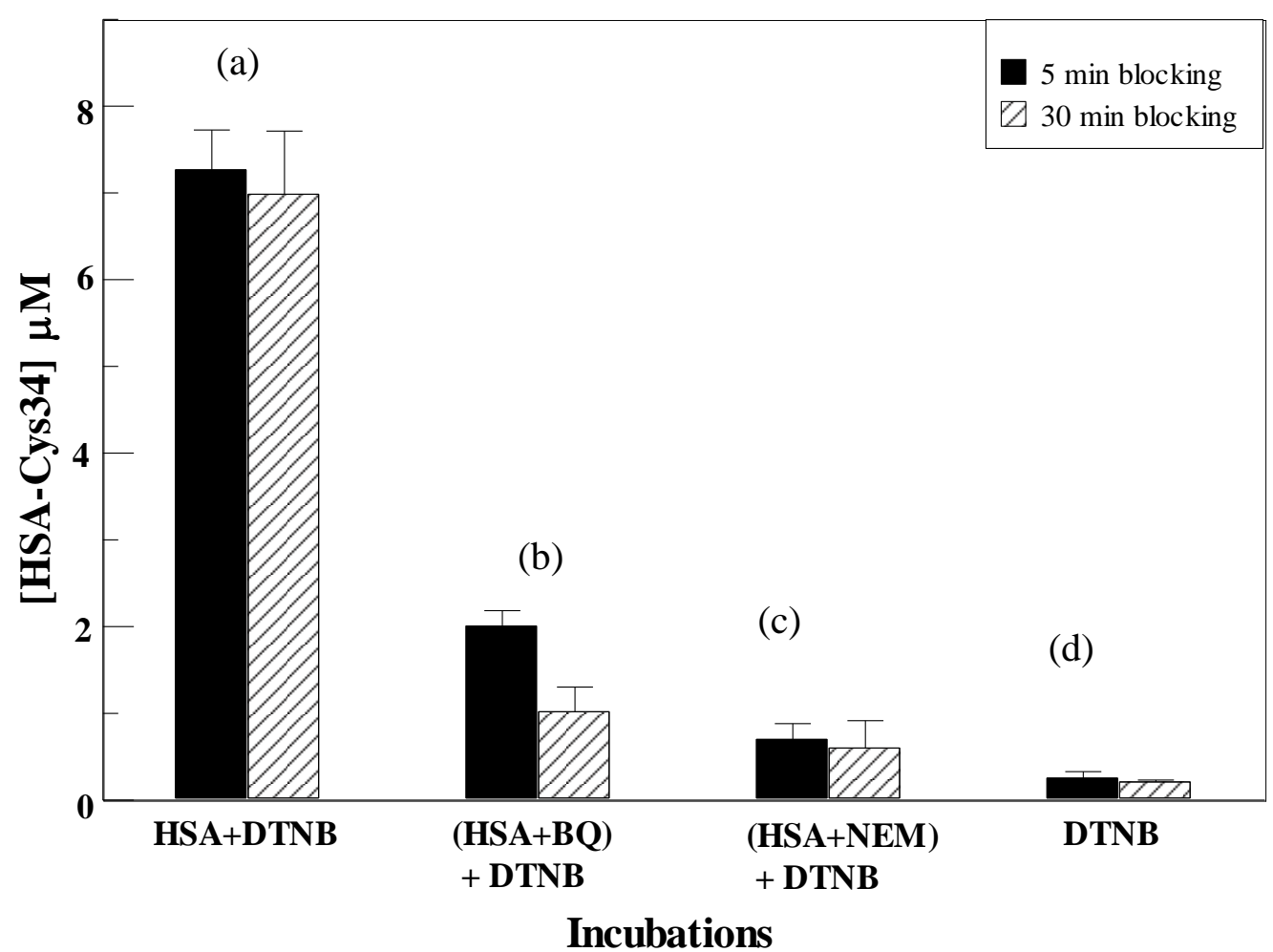

Figure 3.1: Measurement of $B Q$ binding to $H S A$ Cys 34 by loss of DTNB reactivity. $H S A$ was treated with DTT, dialyzed and reacted with $B Q$. NEM was used as a positive control. (a) $0.8 \mathrm{mg} / \mathrm{mL} H S A$ reacted with $1 \mathrm{mM} D T N B$, (b) $0.8 \mathrm{mg} / \mathrm{mL} \mathrm{HSA}$ preincubated with $1 \mathrm{mM} \mathrm{BQ}$ reacted with $1 \mathrm{mM} D T N B$, (c) $0.8 \mathrm{mg} / \mathrm{mL} H S A$ preincubated with $1 \mathrm{mM}$ NEM reacted with $1 \mathrm{mM} D T N B$, (d) $1 \mathrm{mM} D T N B$.

\subsubsection{BQ reactivity to Primary Amines in HSA}

Trinitrobenzene sulfonic acid (TNBS) reactivity of accessible primary amines on non-conjugated HSA was compared to HSA that had been conjugated with BQ. There was $18.4 \pm 2.9 \%$ loss of TNBS amine reactivity when BQ was incubated with HSA in 50 $\mathrm{mM}(\mathrm{NH} 4)_{2} \mathrm{CO}_{3}, \mathrm{pH} 7.4$ buffer. Interestingly, BQ amine binding was enhanced to $35.6 \pm$ $6.6 \%$ of TNBS reactive HSA amines when BQ conjugation was performed in PBS $(\mathrm{pH}$ 
7.4). Dialysis of the HSA-BQ adduct did not result in recovery of primary amine reactivity confirming that BQ also binds irreversibly to primary amines on HSA.

\subsubsection{Serum Thiol - BQ Reactivity}

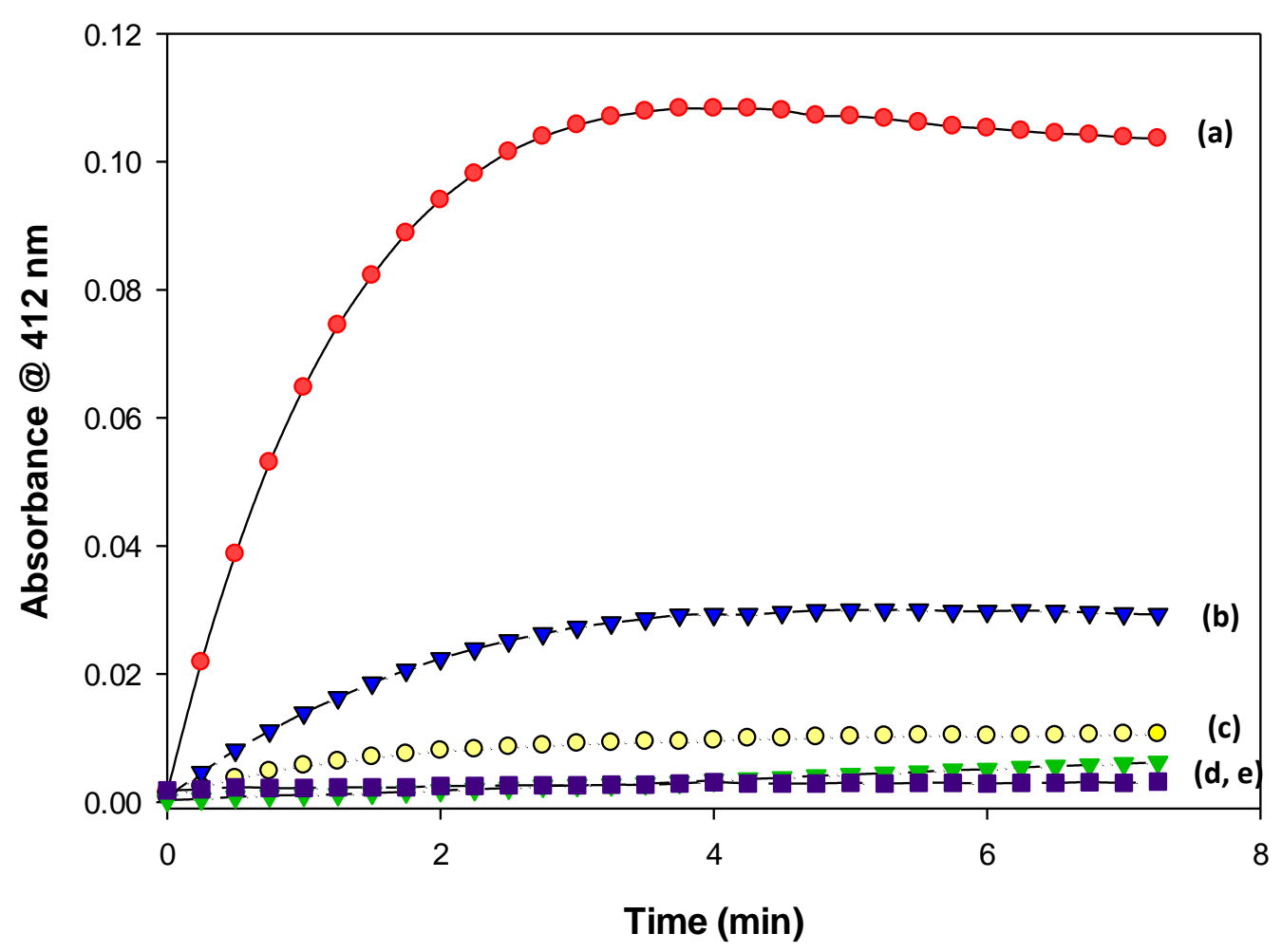

Figure 3.2: Measurement of $B Q$ binding to Serum thiol by loss of DTNB reactivity. (a) $25 \mu \mathrm{L}$ plasma protein stock in $500 \mu \mathrm{L}$ reacted with $0.1 \mathrm{mM} \mathrm{DTNB}$, (b) $25 \mu \mathrm{L}$ plasma protein stock in $500 \mu \mathrm{L}$ preincubated with $0.1 \mathrm{mM} \mathrm{BQ}$ reacted with $0.1 \mathrm{mM} \mathrm{DTNB},(\mathrm{c})$ $25 \mu \mathrm{L}$ plasma protein stock control in $500 \mu \mathrm{L}$ preincubated with $0.1 \mathrm{mM}$ NEM reacted with $0.1 \mathrm{mM} \mathrm{DTNB},(d) 25 \mathrm{uL}$ Plasma protein control into $500 \mathrm{uL}$ and (e) $0.1 \mathrm{mM}$ DTNB control into $500 \mathrm{uL}$.

The serum total sulfhydryl concentration $\left(\left[\mathrm{SH}_{\mathrm{T}}\right]\right)$ following reaction with DTNB for 15 min was $221 \mu \mathrm{M}$. Dialysis of the serum samples removed low molecular weight 
thiols with resultant $\left[\mathrm{SH}_{\mathrm{Td}}\right]$ being $117 \mu \mathrm{M}$. For the undialysized serum BQ and NEM thiol loss $\left(\left[\mathrm{SH}_{\mathrm{r}}\right] /\left[\mathrm{SH}_{\mathrm{T}}\right]\right)$ after 5 min was $74.4 \pm 5.6$ and $89.2 \pm 3.7 \%$, respectively, showing significant difference $(\mathrm{p}<0.05)$ between BQ and NEM. Preincubation for 30 min resulted in $90.7 \pm 6.7$ and $93.5 \pm 5.9 \%$ thiol loss, respectively, which was not statistically significant $(\mathrm{p}>0.05)$. Dialysis of the serum samples incubated with BQ and NEM resulted in reduced DTNB reactivity for the control serum sample and all other samples even though the post-dialysis thiol loss $\left[\mathrm{SH}_{\mathrm{d}}\right]$ per total serum thiol of the control post dialysis $\left[\mathrm{SH}_{\mathrm{Td}}\right]$ did not change. The thiol loss was reduced to $67.9 \pm 4.7$ for $\mathrm{BQ}$ and $70.1 \pm 3.9 \%$ for NEM 5 min preincubations. When the BQ and NEM preincubation period with the dialyzed serum samples was extended to 30 min the thiol losses were 76.9 $\pm 5.3 \%$ and $82.6 \pm 7.1 \%$, respectively (Figure 3.2 )

\subsubsection{NBT-BQ/BQD Reactions}

The previously reported nitrobenzenethiol assay for screening thiol reactive haptens ${ }^{76}$ was used in this study to determine the reactivity of BQD electrophilic species (E). The decrease in absorption of NBT at $412 \mathrm{~nm}\left(\varepsilon_{412 \mathrm{~nm}}=11068 \pm 126 \mathrm{M}^{-1} \mathrm{~cm}^{-1}\right)$ was measured after rapid mixing with BQD. As an example, Figure 3.3 and Figure 3.5 show the consumption of NBT with MBQ and CBQ respectively. 


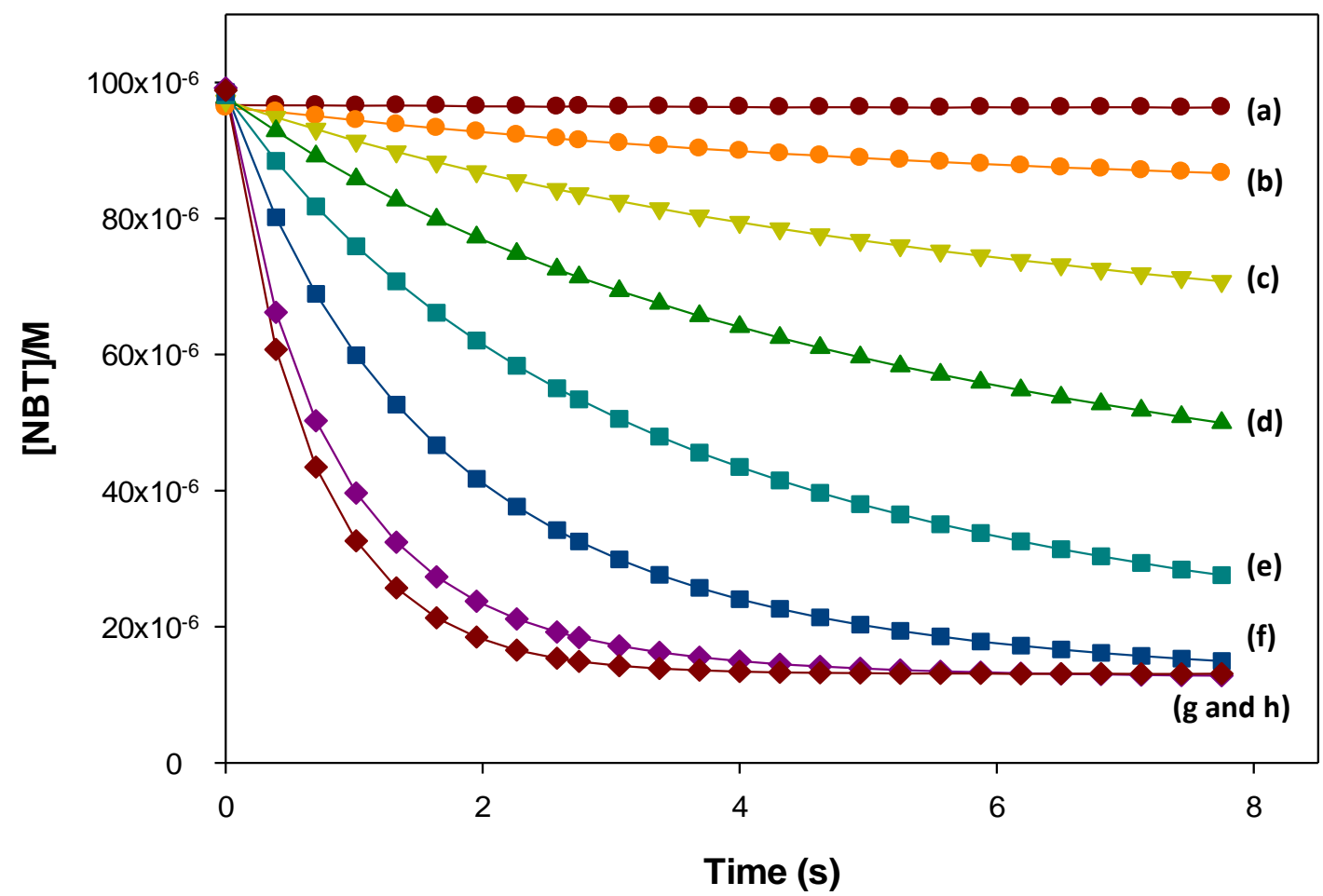

Figure 3.3: Reaction of $M B Q$ with $N B T$ in $50 \%$ acetonitrile in a $p H 7.4$ phosphate buffer at $25{ }^{\circ} \mathrm{C}$. Absorbance readings were performed at $412 \mathrm{~nm}$. Using $[\mathrm{NBT}]_{0}=0.1 \mathrm{mM} \mathrm{BQ}$ concentrations were varied from (a) $0.0 \mathrm{mM}$, (b) $0.0125 \mathrm{mM}$, (c) $0.025 \mathrm{mM}$, (d) $0.05 \mathrm{mM}$, (e) $0.1 \mathrm{mM}$, (f) $0.2 \mathrm{mM}$, (g) $0.4 \mathrm{mM}$ and (h) $0.8 \mathrm{mM}$. 


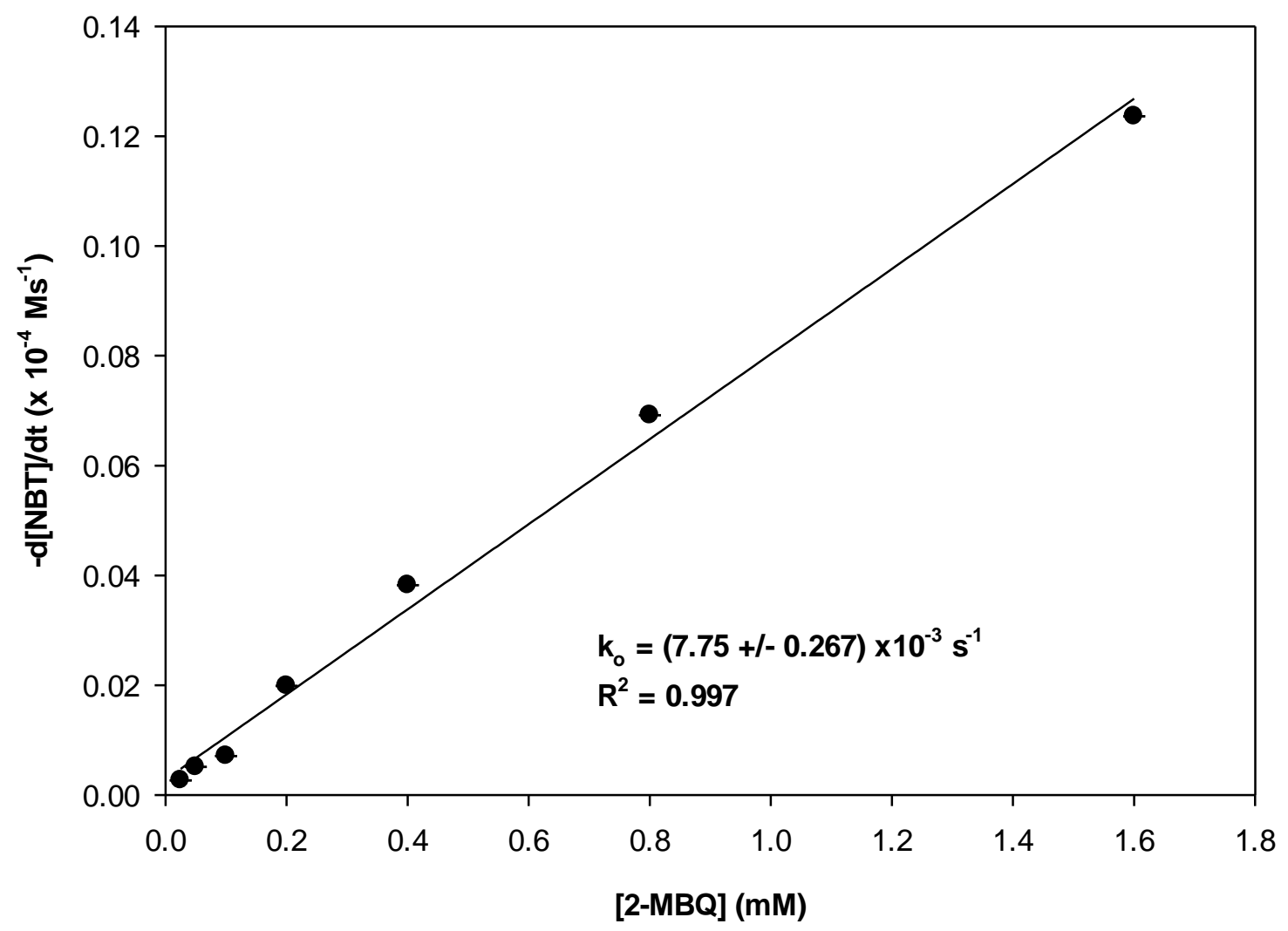

Figure 3.4: Initial rate vs. [2-MBQ] for results taken from Figure 3.3. Rate constants are calculated from the slope of the [E] vs. initial rate for NBT depletion. 


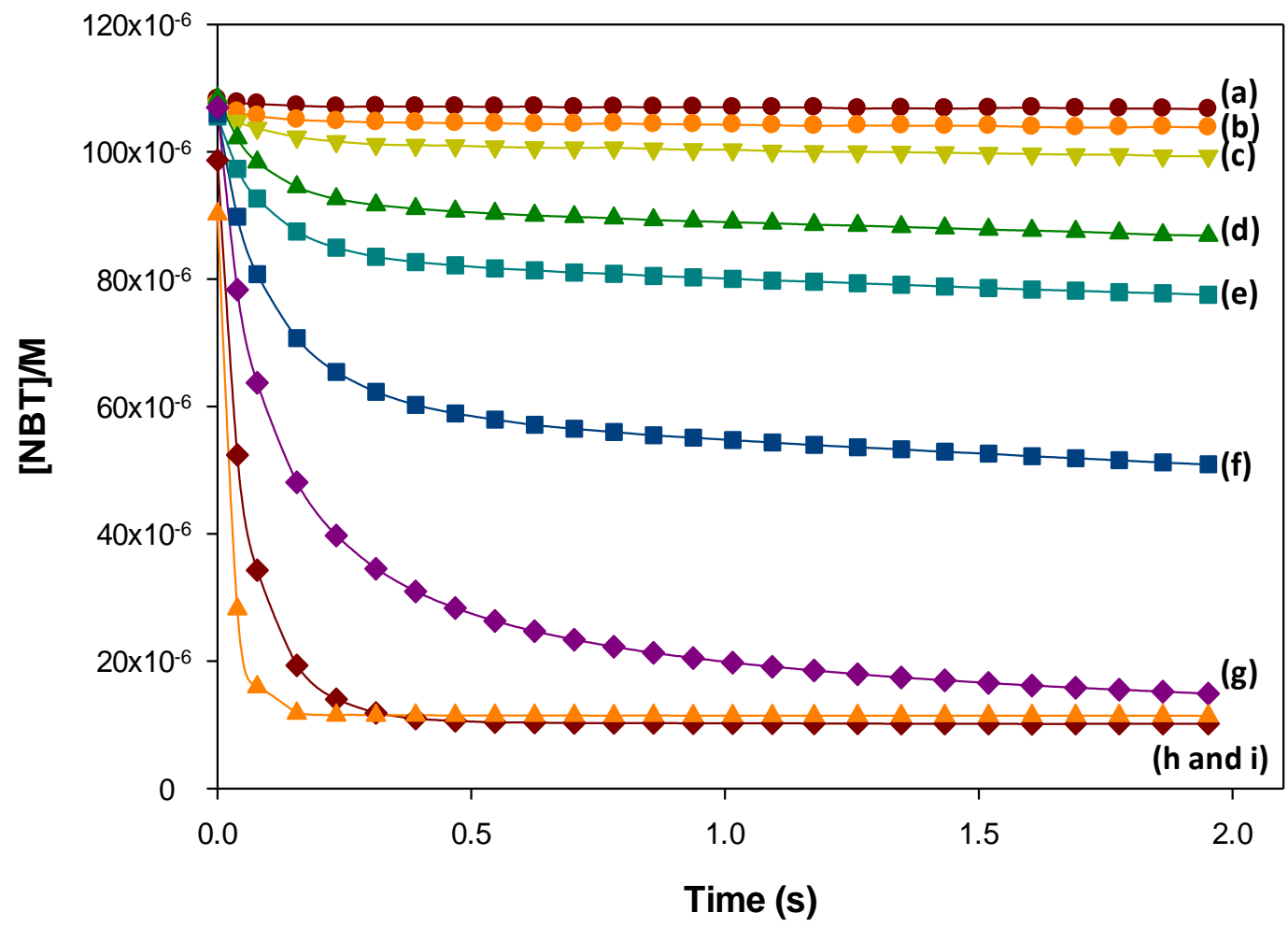

Figure 3.5: Reaction of 2-CBQ with NBT in 50\% acetonitrile in a pH 7.4 phosphate buffer at $25{ }^{\circ} \mathrm{C}$. Absorbance readings were performed at $412 \mathrm{~nm}$. Using $[N B T]_{0}=0.1$ $\mathrm{mM} \mathrm{BQ}$ concentrations were varied from (a) $0.0 \mathrm{mM}$, (b) $0.025 \mathrm{mM}$, (c) $0.05 \mathrm{mM}$, (d) 0.1 $\mathrm{mM}$, (e) $0.2 \mathrm{mM},(f) 0.4 \mathrm{mM},(\mathrm{g}) 0.8 \mathrm{mM}$, (h) $1.6 \mathrm{mM}$ and (h) $3.2 \mathrm{mM}$. 


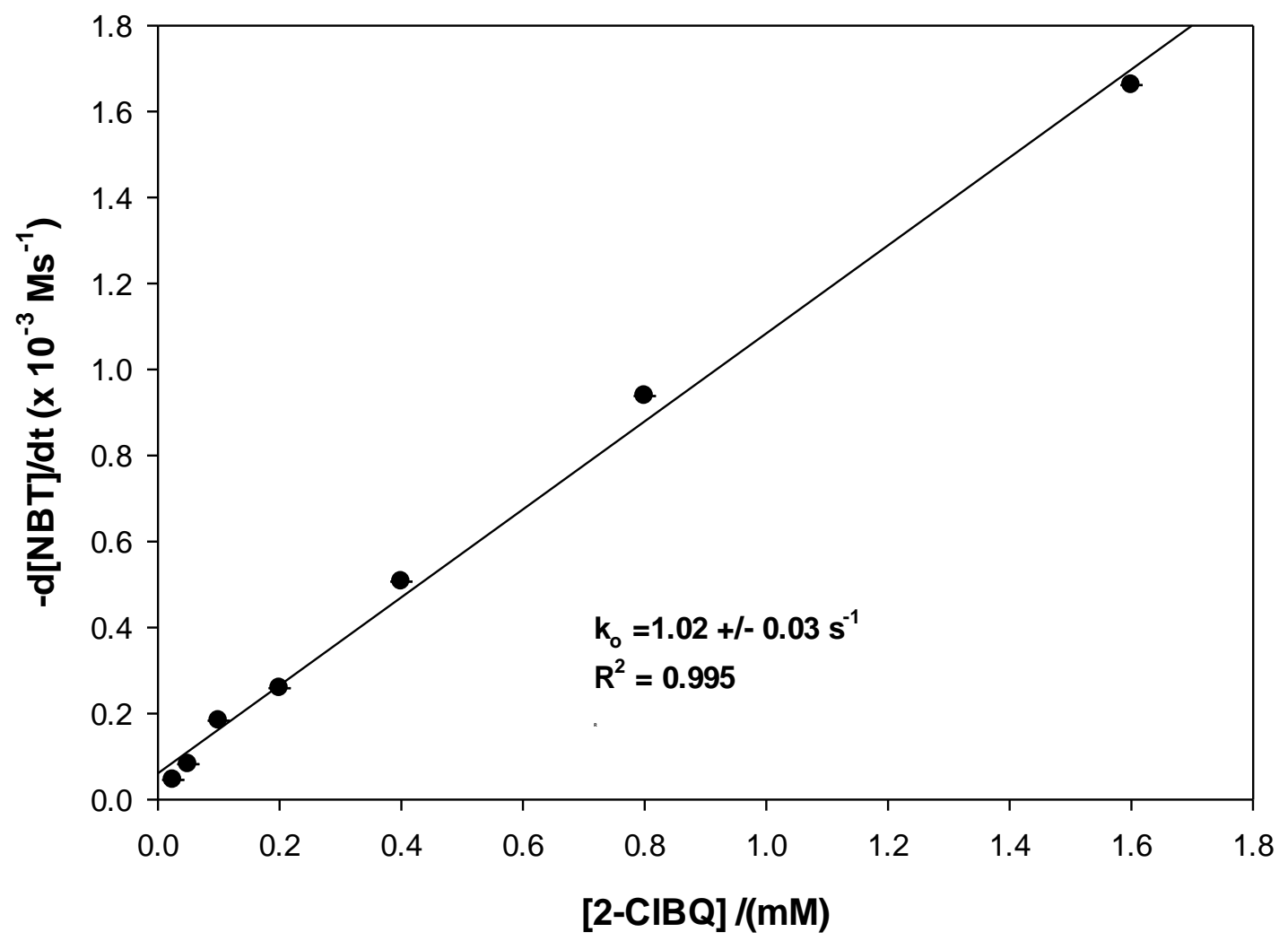

Figure 3.6: Initial rate vs. [2-CBQ] for results taken from Figure 3.5. Rate constants are calculated from the slope of the [E] vs. initial rate for NBT depletion. 
The NBT-E reactions were measured at different time intervals from $0.1 \mathrm{~s}$ to 10 min under pseudo-first order conditions ([NBT) « $[\mathrm{E}])$.

$$
N B T_{0}+E_{0} \rightarrow N B T_{0}-E_{0}+N B T_{t}
$$

The absorbance of the remaining free thiol at time $t$, was used to calculate $[\mathrm{NBT}]_{t}$ using the molar absorptivity of NBT.

$$
\left[N B T_{0}\right]=\left(A_{N B T t}\right) /(\varepsilon)
$$

Figure 3.4 and Figure 3.6 show how the apparent rate constant $\left(k=-k_{a}[N B T]_{0}\right)$ and order of reactions with respect to electrophile were determined from the slope of the at least five initial rates $\left(\mathrm{R}_{\mathrm{i}}\right)$ against five concentration variations of $\mathrm{E}$ for a fixed [NBT]. Linear plots which were obtained with all NBT- E reactions (e.g., Figure 3.4, ${ }^{2}=0.997$ ) confirmed that the reactions were pseudo first order with respect to BQD. The order of reactions of $\mathrm{BQD}$ and the apparent rate constants $(k)$ are listed in Table 3.2. Equation 3.3 for initial rates, derived from Equation 3.1, was integrated to give Equation 3.4 for the overall reaction where $k^{\prime}=k_{a}[E]_{o}$;

$$
\begin{gathered}
R_{i}=d[N B T] / d t=-k_{a}[N B T]_{0}[E]_{o} \\
\ln \left\{[N B T]-[N B T]_{\infty}\right\}=-k^{\prime} t+\ln [N B T]_{0}
\end{gathered}
$$

The NBT depletion data for all initial concentrations of the BQD electrophiles $(E)$ were fitted into the integrated rate law (Equation 3.4) and the $k$ values given in Table 3 
calculated for the given $[E]$ variations for all $\mathrm{BQD}$. NBT is amenable to oxidative reactions such as disulfide formation which can compete with NBT reactions with the BQD. The side reactions for NBT were minimized by varying initial $[E]_{0}$ and plotting the slopes, $\left(-k_{\mathrm{S}}[E]_{0}\right)$, obtained from plots of data fitted into Equation 3.4 against $[E]_{0}$. By assuming that the $k_{i} \ll k_{s}$ within the overall reaction time, where $k_{i}$ is the rate of loss of NBT due side reactions and $k_{s}$ is the rate of NBT reaction with E the Equation 3.5 is reduced to Equation 3.6;

$$
\begin{aligned}
& R=-d[N B T] / d t=-k_{a}[N B T]_{o}[E]_{o}+k_{i}[N B T] \\
& R=-d[N B T] / d t=-k_{a}[N B T]_{o}[E]_{o}
\end{aligned}
$$

Pseudo-first-order rate constants were calculated as the slopes of the resultant linear curves ([E] vs $-k_{a}[E]_{o}$ and intercept gave the pseudo-first-order rate constant $k_{\mathrm{i}}$ for the side reaction. The rate constants $\mathrm{k}_{\mathrm{a}}, \mathrm{k}_{\mathrm{s}}$ and $\mathrm{k}_{\mathrm{i}}$, are listed in Table 3.2.

The rate constant values for $k_{a}$ and $k_{s}$ were not significantly different for all BQD. There was an increase in the disulfide formation or loss of NBT for chlorine substituted BQ as indicated by higher $k_{i}$ values (ranging from $2.98 \mathrm{~s}^{-1}$ for CBQ to $0.387 \mathrm{~s}^{-1}$ for 2,6-DCBQ). The rate constants in Tables 3.1-3.2 demonstrate that reactivity of BQ decreased significantly when electron donating groups were added with the observed order $\left(\mathrm{CH}_{3}\right)_{3} \mathrm{C}$ $<\mathrm{CH}_{3}<\mathrm{H}$. The reaction half-lives ( $\left.\mathrm{t}_{1 / 2}\right)$ ranged from $0.4 \mathrm{~ms}(\mathrm{BQ})$ to $0.95 \mathrm{~s}(\mathrm{tBBQ})$.

In comparison, the rate constants for electron withdrawing substituents (EWG) substituents were much higher than those of electron donating substituents (EDG) at $\mathrm{pH}$ 7.4. For example the rate constant for CBQ was 132 fold higher than that for MBQ and 
that of 2,5-DCBQ was $2.5 \times 10^{6}$ higher than that of DMBQ. The kinetics at $\mathrm{pH} 5.5$ for BQD with EWG were too fast to be measured on the stopped-flow spectrophotometer.

Table 3.1: Rate Constants Derived from the Initial Rate Methods for NBT-BQ/BQD Reactions.

\begin{tabular}{|c|c|c|c|}
\hline Chemical & $k\left(\mathrm{~s}^{-1}\right)$ & $\overline{\mathbf{r}^{2}}$ & Order \\
\hline $\begin{array}{l}\mathrm{BQ}(\mathrm{pH} 7.4) \\
\mathrm{BQ}(\mathrm{pH} 5.5)\end{array}$ & $\begin{array}{l}(6.96 \pm 0.02) \times 10^{-1} \\
1.622 \pm 1.09\end{array}$ & $\begin{array}{l}0.996 \\
0.989\end{array}$ & $\begin{array}{l}1 \\
1\end{array}$ \\
\hline $\begin{array}{l}(E D G) p H 7.4 \\
\text { MBQ } \\
\text { tBBQ } \\
2,5-\mathrm{DMBQ}\end{array}$ & $\begin{array}{l}(7.75 \pm 0.03) \times 10^{-3} \\
(1.91 \pm 0.08) \times 10^{-3} \\
(7.22 \pm 0.24) \times 10^{-5}\end{array}$ & $\begin{array}{l}0.994 \\
0.991 \\
0.994\end{array}$ & $\begin{array}{l}1 \\
1 \\
1\end{array}$ \\
\hline $\begin{array}{l}(\mathrm{EWG}) \mathrm{pH} 7.4 \\
\text { CBQ } \\
2,6-\mathrm{DCBQ} \\
2,5-\mathrm{DCBQ}\end{array}$ & $\begin{array}{l}1.023 \pm 0.03 \\
(8.72 \pm 5.07) \times 10^{1} \\
(1.97 \pm 0.12) \times 10^{2}\end{array}$ & $\begin{array}{l}0.996 \\
0.987 \\
0.989\end{array}$ & $\begin{array}{l}1 \\
1 \\
1\end{array}$ \\
\hline $\begin{array}{l}(E D G) \text { pH } 5.5 \\
\text { MBQ } \\
\text { tBBQ } \\
2,5-\mathrm{DMBQ}\end{array}$ & $\begin{array}{l}(1.31 \pm 0.34) \times 10^{-1} \\
(3.32 \pm 0.04) \times 10^{-2} \\
(2.30 \pm 0.07) \times 10^{-3}\end{array}$ & $\begin{array}{l}0.997 \\
0.999 \\
0.995 \\
\end{array}$ & $\begin{array}{l}1 \\
1 \\
1\end{array}$ \\
\hline
\end{tabular}

The reactivity of BQ was enhanced significantly when the substituents were electron withdrawing. The order of reactivity was $\mathrm{BQ}<\mathrm{CBQ}<2,6-\mathrm{DCBQ}<2,5-\mathrm{DCBQ}$ as demonstrated by the $\mathrm{k}$ values in Table 3.2 and Table 3.2. 
Table 3.2: Rate Constants and Half Lives for $\mathrm{BQ}$ and $\mathrm{BQD}$ at $\mathrm{pH} 7.4$ and 5.5.

\begin{tabular}{lccll}
\hline Chemical & $\boldsymbol{k}_{\boldsymbol{a}}\left(\mathbf{s}^{-1}\right)$ & $\boldsymbol{k}_{\boldsymbol{s}}\left(\mathbf{s}^{-1}\right)$ & $\mathbf{t}_{1 / 2}(\mathbf{s})$ & $\boldsymbol{k}_{\boldsymbol{i}}\left(\mathbf{s}^{-1}\right)$ \\
\hline BQ $(\mathrm{pH} 7.4)$ & $1.66 \times 10^{3}$ & $(1.50 \pm 0.22) \times 10^{3}$ & $4.44 \times 10^{-4}$ & $1.06 \times 10^{-2}$ \\
BQ $(\mathrm{pH} 5.5)$ & $2.61 \times 10^{4}$ & $(2.26 \pm 0.08) \times 10^{4}$ & $3.07 \times 10^{-5}$ & $6.94 \times 10^{-1}$ \\
& & & & \\
\hline$(E D G) p H 7.4$ & & & \\
MBQ & $3.87 \times 10^{2}$ & $(3.23 \pm 0.01) \times 10^{2}$ & $2.14 \times 10^{-3}$ & $5.74 \times 10^{-3}$ \\
tBBQ & $2.39 \times 10^{1}$ & $(2.31 \pm 0.03) \times 10^{1}$ & $3.00 \times 10^{-2}$ & $8.06 \times 10^{-4}$ \\
DMBQ & $7.47 \times 10^{-1}$ & $(7.27 \pm 0.21) \times 10^{-1}$ & $9.54 \times 10^{-1}$ & $2.93 \times 10^{-4}$ \\
& & & & \\
(EWG) pH 7.4 & & & & \\
CBQ & $2.18 \times 10^{5}$ & $(2.62 \pm 0.01) \times 10^{5}$ & $2.64 \times 10^{-6}$ & $3.78 \times 10^{-1}$ \\
$2,6-D C B Q$ & $1.60 \times 10^{6}$ & $(1.21 \pm 0.04) \times 10^{6}$ & $5.74 \times 10^{-7}$ & 2.98 \\
$2,5-D C B Q$ & $2.92 \times 10^{6}$ & $(2.83 \pm 0.09) \times 10^{6}$ & $2.45 \times 10^{-7}$ & $2.99 \times 10^{-1}$ \\
& & & & \\
\hline (EDG) pH 5.5 & & & & \\
MBQ & $1.51 \times 10^{3}$ & $(1.60 \pm 0.07) \times 10^{3}$ & $4.34 \times 10^{-4}$ & $1.71 \times 10^{-3}$ \\
tBBQ & $3.60 \times 10^{2}$ & $(3.37 \pm 0.06) \times 10^{2}$ & $2.06 \times 10^{-3}$ & $3.33 \times 10^{-2}$ \\
DMBQ & $1.05 \times 10^{1}$ & $(1.25 \pm 0.03) \times 10^{1}$ & $5.56 \times 10^{-2}$ & $1.48 \times 10^{-3}$ \\
\hline
\end{tabular}

\subsubsection{Benzoquinone Derivatives and Free Radical Formation}

Figures 3.7(a-e) show the EPR signals that were observed with EWG substituted BQD. No EPR signals were observed with free DMPO and all EDG substituted BQD. The EPR signal intensity was in the order; 2,5-DCBQ $>2,6-\mathrm{DCBQ}>\mathrm{CBQ}>\mathrm{BQ}$. This trend in EPR intensity signal was the same trend which was observed with pseudo-first order rate constants. Reduction of the BQ resulted in a weak signal of approximate 1:2:1, triplet line spectrum $\left(\mathrm{a}^{\mathrm{H} 2}=\mathrm{a}^{\mathrm{H} 3}=\mathrm{a}^{\mathrm{H} 5}=\mathrm{a}^{\mathrm{H} 6}=2.4 \mathrm{G}\right.$ at $\mathrm{pH}$ 7.4). Under the same conditions $(50 \mathrm{mM}$ DMPO and $\mathrm{pH}$ 7.4) there was a 5 fold increase in SQ yield from reduced CBQ compared to the reduced BQ radical. 


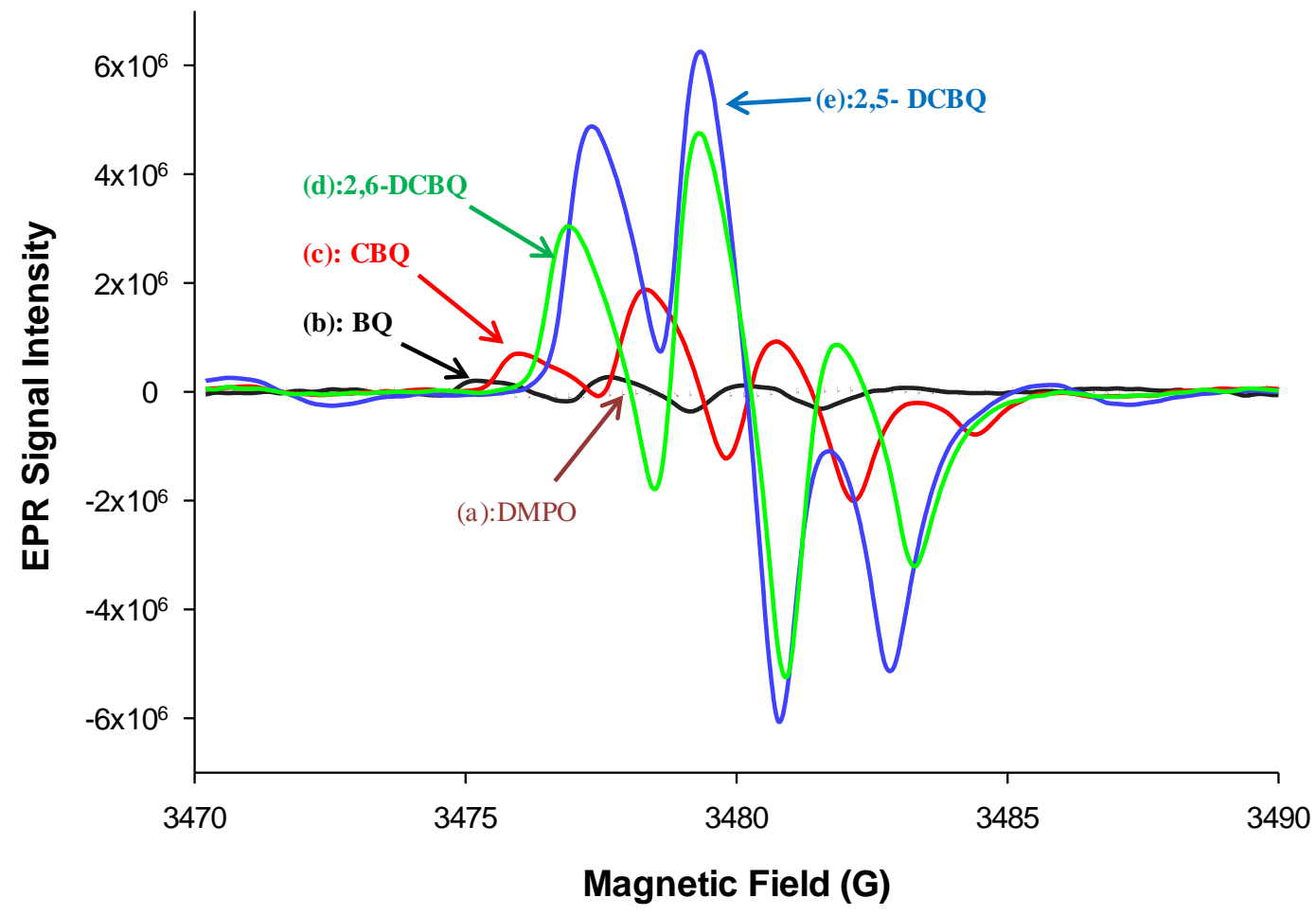

Figure 3.7: Effects of chlorine substitution on $B Q$ on EPR signal intensity for (a) $D M P O,(b) B Q$ (c) CBQ, (d) 2,6-DCBQ and (e) 2,5-DCBQ in $50 \mathrm{mM}$ phosphate buffer, $100 \mathrm{mM} D M P O$ and $50 \mu M$ of the corresponding $B Q D$ at $25^{\circ} \mathrm{C}$.

This demonstrated that the chlorine substituent has an effect on SQ radical yield. CBQ reduction gave a quartet of lines, with a peak height ratio of 1:3:3:1 and hyperfine splitting of $\mathrm{a}^{\mathrm{H} 3}=2.2 \mathrm{G}, \mathrm{a}^{\mathrm{H} 5}=2.4 \mathrm{G}$ and $\mathrm{a}^{\mathrm{H} 6}=2.3 \mathrm{G}$ as shown in Figure 3.7.

The addition of another chlorine atom (2,6-DCBQ) resulted in a 3 fold increase in signal intensity of the corresponding SQ radical compared to the EPR signal from CBQ. 2,6-DCBQ gave the expected triplet line spectrum $(1: 2: 1), \mathrm{a}^{\mathrm{H} 3}=\mathrm{a}^{\mathrm{H} 5}=2.5 \mathrm{G}$. There was an observed 1.3 fold increase in the signal intensity signifying an increase in stabilization effect when the second chlorine was put on the $5^{\text {th }}$ position of the ring to form 2,5 - 
DCBQ. A triplet line spectrum $(1: 2: 1)$ was also observed with $2,5-\mathrm{DCBQ}$, with $\mathrm{a}^{\mathrm{H} 3}=\mathrm{a}^{\mathrm{H} 6}$ $=2.2 \mathrm{G}$.

There was an observed shift in peaks to higher magnetic field and g-value whenever a chlorine atom was added or changed positions on the BQ and the same trend of increase (depending on number and position of chlorine atom) was observed on EPR signal intensity (Table 3.3.

Table 3.3: Summary of Peak shift and g-factor Values.

\begin{tabular}{lcc}
\hline Chemical & Peak shift $(\mathbf{m T})$ & g-factor \\
\hline BQ & 0 (Standard) & 2.001382 \\
CBQ & 0.0782 & 2.001534 \\
$2,6-D C B Q$ & 0.176 & 2.001585 \\
$2,5-D C B Q$ & 0.215 & 2.002077 \\
\hline
\end{tabular}

\subsubsection{The Effect of pH on Radical formation}

The determination of the effect of $\mathrm{pH}$ on radical formation was done using phosphate buffer from $\mathrm{pH} 5.5$ to $\mathrm{pH}$ 8.6. Using 2,6-DCBQ as an example, Figure 3.8 shows that there was no EPR signal detected when $\mathrm{pH}$ was below 6.5. The increase in $\mathrm{pH}$ from 6.5 introduces more $\mathrm{OH}^{-}$ions into the system which act as a reducing agent to quinones giving semiquinone radicals. ${ }^{77}$ The peak signal intensity went up from $\mathrm{pH} 6.5$ to 7.6 and then down after $\mathrm{pH}$ 7.6. 


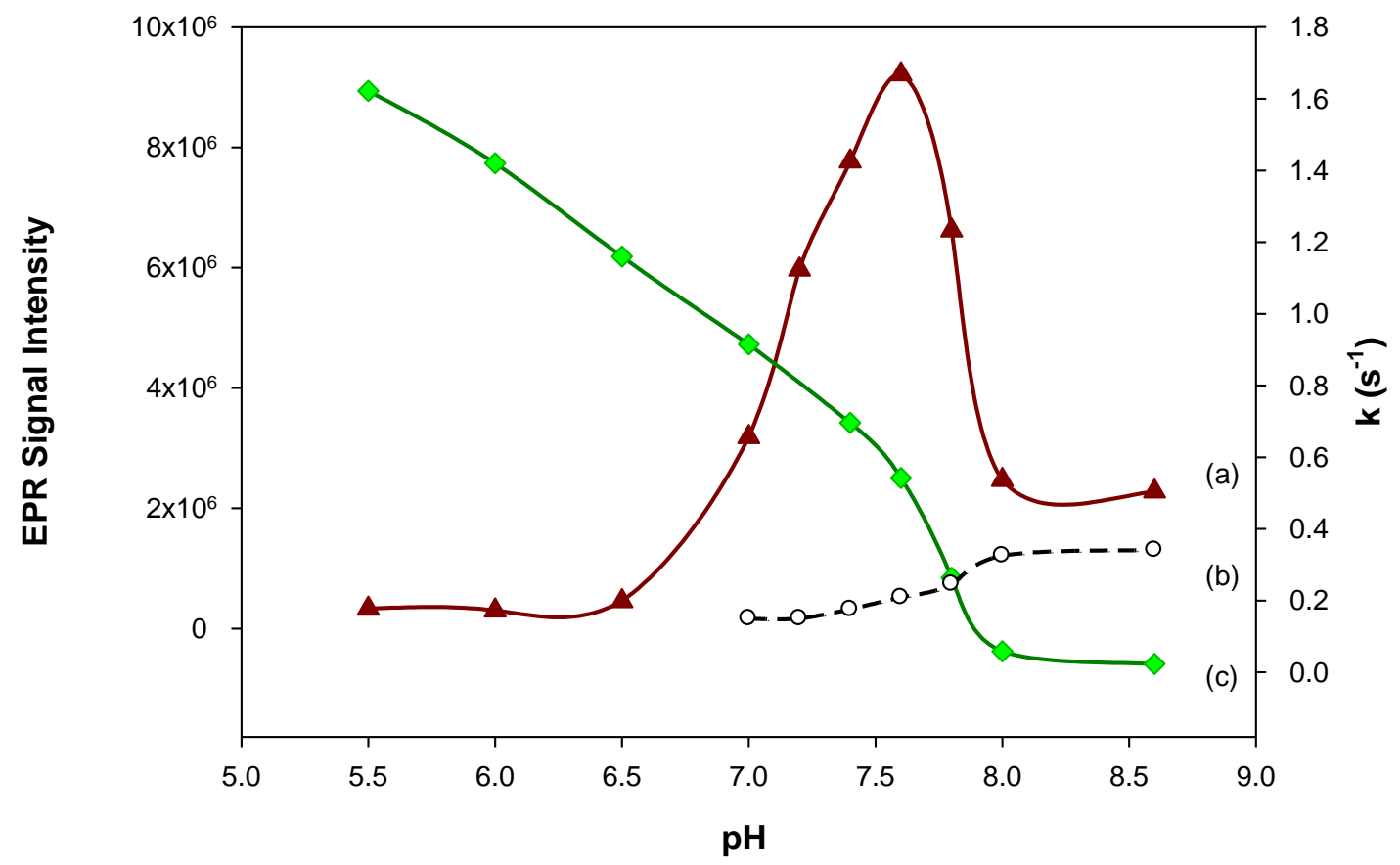

Figure 3.8: The relationship between EPR signal intensity and rate constants due to $\mathrm{pH}$ variation for $[2,6-D C B Q]_{0}=50 \mu M$ in $50 \mathrm{mM}$ of phosphate buffer and $100 \mathrm{mM} \mathrm{DMPO}$ at $25^{\circ} \mathrm{C}$. (a) EPR signal due to DMPO-SQ adduct formation (b) EPR signal due to $D M P O-O H$ and trace (c) shows the effect of $\mathrm{pH}$ on the rate of reaction between 2,6$D C B Q$ and NBT. There is an inverse relationship between the rate constant and EPR DMPO-SQ signal.

Under the aerobic conditions of these experiments the oxygen acts as a fast and efficient radical quencher whilst forming a superoxide or peroxy radical (ROO*). ${ }^{77}$ The decrease in signal intensity peak after $\mathrm{pH} 7.4$ is attributed to the peroxy radicals which are reported to form from dissolved oxygen ${ }^{78}$ The spectrum was composed of a quartet of lines, with a peak height ratio of $1: 2: 2: 1$, with parameters including hyperfine constants, $\mathrm{a}^{\mathrm{H}}=14.8 \mathrm{G}$ and was attributed to the DMPO-OH. These parameters are typical of a DMPO-OH adduct EPR signal generated by the reaction of $\mathrm{OH}$ with DMPO. ${ }^{79}$ The peaks 
at $\mathrm{pHs}>7.6$ increased in intensity then went down as the DMPO-OH adduct peaks appeared and increased in intensity. A proposed scheme leading to DMPO-OH formation is shown in Figure 3.9. The electron g-factors of BQD radicals changed with increasing number of chlorine atoms and position(s) of the chlorine substituents on the BQ ring (Table 3.3). Compared to BQ radical $(g=2.001382)$ the CBQ $(g=2.001534, \Delta \mathrm{g}$ $=0.000152)$ and the $2,6-\mathrm{DCBQ}(\mathrm{g}=2.001585, \Delta \mathrm{g}=0.000203)$ and changing chlorine position to 2,5-DCBQ $(2.002077, \Delta \mathrm{g}=0.000695)$. This increase in g-value was harmonious with the increased spin orbit coupling that is expected with increasing number of chlorine atoms.

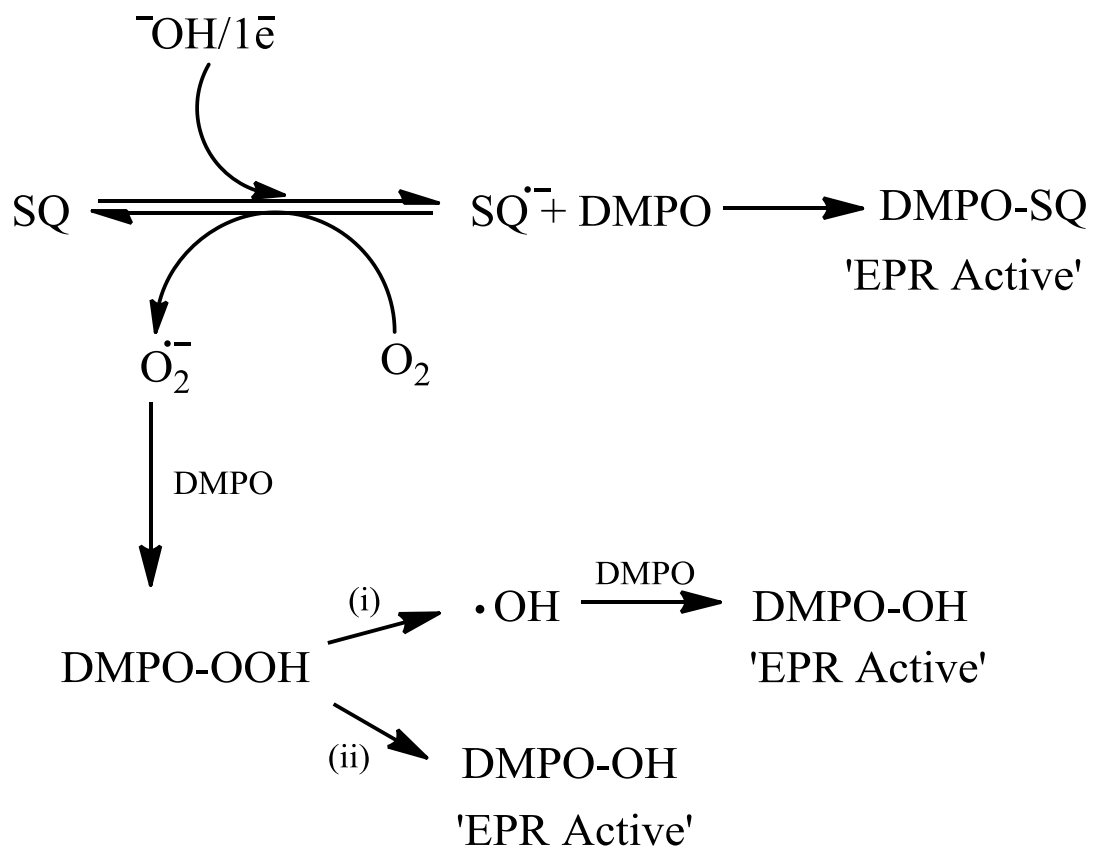

Figure 3.9: Schematic routes which lead to DMPO-SQ and DMPO-OH EPR active adduct formation. 


\subsubsection{EPR Spectrum Simulations}

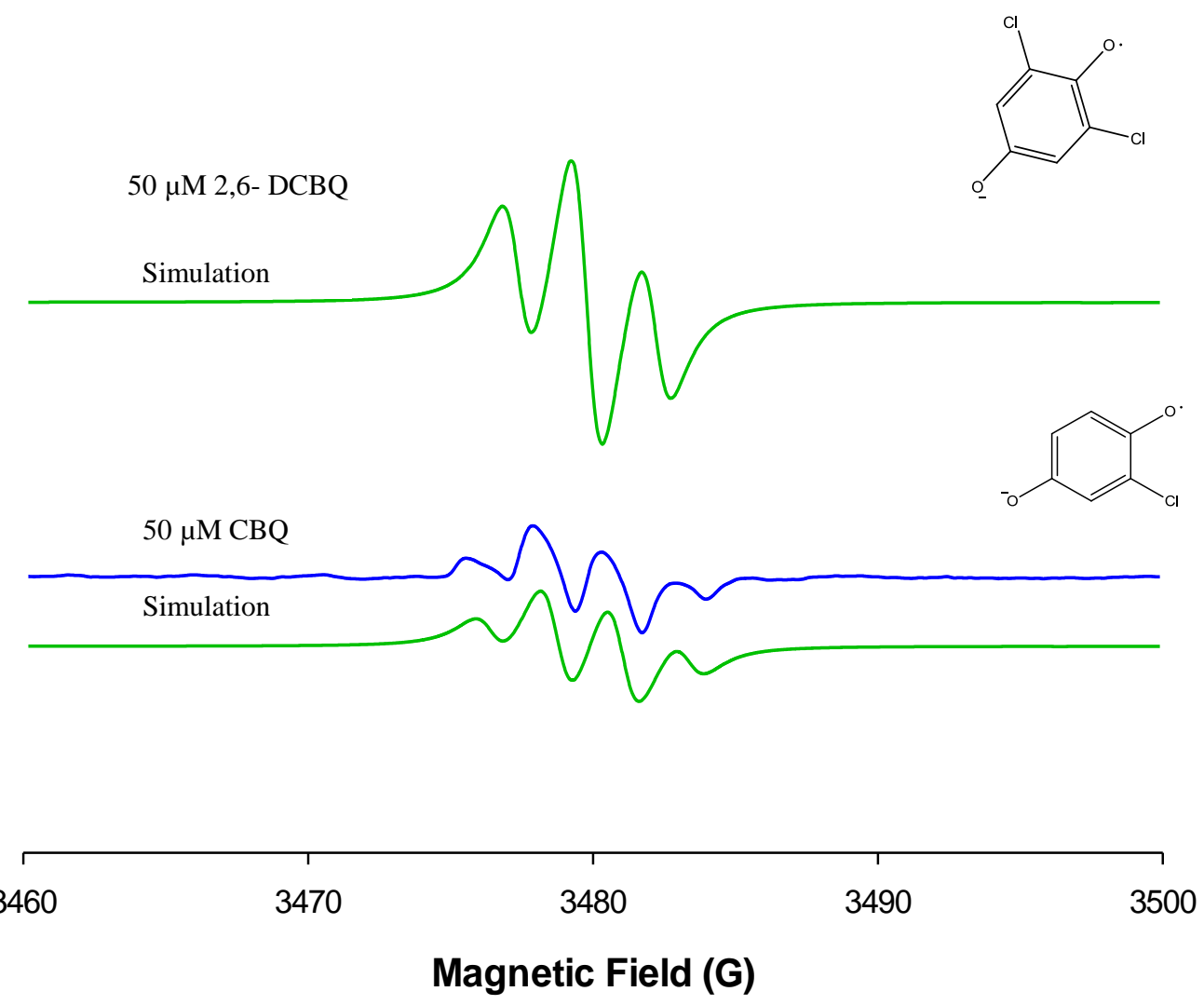

Figure 3.10: Computer simulations on the effects of chlorine substitution on $B Q$ on EPR signal intensity data shown in Figure 5(c) CBQ and (d) 2,6-DCBQ. This model gave a reasonably good fit to the experimental data in both hyperfine splitting constants and the signal intensity.

The main objective with respect to spectrum simulations was to obtain a satisfactory simulation of the room-temperature EPR spectrum for BQ with EWG using CBQ and 2,6-DCBQ as examples (see Figure 3.10). The fitting of the data were simple and the best fit values were obtained with hyperfine splitting constant, $\mathrm{a}^{\mathrm{H} 3}=\mathrm{a}^{\mathrm{H} 5}=2.5 \mathrm{G}$ for 2,6-DCBQ and $\mathrm{a}^{\mathrm{H} 3}=2.2 \mathrm{G}, \mathrm{a}^{\mathrm{H} 5}=2.4 \mathrm{G}$ and $\mathrm{a}^{\mathrm{H} 6}=2.3 \mathrm{G}$ for CBQ. The adopted values 
for hyperfine splitting constant are most likely valid for the BQD radical formation at physiological $\mathrm{pH}$.

\subsubsection{NBT Effect on SQ Radical Formation}

Figure 3.11 shows that the addition of NBT to a DMPO and 2,6-DCBQ mixture decreased the amount of EPR signal formed even when the DMPO was in excess over both the NBT and the 2,6-DCBQ. Control experiments showed no reactivity between DMPO and NBT. Figure 3.9 shows that mixing NBT and 2,6-DCBQ in equimolar quantities resulted in about 50\% loss of EPR signal. When NBT was 3-fold in excess over 2,6-DCBQ the EPR signal loss was > 90\% in agreement with the NBT-2,6-DCBQ reactivity that was observed. The loss of EPR signal is due to NBT-BQ adduct formation overpowering the production of DMPO-SQ adduct formation. This shows that the rate of production of free radicals from 2,6-DCBQ is much slower than the rate of adduct formation between NBT and the 2,6-DCBQ. The NBT quenches the system of any available 2,6-DCBQ thus no radicals are produced. This suggests that the free radical mechanism is overshadowed by the MA and therefore has minimal contribution to the rate constants obtained for the rapid depletion of NBT. 


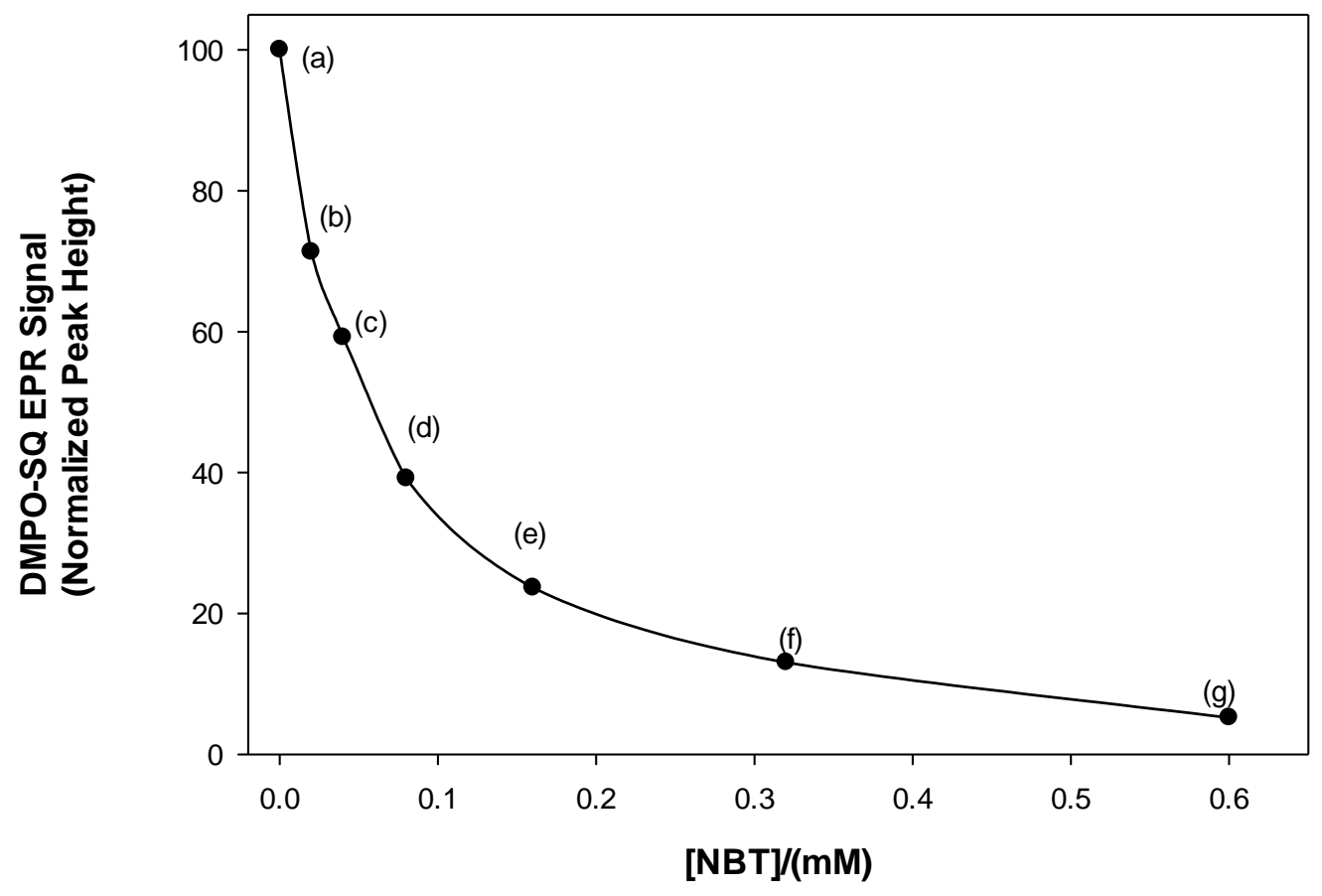

Figure 3.11: Plot of depletion of DMPO-SQ signal versus [NBT] at $25^{\circ} \mathrm{C}$. [DMPO]o $=100 \mathrm{mM},[2,6-D C B Q]_{0}=0.05 \mathrm{mM}$, and varied $[N B T]=($ a) $0 \mathrm{mM},(b) 0.02 \mathrm{mM},(\mathrm{c})$ $0.04 \mathrm{mM}$, (d) $0.08 \mathrm{mM}$, (e) $0.16 \mathrm{mM}$, (f) $0.32 \mathrm{mM}$ and $0.6 \mathrm{mM}$ in $100 \mathrm{mM}$ phosphate buffer of $\mathrm{pH} 7.4$.

\subsection{DISCUSSION}

Murine local lymph node (LLNA) studies rank BQ as an extreme dermal sensitizer with an EC3 (threshold) value of $0.013 \% .{ }^{80} \mathrm{BQ}$ covalent binding to proteins resulting in immunogenic complexes has been attributed to BQ's reactivity as a Michael acceptor. New evidence ${ }^{81,82}$ on both the quinone's unique electrophilic chemistry and high reactivity, however, provides alternative hypothesis on the possible contributory role of other reaction pathways to BQ's overall reactivity towards nucleophiles such as 
cysteinyl amino acids on proteins.$^{83}$ The impact of substituents on BQ's reactivity and ultimate in vivo allergenicity had not been previously assessed.

Binding experiments with HSA demonstrated that Cys34 (the only reduced thiol in HSA) on the protein is the preferred target for BQ binding and the bond formed is an irreversible covalent bond. BQ was shown to have high affinity for thiols when serum was used as the source for thiols. Comparison of BQ and NEM blocked thiols pre- and post-dialysis showed that the ratios $\left[\mathrm{SH}_{\mathrm{r}}\right] /\left[\mathrm{SH}_{\mathrm{T}}\right]$ and $\left[\mathrm{SH}_{\mathrm{d}}\right] /\left[\mathrm{SH}_{\mathrm{Td}}\right]$ were equal demonstrating the binding of $\mathrm{BQ}$ to both high and low molecular weight thiols such as cysteine and glutathione. The binding of BQ to cysteine and glutathione may result in reduced BQ available for protein binding, but its extreme potency ${ }^{80}$ in the LLNA assay shows that the concentrations absorbed through the skin during the in vivo assay are high enough to overcome any clearance which may result from low molecular weight thiol binding. The observed $85.5 \%$ loss of reactivity to thiols compared to $18 \%$ loss of reactivity to primary amines under identical conjugation conditions, demonstrates that $\mathrm{BQ}$ is much more reactive to thiols than amines, in agreement with previously reported observations. ${ }^{84}$

The thiol nucleophile, NBT, was used to measure reactivity of six BQD. NBT has previously been utilized as a model nucleophile where relative reactivity of electrophilic allergens to NBT was highly correlated to LLNA EC3 values. ${ }^{76}$ All the BQD tested rapidly reacted with NBT. There was, however, a 90 fold decrease in reactivity of the BQ ring when MBQ was reacted with NBT. The methyl group donates electrons into the $\mathrm{BQ}$ $\pi$ system leading to an increase in electron density on the $\pi$ system with consequent 
reduction of the partial positive charges on the electrophilic carbons on BQ. The $\pi$ electrons also repelled the electrons on the $-\mathrm{SH}$ group on NBT thus slowing down the reaction. The positive inductive effect became more apparent when the methyl group was replaced with the tert-butyl group. The reaction dropped by approximately 4 fold from MBQ to tBBQ. This was due to more electron donating ability of tert-butyl compared to methyl group. The steric hindrance offered by tert-butyl, to the incoming NBT, compared to the methyl group could also have contributed the decreased reactivity of tBBQ. For NBT-DMBQ reactions, the further 26-fold loss of reactivity relative to tBBQ can be attributed to the increased positive inductive effect of two methyl groups in close proximity to the reacting $\beta$ carbocations. The repulsive force of $\pi$ electron cloud around the electrophilic carbon was increased by having two methyl groups on the ring.

For activated $\mathrm{BQD}$ the pseudo-first order rate constants for $\mathrm{NBT}$ reactivity at $\mathrm{pH}$ 7.4 increased in the following order $\mathrm{BQ}<\mathrm{CBQ}<2,6-\mathrm{DCBQ}<2,5$-DCBQ (Table 3.2). The effect of the increased negative inductive effect on the rate constants is apparent from CBQ to the dichloro-substituted BQD. When 2,6-DCBQ was reacted with NBT there was an 85 -fold increase in NBT reactivity compared to CBQ. There was an observed increase in rate constants by 2 fold between 2,6-DCBQ and 2,5-DCBQ with the latter being faster. The difference in reactivity between the dichloro substituted derivatives may be attributed to the fact the 2,5-DCBQ has its chlorine atoms in para positions to each other which makes the carbon atoms on which the chlorine atoms are attached more partially positive due to inductive withdrawal of electrons, unlike the 2,6DCBQ which has chlorine atoms on meta positions to each other and do not influence 
each other by inductive electron withdrawal. This makes 2,5-DCBQ more reactive than 2,6-DCBQ. This strongly agrees with the findings of Enoch et al. ${ }^{85}$ in which a direct relationship between electrophilic effects of a chemical and rate reaction by Michael addition reaction were observed and used in an electrophilicity index for prediction of skin sensitization potential. For both 2,6-DCBQ and 2,5-DCBQ, the -SH on NBT adds on to position on which the chlorine atom is attached by MA and then nucleophilic elimination of the chlorine atoms (reaction of $1^{\text {st }}$ mole on Scheme 4.3).

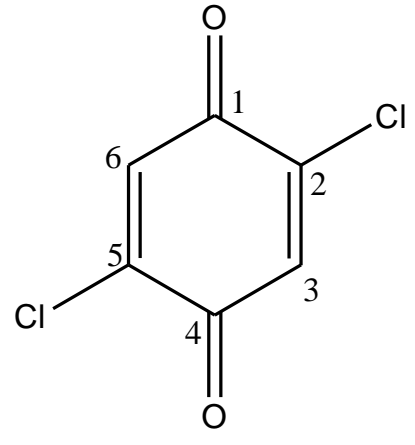

2,5-DCBQ

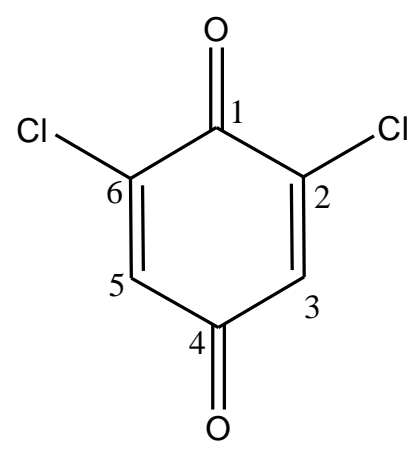

2,6-DCBQ

The structure for 2,5-DCBQ is such that it will undergo MA and then nucleophilic substitution onto position 2 and 5 which have the higher electrophilicity. 2,6-DCBQ where positions 2 and 6 are not influenced by the negative inductive effect of the chlorine atoms possess a lesser partial positive charge on these positions This makes 2,5-DCBQ more reactive than 2,6-DCBQ. Increased rate constants increased several-fold for MBQ, DMBQ and tBBQ when NBT reactivity was measured at $\mathrm{pH} 5.5$ suggesting that the MA reactions are acid catalyzed, Figure 3:6 shows an inverse relationship between rate constant and $\mathrm{pH}$. The acid catalysis is more pronounced for CBQ, 2,5-DCBQ and 2,6- 
DCBQ reactions performed at $\mathrm{pH} 5.5$ which could not be measured using the stopped flow technique. The fact that rate constants for MBQ, DMBQ and tBBQ had increased several-fold under $\mathrm{pH} 5.5$ but were still lower than those of CBQ, 2,5-DCBQ and 2,6DCBQ at $\mathrm{pH} 7.4$ demonstrates the agreement on the effect of electron donating versus electron withdrawing substituents on BQ reactivity under pH's 7.4 and 5.5.

BQ has been hypothesized to haptenate proteins via MA. The production of semiquinone (SQ) radicals as a mechanism of BQD protein haptenation was investigated and EPR signal intensity was of the order; 2,5-DCBQ > 2,6-DCBQ > CBQ > BQ. No EPR signals were observed with methyl- and tert-butyl-substituted BQD. BQ generated radicals are known to form through the one electron reduction of $\mathrm{BQ}$, followed by hemolytic cleavage of the O-O bonds on the carbonyl functional group. The resulting SQ radical may potentially bind directly to a protein. ${ }^{86}$ Thus the presence of the SQ radical indicated the potential of free radical mechanisms as another mechanism of BQD covalent modification of proteins. Increased production of free radicals from chlorosubstituted BQD (Figure 3.7) is a result of the high negative inductive effect arising from the highly electronegative chlorines. This activates the BQ in contrast to the positive inductive effect of the electron donating groups. The increase in g-values from the monochloro-substituted to the dichloro-substituted BQD is harmonious with the increased spin orbit coupling that was expected with increasing number of chlorine atoms. Halogenation of BQ has been known to increase the persistence of SQ radicals. ${ }^{87}$ The EPR results show that the yield of the SQ radicals resulting from chlorine substituted BQD depend on $\mathrm{pH}$ and on the position and number of chlorines on the SQ ring. 
The trend in EPR intensity signal agreed with the observed order of reactivity indicating that inductive effects have a dominant influence on the chemistry of the BQD compared with other factors such as steric hindrance. The effect of $\mathrm{pH}$ on radical formation (Figure 3.8) highlights the sensitivity of the SQ radicals to either acidic or basic conditions. The increase in $\mathrm{pH}$ from 6.5 to 7.6 might have introduced more $\mathrm{OH}^{-}$ ions into the system which act as a reducing agent to quinones giving semiquinone radicals. ${ }^{77}$ Beyond $\mathrm{pH} 7.6$ the $\mathrm{OH}^{-}$effect might have been overcome by the presence of produced oxygen which has been reported to act as a fast and efficient SQ radical quencher, forming a superoxide radical or peroxy radical (ROO) $)^{77}$ in the process (Figure 3.9). Peroxy radicals have been shown to produce dissolved oxygen in alkaline conditions thus availing more oxygen which quenches the SQ radical. The observed decrease in SQ radical peaks intensity at $\mathrm{pH}>7.6$ (Figure 3.8) as the peaks of DMPO-OH adduct simultaneously started appearing can explain the minimum or no role of $\mathrm{OH}^{-}$and oxygen quenching in the temporary increase in SQ radical intensity at pHs 7.6 and below followed by oxygen quenching at $\mathrm{pHs}$ beyond 7.6.

The contribution of a free radical pathway to protein haptenation may not be significant because of lack of production of SQ radicals at acidic $\mathrm{pH}$, in contrast with the increased NBT reactivity which was observed at $\mathrm{pH}$ 5.5. Skin $\mathrm{pH}$ is around 5.5 and lack of formation of radicals shown herein means that $\mathrm{BQ}$ and $\mathrm{BQD}$ binding to proteins will occur via MA with additional vinylic substitution where the substituents such as chlorine are good leaving groups. The dominance MA versus free radical formation was also demonstrated with the inclusion of NBT to (DMPO + BQ) mixture (pH 7.4) which 
resulted in quenching of the EPR signal even when the DMPO >> NBT and the BQD. The loss of EPR signal was due to NBT-BQ adduct formation (Figure 3.11) which formed at rate that was faster than the production of DMPO-SQ adduct formation. It may have been possible that NBT quenching of the EPR signal was due to the SQ radical forming quickly and then reacting with NBT to form an EPR silent adduct. This argument was, however, dismissed when MS and NMR characterization of adducts formed in the reaction mixture showed no presence of NBT-SQ adducts. NBT mops the system of any available BQD thus no radicals are produced. This aspect proves that the free radical mechanism plays a minimal role, at best, in BQD binding. The dominance of MA as a pathway is further supported by quantitative mechanistic read-across based estimation of BQ EC3 values which utilized known potency data for sensitizers in the MA domain. A theoretical EC3 value of $0.013 \%$ was obtained in agreement with actual LLNA EC3 value of $0.01 \% .^{80}$

The inclusion of substituents on BQ has been shown to have a profound effect on the overall chemistry of BQ. This is manifested in an increased or decreased reactivity of BQD toward NBT and the emergence of other mechanistic pathways such as free radical mechanism and vinylic substitution. From the hapten hypothesis ${ }^{88}$ perspective the effect of vinylic substitution for the chloro-substituted BQD would not lead to any immunogenic adducts that are different from those formed with BQ as this step is subsequent to MA which results in adduct formation. The substituted chlorine leaves as a salt which would not be expected to modify any proteins. 


\subsection{CONCLUSION}

It can be concluded that the order of reactivity of BQD to NBT was 2,5-DMBQ < $\mathrm{tBBQ}<2-\mathrm{MBQ}<\mathrm{BQ}<\mathrm{CBQ}<2,6-\mathrm{DCBQ}<2,5-\mathrm{DCBQ}$ as demonstrated by the $\mathrm{k}$ values. MA is the dominant mechanism for BQ and methyl-BQD haptenation of proteins and that MA followed by vinylic substitution is dominant for chlorine-BQD. Based on the findings in these studies SQ radical induced binding of proteins may play a minimal to no role in the development of BQD sensitization. 


\section{CHAPTER FOUR}

\section{CHARACTERISATION OF ADDUCTS AND REACTION MECHANISMS}

\subsection{INTRODUCTION}

Chemically induced modification of proteins by natural toxins and synthetic toxicants can alter protein function, disrupt signal transduction, and interfere with subcellular protein localization. This section gives an outline of the reaction mechanisms between BQD and NBT as well as identifying the corresponding adducts formed in the process. Chemical characterization is important to determine whether conjugation has been achieved and to quantitate the ratio of chemical ligands bound per molecule of carrier protein. Conjugate addition of one molecule of various sulfur nucleophiles to pbenzoquinones is well known. However, double conjugate additions of sulfur nucleophiles to p-benzoquinones are rare and only one such example was found in the literature. $^{14}$

The BQD-NBT products formed in phosphate buffer ( $\mathrm{pH}$ 7.4) were characterized. All reactions and products were separated using reversed-phase liquid chromatography (LC) with ultraviolet absorbance (UV), and mass spectrometric (MS) detection. It was very important that only reagent grade chemicals with a high degree of purity be used for the preparation of samples. The section serves to determine the stoichiometric binding ratio between $\mathrm{NBT}$ and $\mathrm{BQD}$, identification of adducts formed and relative abundance of 
reaction products observed using ESI-MS and identify the specific binding site(s) of NBT on BQD using ${ }^{1} \mathrm{HNMR}$.

\subsection{RESULTS AND DISCUSION}

2-((4-nitrophenyl) thiol) benzene-1, 4-diol(2a and 5a), was a product of both BQ and CBQ reaction with NBT. 2a was recovered by solvent extraction using n-hexane which was evaporated using a rotor evaporator. ${ }^{1} \mathrm{H} \mathrm{NMR}\left(\mathrm{CDCl}_{3}, 400 \mathrm{MHz}\right) \delta 8.10(\mathrm{~d}, \mathrm{~J}=$ $9.0 \mathrm{~Hz}, 2 \mathrm{H}), 7.14(\mathrm{~d}, \mathrm{~J}=9.0 \mathrm{~Hz}, 2 \mathrm{H}), 7.05-6.94(\mathrm{~m}, 3 \mathrm{H})$. ESI-MS exact mass calculated for $[\mathrm{M}-\mathrm{H}]^{-}$requires $m / z$ 262.01795, found 262.01779 2a and 262.01746 for 5a and ESIMS data was recorded using a scan range of $m / z$ 100-600.

2-methyl-6-((4-nitrophenyl)thio)benzene-1,4-diol (3a) was a produced as yellow crystals from the reaction of MBQ with NBT. The reaction mixture was purified by preparative TLC with the eluent ethyl acetate/n-hexane (1.5:8.5 ratio). ${ }^{1} \mathrm{H}$ NMR $\left(\mathrm{CDCl}_{3}, 400 \mathrm{MHz}\right) \delta(\mathrm{ppm}) 8.32(\mathrm{~d}, \mathrm{~J}=8.9 \mathrm{~Hz}, 9 \mathrm{H}), 7.71(\mathrm{~d}, \mathrm{~J}=8.9 \mathrm{~Hz}, 11 \mathrm{H}), 6.56(\mathrm{~s}$, 1H), 5.90 (s, 2H), 2.12 (s, 7H). For MS analysis ESI-MS solvent was 50:50 water: methanol which resulted in the $m / z$ 276.03259, against the exact mass $m / z=276.03360$ calculated for $[\mathrm{M}-\mathrm{H}]^{-}$.

2,5-bis((4-nitrophenyl)thio)benzene-1,4-diol (7a), The reaction mixture was purified by preparative TLC, eluent ethyl acetate/n-hexane (1:9 ratio) and orange crystals were obtained. ${ }^{1} \mathrm{H} \mathrm{NMR}\left(\mathrm{CDCl}_{3}, 400 \mathrm{MHz}\right) \delta(\mathrm{ppm}) 8.13(\mathrm{~d}, \mathrm{~J}=9.1 \mathrm{~Hz}, 2 \mathrm{H}), 7.30(\mathrm{~s}$, 1H), $7.17(\mathrm{~d}, \mathrm{~J}=9.1 \mathrm{~Hz}, 2 \mathrm{H})$. 


\section{2,5-dimethyl-3-((4-nitrophenyl)thio)benzene-1,4-diol (8), Flash}

chromatography eluent, $\mathrm{n}$-hexane $=100 \%$ with reaction time of $1 \mathrm{~min}$, then ethyl acetate/n-hexane $=1: 1$ for $12 \mathrm{~min}$. Fine yellow crystals after drying the solvent on a rotor vapor. ${ }^{1} \mathrm{H} \mathrm{NMR}\left(\mathrm{CDCl}_{3}, 400 \mathrm{MHz}\right) \delta(\mathrm{ppm}) 8.08(\mathrm{~d}, J=8.7 \mathrm{~Hz}, 2 \mathrm{H}), 7.09(\mathrm{~d}, J=8.7 \mathrm{~Hz}$, $2 \mathrm{H}), 6.82(\mathrm{~s}, 1 \mathrm{H}), 4.77(\mathrm{~s}, 2 \mathrm{H}), 2.35-2.15(\mathrm{~m}, 6 \mathrm{H}) .{ }^{13} \mathrm{C} \mathrm{NMR}\left(\mathrm{CDCl}_{3}, 100 \mathrm{MHz}\right) \delta$ (ppm) $125.76(\mathrm{~d}, \mathrm{~J}=7.3 \mathrm{~Hz}), 124.30,121.14,77.34,16.39,13.79$.

\subsubsection{Characterization of BQD-NBT Adducts}

Based on NMR and MS characterization of the NBT-BQD reaction products, NBT was shown to react with BQ 2 to give a 1:1 ratio product 2-((4-nitrophenyl) thiol) benzene-1, 4-diol 2a in phosphate buffer at pH 5.5 after $1 \mathrm{~h}$. The electron-donating group substituted benzoquinones reacted through MA (Scheme 4.2) giving a 1:1 ratio with NBT; MBQ 3 gave 2-methyl-6-((4-nitrophenyl)thio)benzene-1,4-diol 3a, tBBQ 4 gave 2(tert-butyl)-6-((4-nitrophenyl)thio)benzene-1,4-diol 4a and DMBQ 8 gave 2,5-dimethyl3-((4-nitrophenyl)thio)benzene-1,4-diol 8a. The reaction between CBQ 5 and NBT was involved two reaction mechanisms in the following order; MA reaction followed by vinylic substitution (Scheme 4.3). Reaction between NBT and CBQ gave 2 products as confirmed by ESI-MS (Figure 4.1); a monosubstituted benzoquinone, 2-((4nitrophenyl)thio)benzene-1,4-diol 5a, and disubstituted benzoquinone; 2,6-bis((4nitrophenyl)thio)benzene-1,4-diol 5b. The reaction between the di-substituted chlorobenzoquinones 2,5-DCBQ and 2,6-DCBQ gave corresponding di-substituted benzoquinone with chlorines being substituted by NBT in 1:2 ratios (BQD:NBT). 


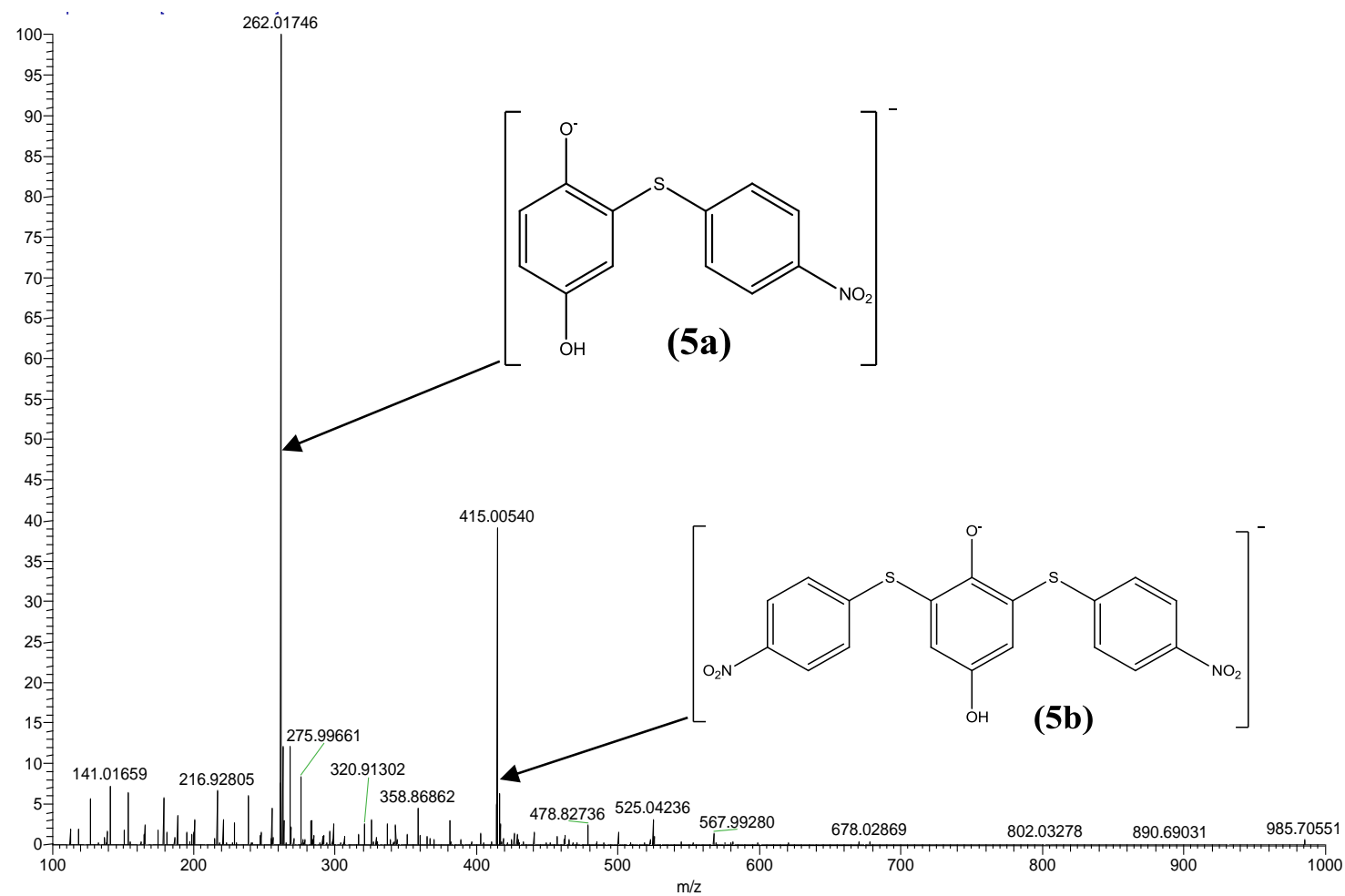

Figure 4.1: Negative ESI-MS spectra of p-nitrobenzenethiol adduct(s) formation with $C B Q$ giving a mono-NBT-hydroxyl BQ adduct $(\mathrm{m} / \mathrm{z}$ 415.00540) and a di-NBT-hydroxyl $B Q$ adduct $(\mathrm{m} / \mathrm{z}, 262.01746)$ and spectrum.

Reaction between 2,5-DCBQ 6 and NBT gave 2,5-bis((4-nitrophenyl)thio)benzene-1,4diol 6a whilst 2,6-DCBQ 7 gave a corresponding di-substituted benzoquinone ,2, 5bis((4-nitrophenyl)thio)benzene-1,4-diol 7a.

The BQD-NBT reaction is acid catalyzed as shown by the faster reaction rate at lower $\mathrm{pH}$. Acid facilitated the creation of a carbocation center on which the nucleophile attacks (Schemes 4.2 and 4.3). The reactions between electron donating substituted benzoquinone and NBT were direct 1:1 ratio MA reactions (Scheme 4.2). 


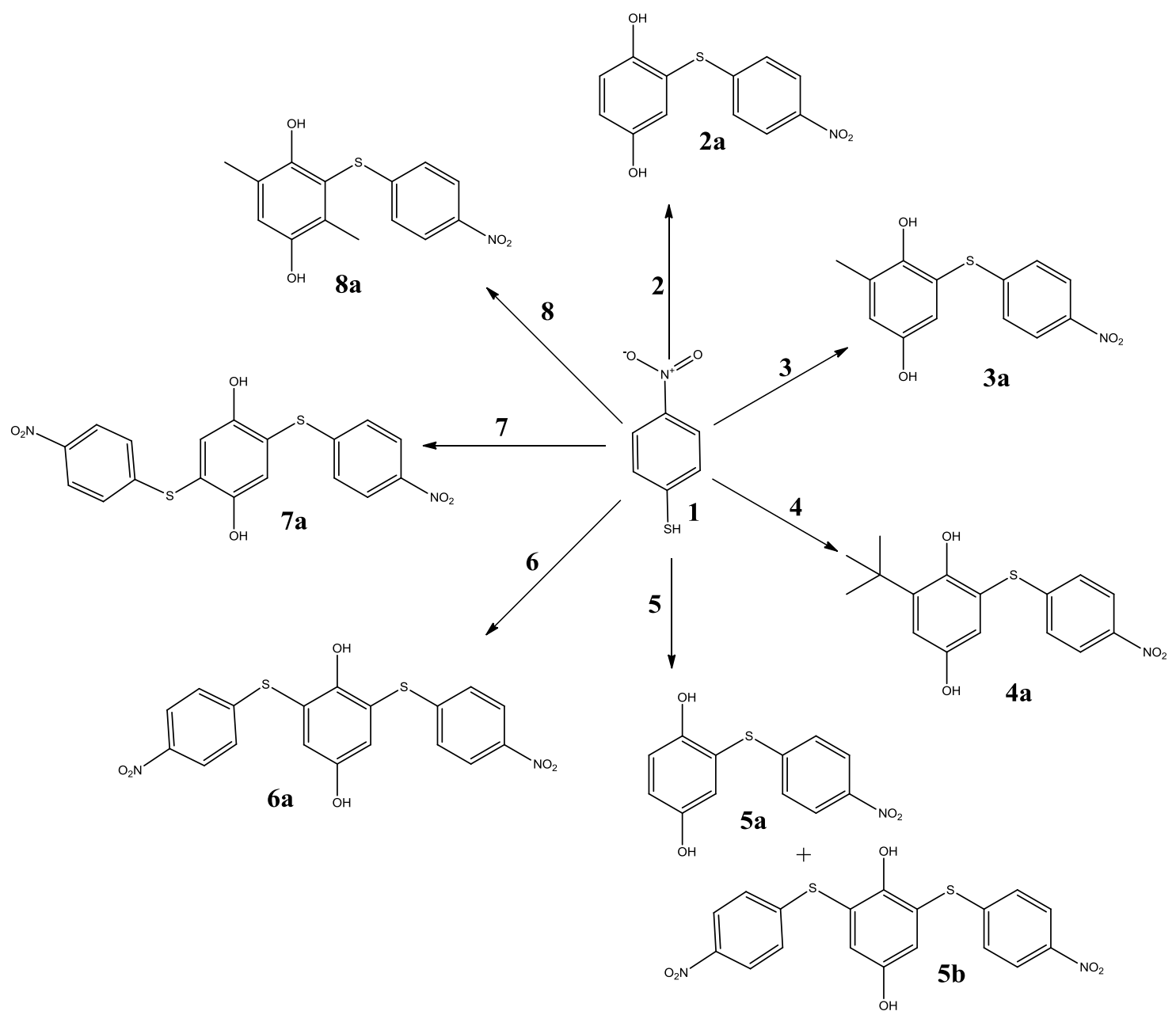

Scheme 4.1: Reaction mechanisms for electron withdrawing and electron donating substituted benzoquinones with NBT

NBT went onto position 6 for mono-substituted BQ and position 3 for disubstituted BQ (Scheme 4.1), and this was confirmed by ESI-MS (Figure 4.2). 


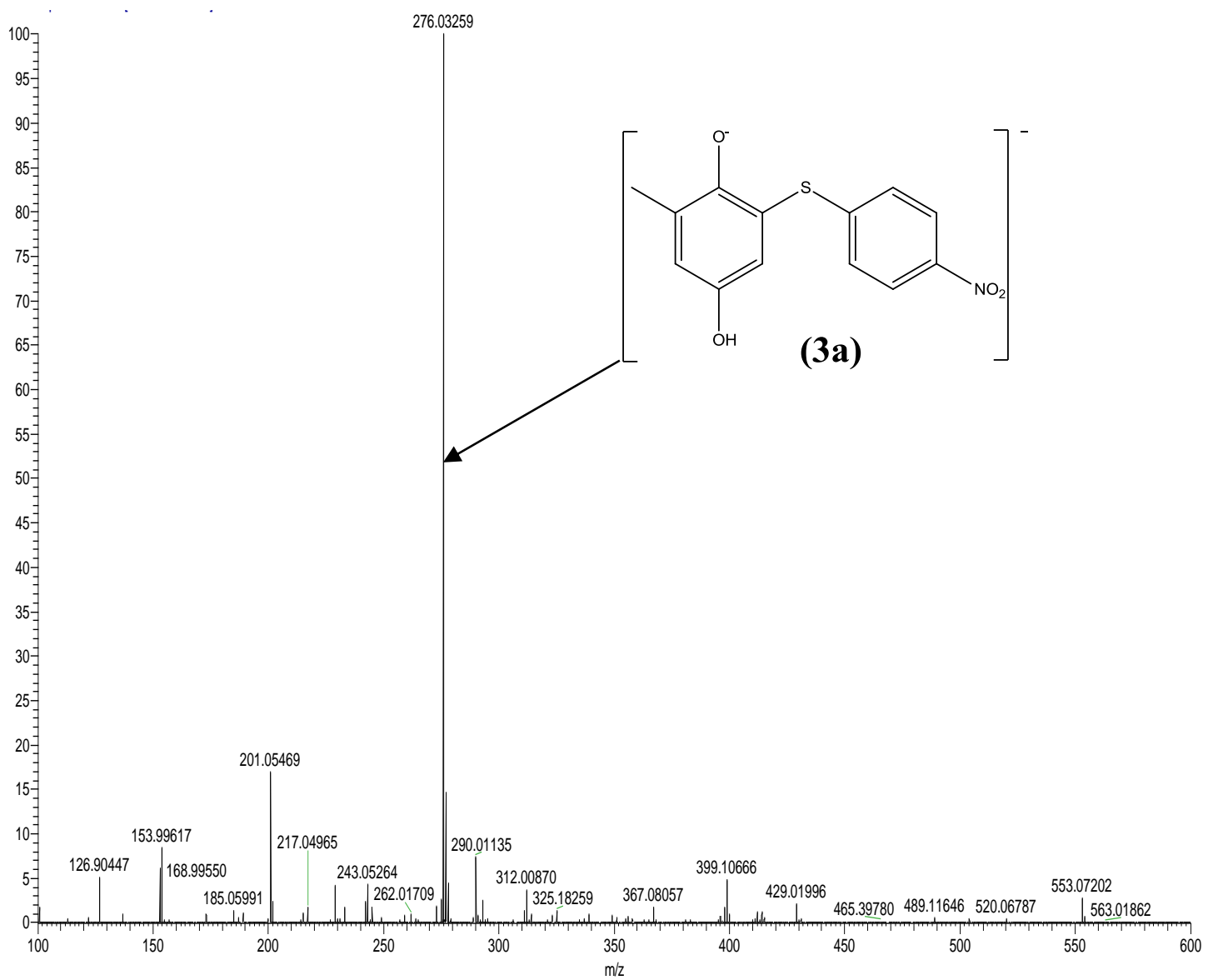

Figure 4.2: Negative ESI-MS spectra of p-nitrobenzenethiol adduct(s) formation with $M B Q$ giving a mono-NBT-hydroxyl MBQ adduct ( $\mathrm{m} / \mathrm{z}$ 276.03259).

For electron withdrawing substituted benzoquinones, the carbocation center created on the carbon on which chlorine atom was attached and this was the target for the -SH group on NBT followed by the substitution of the chlorine atom. In contrast to the methyl and tert-butyl substituted BQ the mechanism for the chlorine substituted BQs the reaction mechanism was direct nucleophilic vinylic substitution (SNV) with subsequent Michael addition (MA) reaction. As a result of the electron withdrawing substituents 
CBQ gave 2-((4-nitrophenyl)thio)benzene-1,4-diol 5a as a product and 2,5-DCBQ gave 2, 5-bis((4-nitrophenyl)thio)benzene-1,4-diol 7a.

\subsubsection{Reaction Mechanisms}

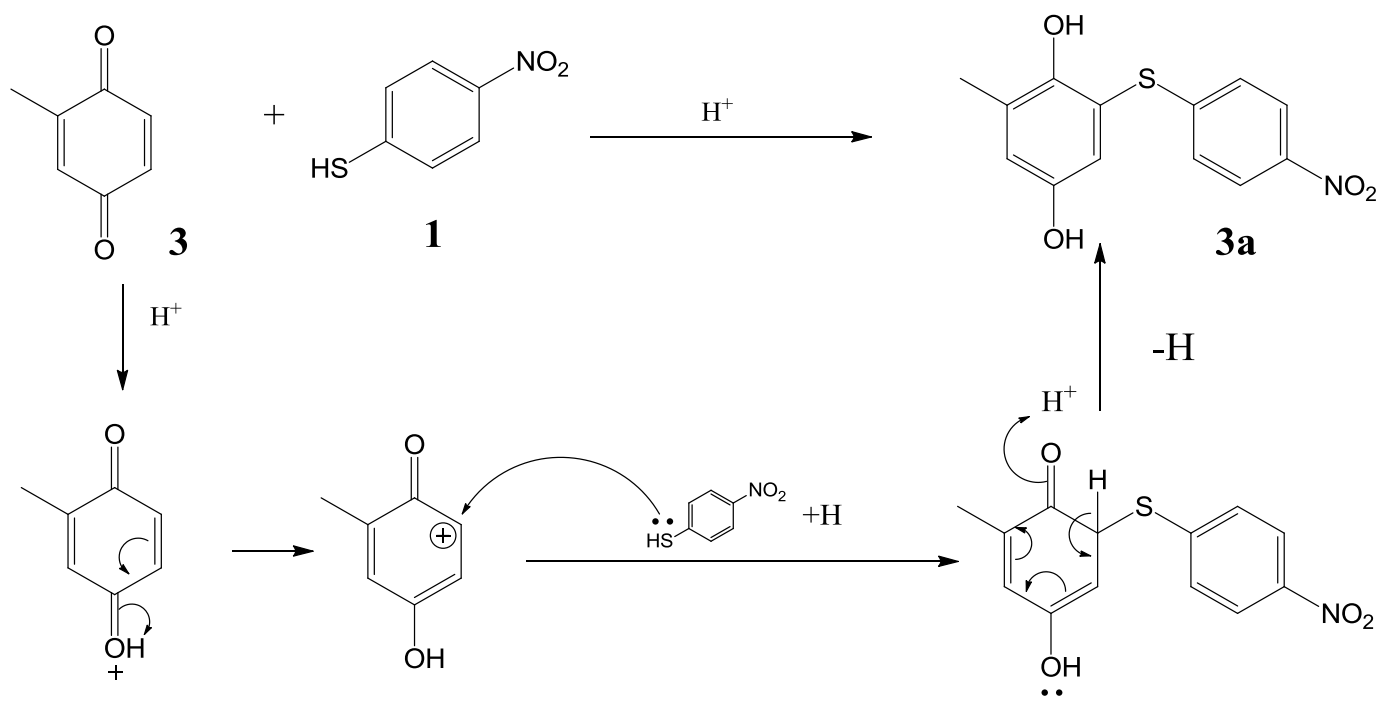

Scheme 4.2: The proposed MA reaction between MBQ and p-nitrobenzenethiol

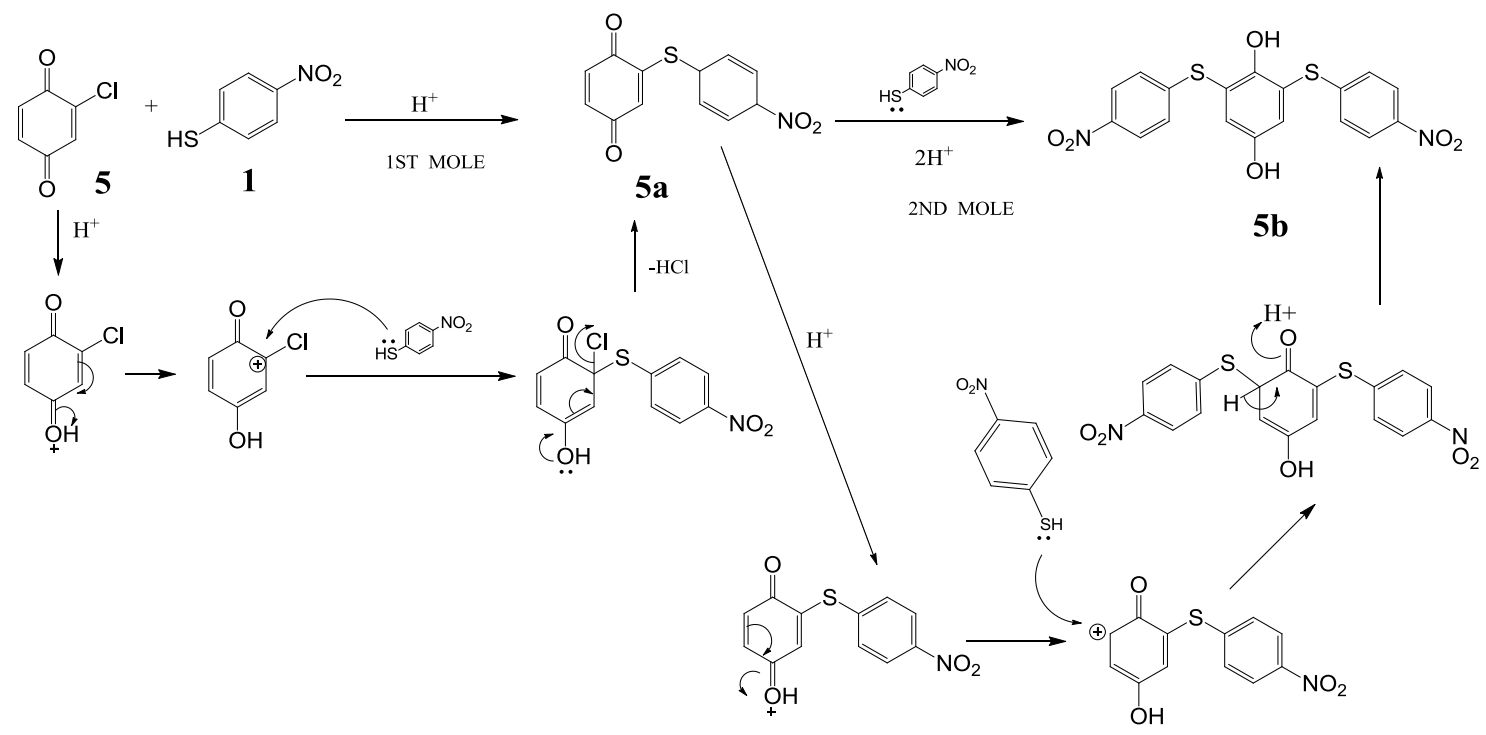

Scheme 4.3: The proposed reaction between CBQ and p-nitrobenzenethiol 


\subsection{CONCLUSION}

It can be concluded that EDG BQD (e.g. 2-MBQ) react with thiols by MA mechanism whilst EWG BQD haptenate to thiol proteins by vinylic substitution. These studies show that mono-substituted CBQ covalently binds to NBT to give 2 adducts (a mono-substituted BQ and a disubstituted BQ), while DCBQ give out 1 major adduct (1:2 ration BQ: thiol). NMR results also demonstrate the variations in the stoichiometry of the NBT-BQD reactions as well as the shifting of positions for nucleophilic addition. 


\section{CHAPTER FIVE}

\section{LOCAL LYMPH NODE ASSAY AND QUALITATIVE MECHANISTIC MODELS}

\subsection{INTRODUCTION}

Existing animal based assays such as the murine local lymph node assay (LLNA) ${ }^{89}$ which is based on the proliferation of lymph node cells in the induction phase or the $\operatorname{MEST}^{30}$ and Guinea Pig Maximization Test $\left(\right.$ GPMT) ${ }^{90}$ which are based on the observation of the allergic responses in the elicitation phase of ACD are widely used to screen for allergenic chemicals. Mandated reduction/elimination of animals used in cosmetics testing in Europe has led to an increased need for alternatives to animal testing in the prediction of skin sensitization potential. ${ }^{91}$ Published datasets consisting of quantitative reactivity test results for compounds tested in the LLNA are being used to develop and evaluate (validating or invalidating) alternative approaches. ${ }^{92}$ Hundreds of chemicals belonging to different mechanistic domains have been shown to possess the ability to induce skin sensitization. Of these, $\mathrm{BQ}$ is an extreme skin sensitizer $(\mathrm{EC} 3=$ $0.013)^{93}$ which has been well recognized over the years. The effect of inserting substituents on the BQ ring has not been studied in animal assays.

\subsubsection{Local Lymph Node Assay}

The EC3 for BQ has been published by Roberts et al. ${ }^{56}$ Since this EC3 for BQ was calculated from BQ doses that resulted in SI values that were all $\gg \mathrm{SI}=3$, the 
accuracy of the EC3 was overestimated. This study performed a preliminary LLNA to establish a measured EC3 for BQ that was subsequently adopted and informed the BQ dose to be used as a positive control for all other LLNA experiments with BQD. A wide range of doses was used ensuring that one dose is below the predicted EC 3 and two doses are above those predicted to be greater than 10-fold (over vehicle) lymph node cell proliferation (Figure 5.1 and Figure 5.2).

After performing the LLNA for the BQD as outlined above dose response curves were utilized to calculate EC3 values for all BQD tested. Comparison of predicted EC3 values with reactivity data was performed to test the predictive power of the reactivity assay. The following criteria (Table 5.1) adopted from the European Center for Ecotoxicology and Toxicology of Chemicals (ECETOC) ${ }^{94}$ was be used for potency classes:

Table 5.1: Potency rating of skin sensitizers

\begin{tabular}{|c|c|}
\hline Potency Rating & $\begin{array}{c}\text { Concentration Threshold } \\
(\mathbf{E C 3} ; \boldsymbol{\%})\end{array}$ \\
\hline Extreme & $<0.1$ \\
\hline Strong & $>0.1-<1.0$ \\
\hline Moderate & $>1.0-<10$ \\
\hline Weak & $>10$ \\
\hline Non-sensitizer & $>100$ \\
\hline
\end{tabular}

In the present study, allergenic potency of BQ and BQD were assessed in the LLNA to test the predictive power of previously reported reactivity data ${ }^{95}$ on skin sensitization. To check if the effect of substituents on the concentration required producing a threshold 
positive response, the candidate chemicals were placed into the categories in Table 2.5 based on their reaction chemistry and LLNA potency. The 7 test chemicals which make the basis of this study with expected sites of nucleophilic attack on the ring are shown in Figure 5.2.

The reported ${ }^{95}$ reactivity constants $\left(k_{a}\right)$ were used to predict the LLNA EC3 values for the BQD. LLNA studies were then performed for BQ and BQD to determine the actual EC3 values and test the predictive power of the reactivity data as a way of validating the potential utility of the reactivity approach as an alternative method for skin sensitization testing. In this article, we also present skin sensitization quantitative structure-activity relationships (QSARs) analysis for the Michael addition (MA) and nucleophilic vinylic substitution (SVN) mechanistic applicability domains, in which BQD possess either $\mathrm{X}$ or $\mathrm{Y}$ substituents ( $\mathrm{X}$ and $\mathrm{Y}$ ) on different positions.

\subsection{RESULTS}

\subsubsection{LLNA: Allegenicity Assessment}

The LLNA was performed for BQ to derive a more accurate EC3 estimate rather than use the literature EC3 value for BQ which was exptrapolated from doses that produced high stimulation indexes (SI) well above three fold threshold. Figures 5.1 and 5.2 show the doses of each BQD and the stimulation indexes. The LLNA EC3 values derived from these SI values using linear interpolation provided in the Figure 5.3. BQ and chlorine substituted BQ allergenic potency increased in the following order: BQ (EC3 = 
$0.043 \%)<\mathrm{CBQ}(\mathrm{EC} 3=0.039)<2,6-\mathrm{DCBQ}(\mathrm{EC} 3=0.028 \%)<2,5-\mathrm{DCBQ}(\mathrm{EC} 3=$ $0.013 \%$ ) in agreement with the trend predicted by rate constants (listed in Table 5.2). Methyl substituted BQ EC3 values which ranged from $<0.1 \%$ to $0.238 \%$ were higher than those of chloro BQD. The predicted LLNA by reactivity of 2-MBQ and 2,5-DMBQ were different, with the EC3 of 2,5-DMBQ being 18 fold higher than the EC3 value of 2-MBQ. The actual EC3 values of 2-MBQ and 2,5-DMBQ from the LLNA were very similar to each other, but in the reverse order than predicted. However, Figure 5.2 demonstrate that 10\% 2-MBQ produced a significantly higher SI than 10\% 2,5-DMBQ (SI $=31.7 \%$ vs. $11.5 \%$, respectively) suggesting that it may actually be a more potent allergen than 2,5-DMBQ as predicted from the reactivity data. The difference in the mean SI values of 2-MBQ and 2,5-DMBQ is greater than would be expected by chance; there is a statistically significant difference between the input test chemicals $(\mathrm{P}<0.001)$. 


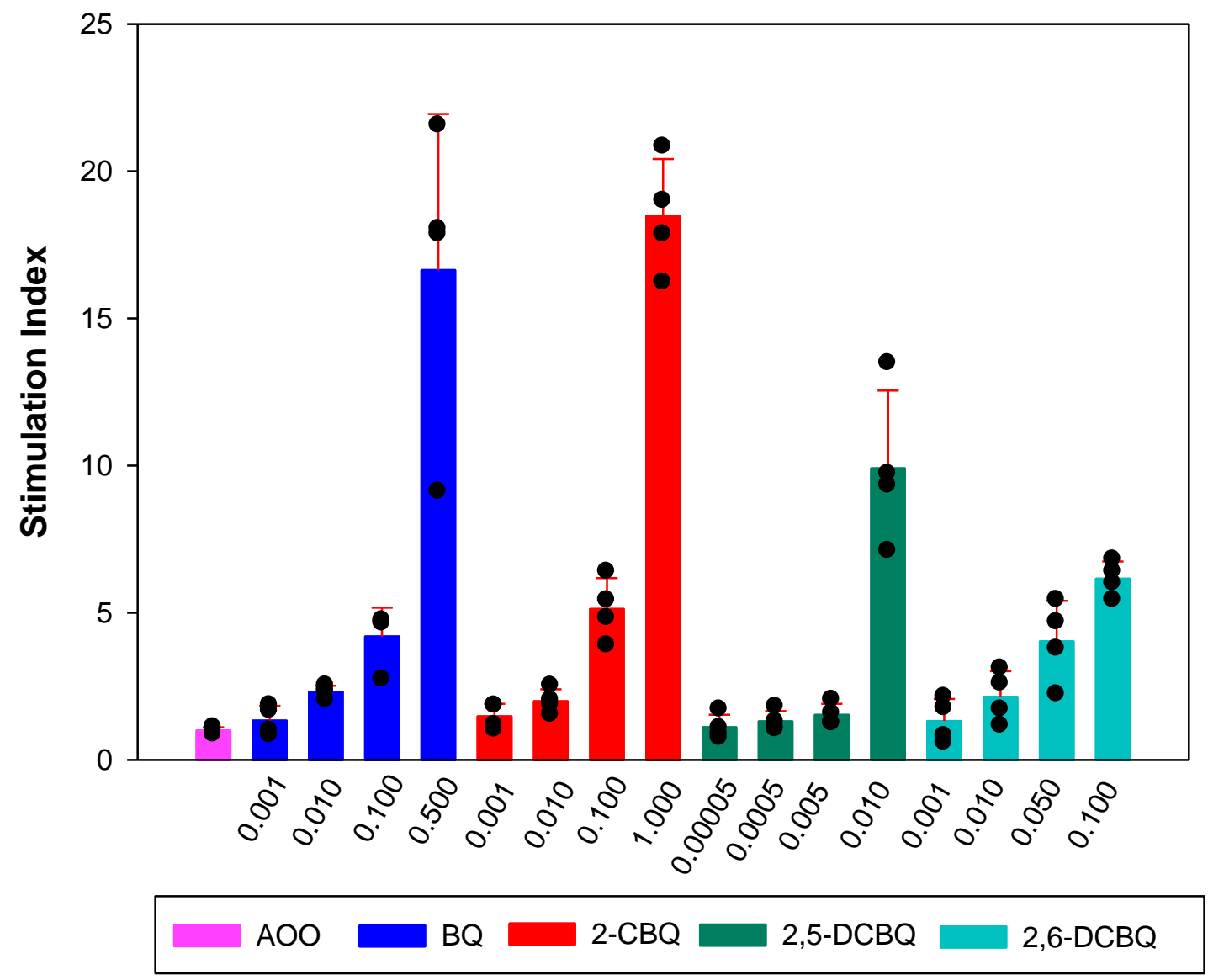

Figure 5.1: Murine local lymph node assay (LLNA) for $B Q$ and its derivatives (a): $B Q$, 2-CBQ, 2,5-DCBQ and 2,6-DCBQ, 


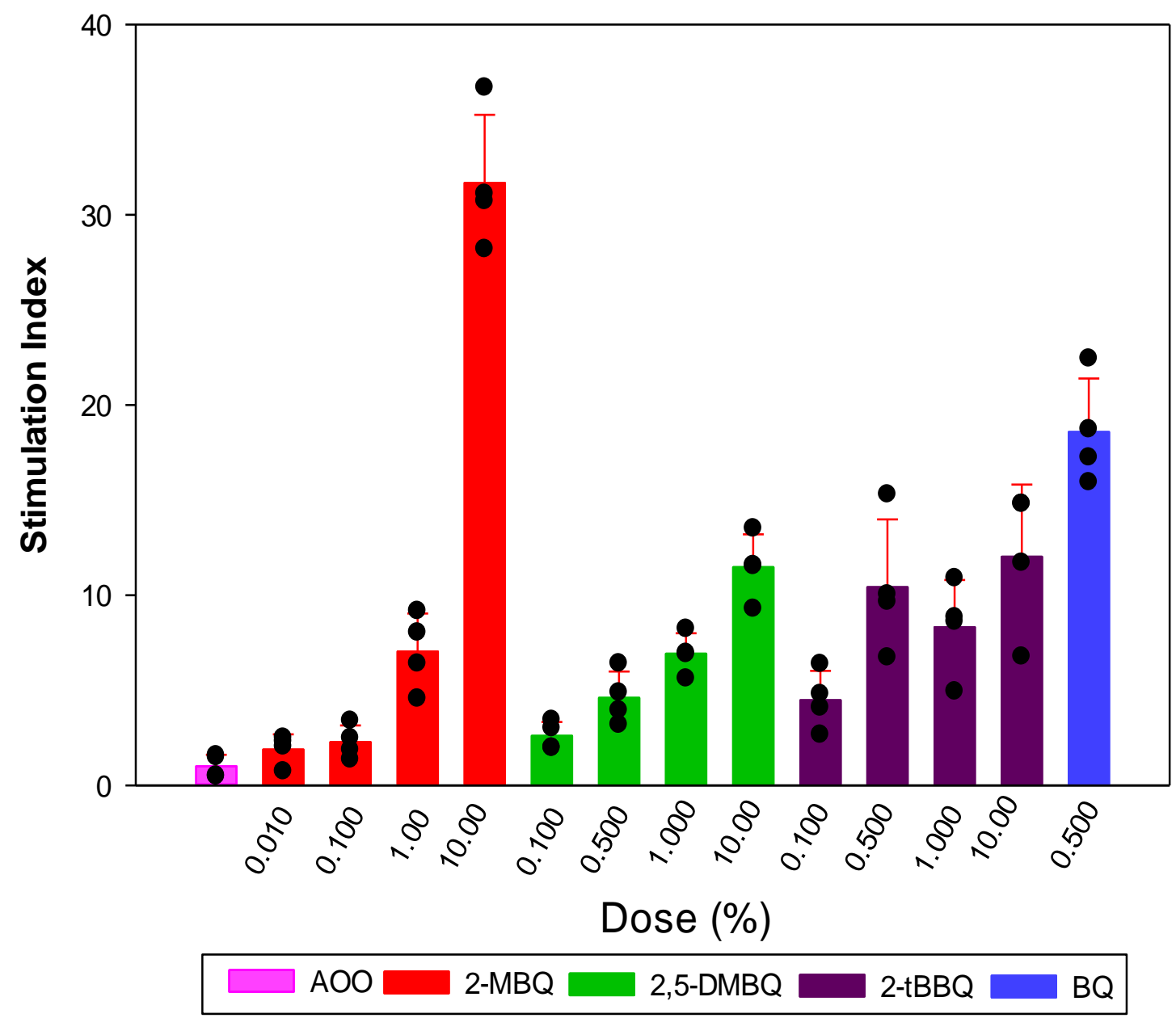

Figure 5.2: Murine local lymph node assay (LLNA) for $B Q$ and its derivatives :2-MBQ, 2,6-DMBQ and $t B B Q$ produced clinical signs of systemic toxicity including weight loss, lethargy and ruffled fur that gave poor dose-dependent proliferative responses and preventing a reliable EC3 determination.

2-tBBQ EC3 could not be estimated using the LLNA due to systemic toxicity observed and lack of dose-dependency of the lymph node cell proliferation in dosed mice. In general, the predictive equation of Chipinda et al. ${ }^{57}$ that was generated from data for multiple structurally diverse chemicals in the MA domain consistently overestimated 
the potency of the BQD series.

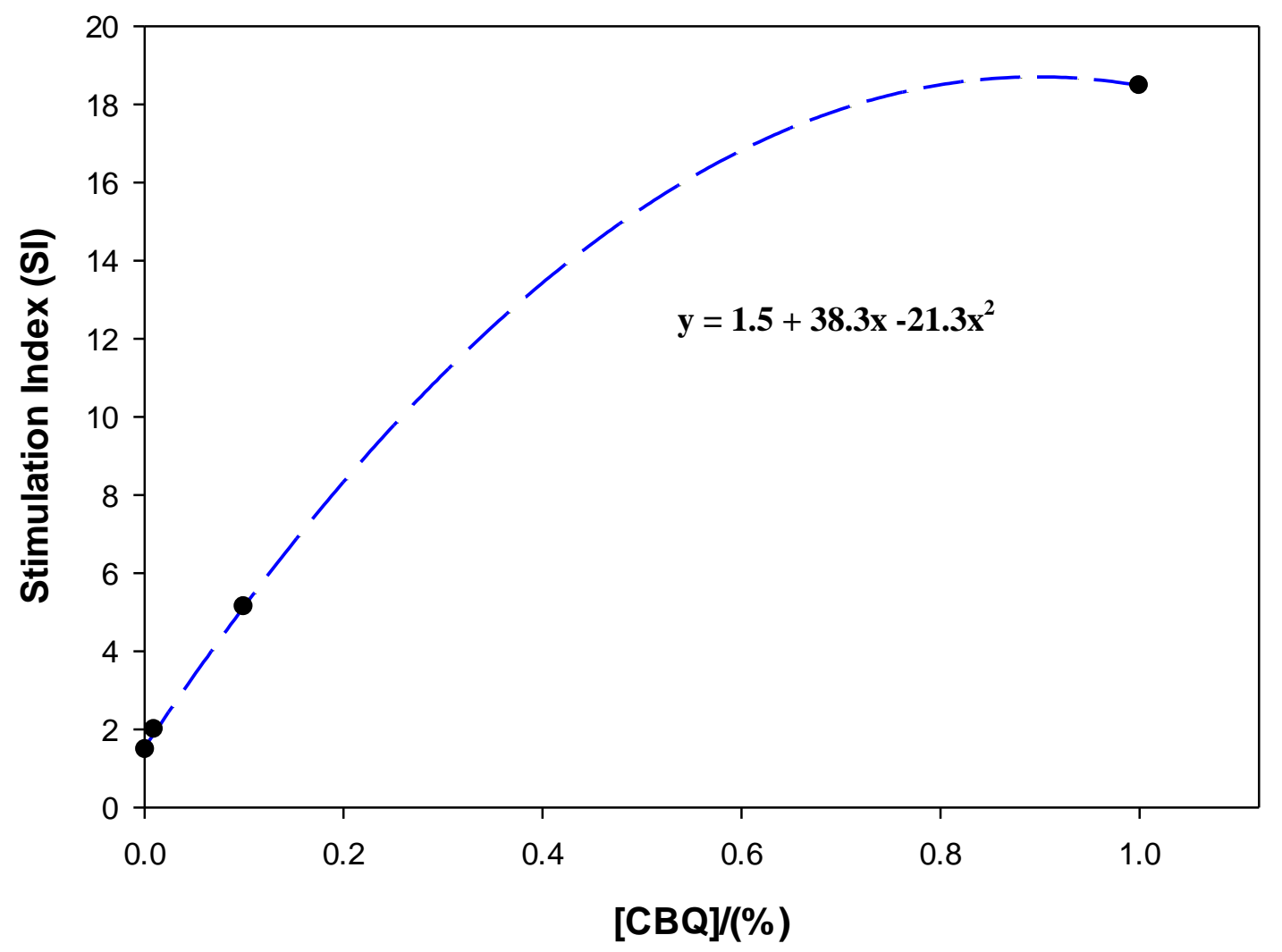

Figure 5.3: Stimulation index against concentration of $C B Q$.

Figure 5.3 is a dose response curve for shows the same results as Figure 5.1 for CBQ results. The vehicle used to dissolve or suspend the test agent can influence the results of the LLNA. When acetone olive oil (AOO; 4:1; v/v) was used as the vehicle, ${ }^{3} \mathrm{H}$-thymidine incorporation into proliferating mouse lymph node cells resulted in the proliferative response shown in Figure 5.1 and 5.1 for BQD. There was a direct relationship between SI and the concentrations of BQD. From this graph equation of the 
graph was used to calculate the LLNA EC3 values which are listed on test compounds listed in Table 5.2.

\subsubsection{Correlation Analysis of Reactivity Data with LLNA EC3 Values}

The pEC3 values for the test chemicals listed in Table 5.2 were plotted against $\log k_{a}$ values to determine the relationship of the reactivity to the chemicals' potency as skin sensitizers. A plot of pEC3 values for 6 test chemicals is shown in Figure 2.5.

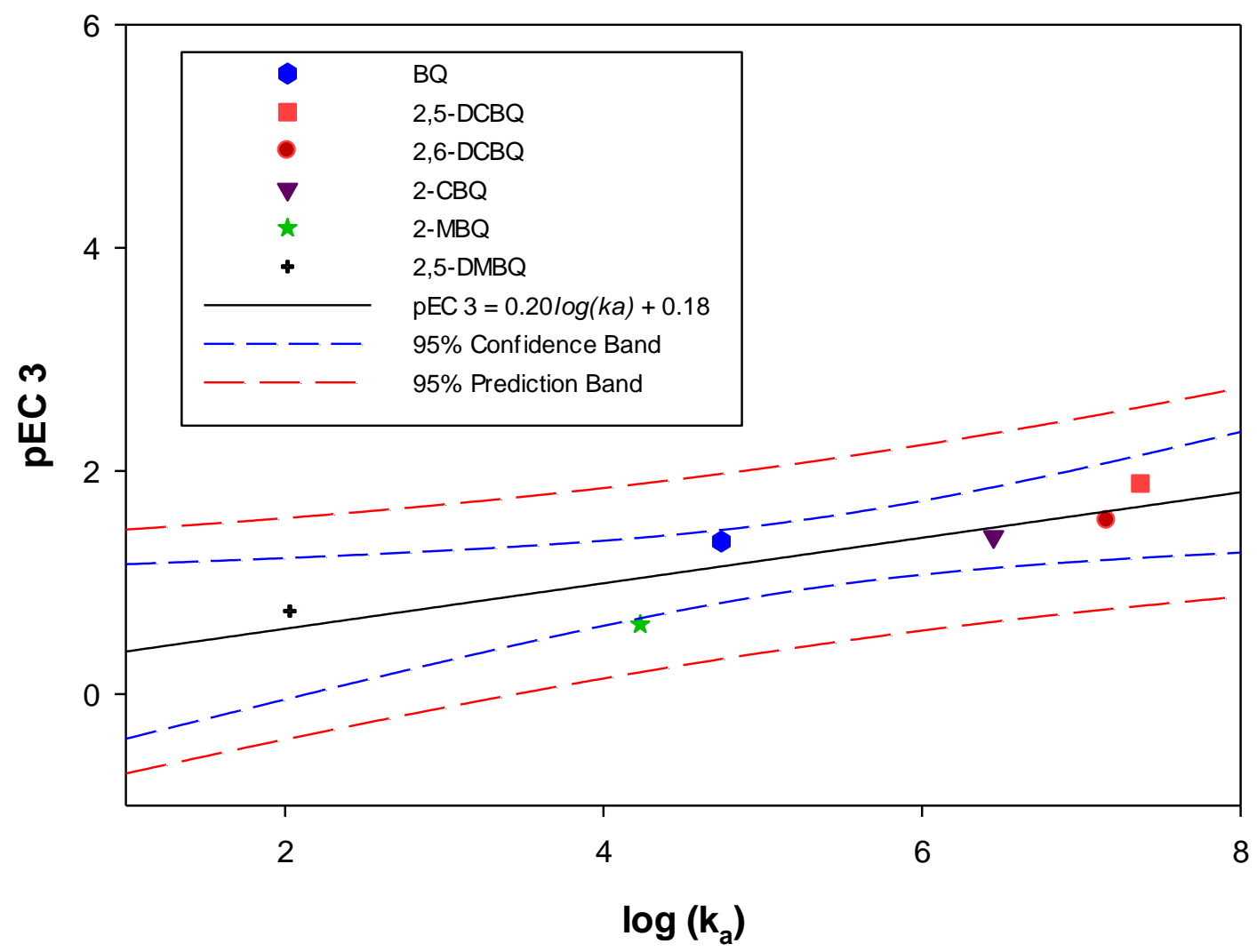

Figure 5.4: Plot of pEC 3 vs log ka of the 6 test chemicals in the Michael addition and nucleophilic vinylic substitution reactivity domains. pEC3 was estimated using the LLNA and log ka derived from reactivity toward NBT as previously reported. ${ }^{20}$ 
A strong positive correlation $\left(\mathrm{R}^{2}=0.74\right)$ between potency in LLNA and reactivity was observed as indicated by the following linear equation (with statistical parameters);

$$
\begin{gathered}
\mathrm{pEC} 3=0.20( \pm 0.05) \log \left(k_{a}\right)+0.17( \pm .033) \\
\mathrm{n}=6, \mathrm{R}^{2}=0.74, \mathrm{R}_{\text {adj }}^{2}=0.68, \mathrm{~s}=0.27 \text { and } \mathrm{F}=11.6
\end{gathered}
$$

\subsubsection{NBT-BQ/BQD Reactions}

Table 5.2: Predicted EC3 Values from Reactivity Data

\begin{tabular}{|l|l|l|c|c|c|}
\hline Chemical & $\begin{array}{l}\text { Mwt } \\
(\mathbf{g} / \mathbf{m o l})\end{array}$ & $\boldsymbol{k}_{\boldsymbol{a}}\left(\mathbf{s}^{-\mathbf{1}}\right)$ & $\begin{array}{c}\text { Predicted } \\
\mathbf{p E C 3}\end{array}$ & $\begin{array}{l}\text { LLNA } \\
\text { derived } \\
\mathbf{p E C 3}\end{array}$ & Log $\boldsymbol{P}$ \\
\hline 2,5-DCBQ & 176.98 & $2.92 \times 10^{6}$ & 7.37 & 4.13 & 1.34 \\
\hline 2-CBQ & 142.5 & $2.17 \times 10^{5}$ & 6.45 & 3.56 & 0.98 \\
\hline 2,6-DCBQ & 176.98 & $1.60 \times 10^{6}$ & 7.16 & 3.80 & 1.34 \\
\hline BQ & 108.1 & $1.66 \times 10^{3}$ & 4.74 & 3.40 & 0.50 \\
\hline 2-MBQ & 122.1 & $1.51 \times 10^{3}$ & 4.23 & 2.71 & 0.75 \\
\hline 2-tBBQ & 164.2 & $3.60 \times 10^{2}$ & 3.25 & ---- & 1.20 \\
\hline 2,5-DMBQ & 136.2 & $1.05 \times 10^{1}$ & 2.03 & 2.88 & 1.07 \\
\hline
\end{tabular}

${ }^{1}$ Estimations of EC3 were performed using the regression equation $\mathrm{pEC} 3=0.81 \log \mathrm{ka}+$ 2.13 as reported by Chipinda et. al (2010.) where $p E C 3=\log (\mathrm{Mwt} / E C 3)$.

It must be stated that due to the limited number of the test chemicals used in this study conclusions concerning the potential relationship between chemical reactivity and allergenic potency cannot be made from these results. $\mathrm{R}^{2}$ of 0.74 between the overlapping 
data of MA and SVN domains suggests that reactivity rate has greater influence than chemical mechanistic domain toward a chemical's allergenic potency.

Reaction rate constants of $\mathrm{BQ}$ and $\mathrm{BQD}$ toward NBT that were previously determined, ${ }^{95}$ along with predicted EC3 values derived from equations reported by Chipinda et al. ${ }^{21}$ correlating electrophilic allergen reactivity to $\operatorname{NBT}\left(\mathrm{k}_{\mathrm{a}}\left(\mathrm{s}^{-1}\right)\right)$ to $\mathrm{pEC} 3$ are shown in Table 5.2. There was no observable relationship between solubility $(\log \mathrm{P})$ and EC3 predicted by chemical reactivity across the entire set of test chemicals.

\subsubsection{Prediction of EC3 Values from Reactivity Data}

The $k_{a}$ values taken from Table 5.2 were used to predict EC3 values using linear equation 5.2 which was derived by Chipinda $e t . a l .{ }^{57}$ utilizing a structurally diverse MA domain data set where pEC3 is obtained by dividing the molecular weight $(M w t)$ of the chemical by EC3 value and calculating the log. The results were compared with EC3 values obtained from the LLNA performed for these BQD.

$$
\begin{aligned}
& \mathrm{pEC} 3=0.81 \log \left(k_{a}\right)+2.13 \\
& \mathrm{pEC} 3=\log ((M w t / \mathrm{EC} 3))
\end{aligned}
$$

From the predicted EC3 values it was observed that the presence of the EDG on the BQ reduces the LLNA potency of $\mathrm{BQ}(\mathrm{EC} 3 ; 0.002 \%)$ from an extreme sensitizer to a strong sensitizer $(2,5-\mathrm{DMBQ}$; EC3 $=1.28 \%)$. EWG were observed to increase the potency rating of $\mathrm{BQ}$ by reducing the threshold that is needed to cause skin sensitization as shown in Table 5.2. 


\subsubsection{Quantitative Mechanistic Modeling (QMM)}

Hammett and Taft substituent constants were taken from Perrin et al. ${ }^{96}$ The Hammett and Taft substituents and their constants are listed in Table 5.2, whilst the structures of test compounds are given in Figure 5.2. The reaction sites are indicated by the arrows.

Table 5.3: Substituent Constants, $\sigma$ - and $\sigma^{*}$ Used to Calculate Values in Table 5.3

\begin{tabular}{|c|c|c|c|}
\hline Chemical & $\begin{array}{c}\text { Hammett Constant } \\
(\boldsymbol{\sigma}-)\end{array}$ & $\begin{array}{c}\text { Taft Constant } \\
\left(\boldsymbol{\sigma}^{*}\right)\end{array}$ & Reference \\
\hline $\mathrm{p}-\mathrm{Cl}$ & 0.24 & 2.96 & 96 \\
\hline $\mathrm{m}-\mathrm{Cl}$ & 0.37 & 2.96 & 96 \\
\hline $\mathrm{o}-\mathrm{Cl}$ & 0.68 & 2.96 & 96 \\
\hline $\mathrm{H}$ & 0 & 0.49 & 96 \\
\hline $\mathrm{p}-\mathrm{CH} 3$ & -0.14 & 0.00 & 96 \\
\hline $\mathrm{m}-\mathrm{CH} 3$ & -0.06 & 0.00 & 96 \\
\hline $\mathrm{o}-\mathrm{CH} 3$ & -0.13 & 0.00 & 96 \\
\hline
\end{tabular}

The calculated Hammett constants $\left(\sum \sigma-\right)$, for test compounds $\mathbf{2 , 3 , 5 , 6}$ and $\mathbf{7}$ were used whilst the calculated Taft constants $\left(\sigma^{*}\right)$ for test compounds $\mathbf{1}, \mathbf{5}, \mathbf{6}$ and $\mathbf{7}$ were used, and these are listed in Table 5.3.

Table 5.4: Calculated $\Sigma \sigma-$ and $\sigma^{*}$ Values Used to Plot Figures 5.5 and 5.6

\begin{tabular}{|c|c|c|c|}
\hline Chemical & $\mathbf{p E C ~ 3}$ & $\begin{array}{c}\text { Hammett Constant } \\
(\boldsymbol{\Sigma} \boldsymbol{\sigma}-)\end{array}$ & $\begin{array}{c}\text { Taft Constant } \\
\left(\boldsymbol{\sigma}^{*}\right)\end{array}$ \\
\hline BQ & 1.36 & 0 & 0.49 \\
\hline 2,5-DCBQ & 1.88 & -0.89 & $10.95^{*}$ \\
\hline $2,6-\mathrm{DCBQ}$ & 1.55 & -1.33 & 5.92 \\
\hline 2-CBQ & 1.41 & -1.57 & 2.96 \\
\hline 2-MBQ & 0.62 & -1.63 & - \\
\hline 2,5-DMBQ & 0.74 & -1.77 & - \\
\hline
\end{tabular}


Quantitative mechanistic modeling that correlates skin sensitization potency and quantified by murine local lymph node assay (LLNA) EC3 data on a range of MA and SVN domain electrophiles was used. The model takes the form $\mathrm{pEC} 3=\mathrm{a} \sum \sigma-+\mathrm{c}$ for Hammett constants or $\mathrm{pEC} 3=\mathrm{b} \sigma^{*}+\mathrm{c}$ for Taft constants $\left(\mathrm{a}, \mathrm{b}, \mathrm{c}\right.$ and $\mathrm{d}$ being constants). ${ }^{97}$ This model is based on the Hammett $\sigma$ - constant of the activating groups (Y) and the Taft $\sigma^{*}$ constants of the leaving groups (X). Figure 5.2 shows the test chemicals used with compounds $\mathbf{2}, \mathbf{3}$ and $\mathbf{4}$ having the deactivating groups (methyl and tert-butyl groups), compounds 5, 6 and $\mathbf{7}$ with leaving groups (chlorine atom(s)) and compound $\mathbf{1}$ (with hydrogen) which is the standard. The arrows on the compounds in Figure 5.2 indicate the point of attack by soft nucleophile. Schemes 5.1 show the MA reaction mechanisms for Y substituents and scheme 5.2 shows the SVN reaction mechanism for X substituents.

The MA reaction shown in Scheme 5.1 depends on the effectiveness of the $\mathrm{Y}$ group to stabilize a negative charge on the carbon atom to which it is bound. Substituents on the $\alpha$ - and $\beta$-carbon atoms can have strong influences on Michael reactivity. Electrondonating substituents such as methyl groups reduce reactivity of compounds in the MA domain, by an electronic effect and at times by steric effect depending on the size of the substituent. ${ }^{98}$ 


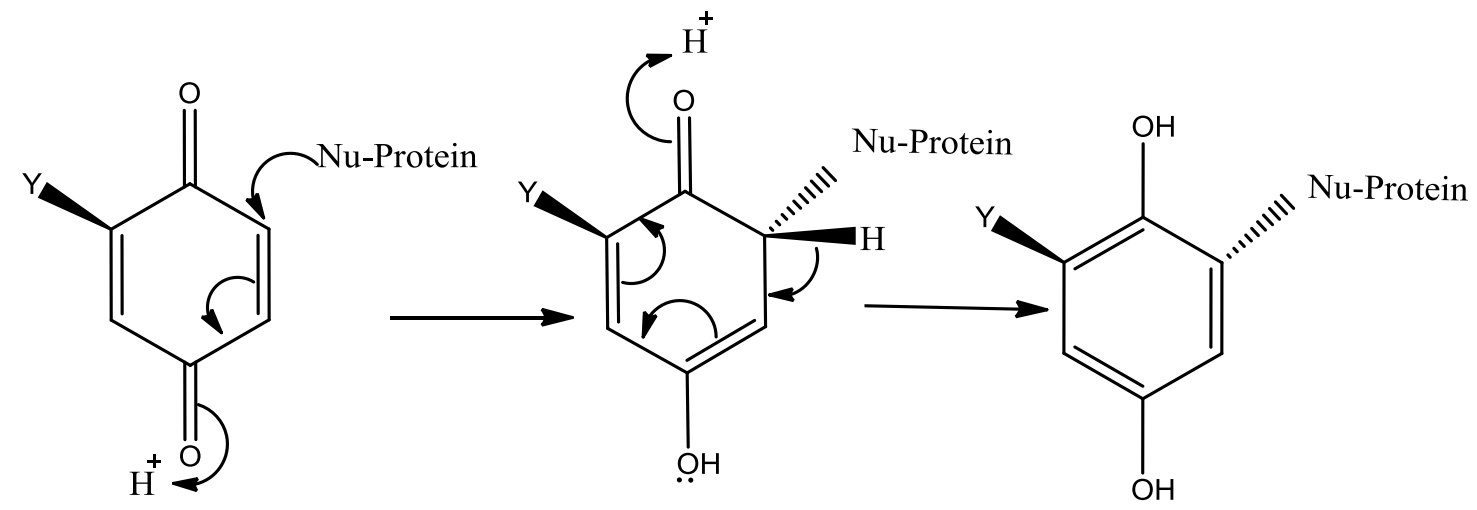

Scheme 5.1: Michael addition reaction mechanism for methyl/tert-butyl substituted benzoquinone derivatives with thiol containing proteins<smiles>[Y]C1=CC(=O)C=CC1=O</smiles>

Scheme 5.2: Nucleophilic vinylic substitution reaction mechanism for chlorine substituted benzoquinone derivatives with thiol containing proteins

For present purposes, we define a strong activating group as an electronegative substituent $(\mathrm{X})$, ortho or para to the leaving group that is able to stabilize a negative charge both by resonance and inductive effects. We also used ortho or para chloro group as an example of a strong activating group. The ability of $\mathrm{X}$ to stabilize the negative charge created in the transition state, when the bond between the attacking nucleophile in 
not fully formed depends on its inductive effect which is modeled by Taft constant. ${ }^{99}$ If this was the only effect to be considered, then we expected 2,6-DCBQ and 2,5-DCBQ to have different Taft constants because difference in inductive effects of meta and para chloro substituent(s).

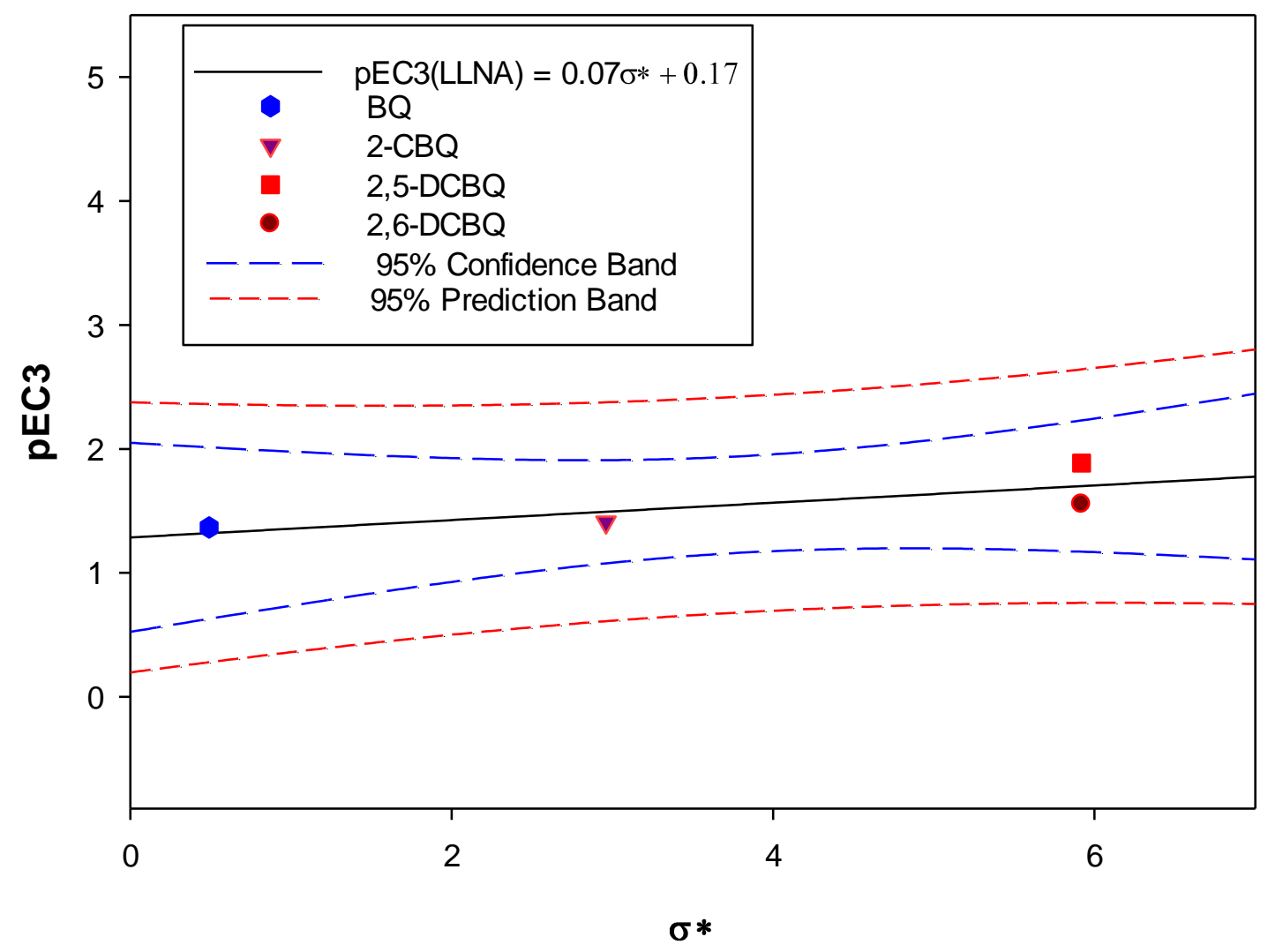

Figure 5.5: Plot of pEC3 vs Taft Constant $\left(\Sigma \sigma^{*}\right)$ for test compounds 1, 5, 6 and 7.

We got an equation of the linear plot of pEC3 against $\sigma^{*}$ for test compounds $\mathbf{1 , 5 , 6}$ and $\mathbf{7}$ as shown in Figure 5.6. The equation A4 is as follows,

$$
\begin{aligned}
& \operatorname{pEC} 3=0.07( \pm 0.04) \sigma^{*}+1.28(0.18) \\
& \mathrm{n}=4, \mathrm{R}^{2}=0.60, \mathrm{R}^{2} \text { adj }=0.40, \mathrm{~s}=0.18, \mathrm{~F}=3.08
\end{aligned}
$$


Equation 5.4 is a QMM for LLNA skin sensitization potency of MA nucleophiles. Figure 5.5 shows the how equation 5.4 was obtained from the Taft constants of BQ and chloro BQD. Equation 5.4 had $\mathrm{R}^{2}$ value of 0.60 , and this lower correlation constant is due to the fact that 2,5-DCBQ and 2,6-DCBQ are treated as if they have the same reactity by Taft constants and yet LLNA EC3 values and the reactivity constants suggest that 2,5-DCBQ is more reactive than 2,6-DCBQ. The order of the influence of the leaving group was 2,5$\mathrm{DCBQ}=2,6-\mathrm{DCBQ}>2-\mathrm{CBD}>\mathrm{BQ}$ and this agreed with the order of reactivity of the EWG BQD to NBT.

In the other model a different combination of activating groups (test compound $\mathbf{2}$, 3, 5, 6 and 7) were used. Regression analysis for the plot in Figure 5.6 using pEC3 against $\Sigma \sigma^{-}$gave the following equation:

$$
\begin{aligned}
\operatorname{pEC} 3= & 1.34( \pm 0.37) \sum \sigma-+3.18( \pm 0.56) \\
& n=5, \mathrm{R}^{2}=0.76, \mathrm{R}^{2}{ }_{\text {adj }}=0.70, \mathrm{~s}=0.26, \mathrm{~F}=12.83
\end{aligned}
$$

This equation (5.5) is a QMM for LLNA skin sensitization potency for SVN and MA nucleophiles. Equations 5.4 and 5.5 together with equation 5.1 should act as the first screening line for skin sensitizers which belong to MA and SVN domains, without the inchemico studies. 


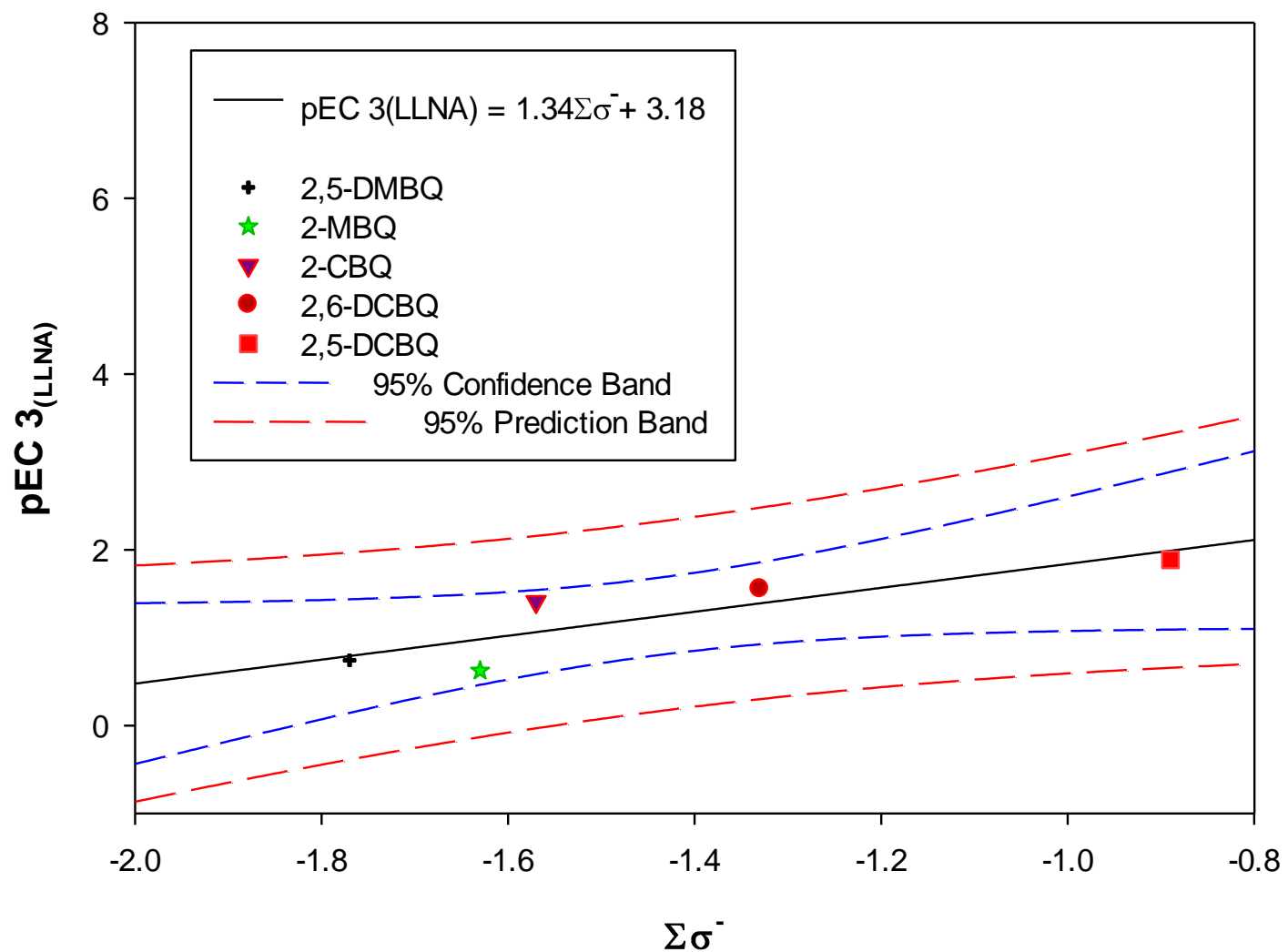

Figure 5.6: Plot of pEC3 vs Hammett Constant ( $\sigma$-) for test compounds 2, 3, 5, 6 and 7.

\subsection{DISCUSSION}

The BQ moiety common to all test chemicals within this series was considered important to allow an accurate comparison of the reactivity to NBT as well as allergenic potency in the LLNA while avoiding potential confounders that may arise from structural differences. From the LLNA data and prediction of EC3 values using rate constants, we observed that $\mathrm{BQD}$ with electron withdrawing groups had the highest chemical potency followed by unsubstituted BQ and the least potent were the BQD with electron donating groups. This trend agreed well with what was expected because electron-donating 
substituents such as methyl groups reduce reactivity while electron withdrawing substituents such as halogens increase reactivity of compounds in the MA domain. ${ }^{98}$ It is particularly striking that a relatively small changes in the BQ structure have a dramatic impact on the LLNA EC3. This is observed when the LLNA EC3 decreases with increasing number of chlorine atoms added to $\mathrm{BQ}(\mathrm{BQ}>\mathrm{CBQ}>\mathrm{DCBQ})$. The effect of different positions on reactivity is observed between 2,5-DCBQ and 2,6-DCBQ in which 2,5-DCBQ $(\mathrm{EC} 3=0.013 \%)$ was 2.15 times more reactive than the 2,6-DCBQ $(\mathrm{EC} 3=$ $0.028 \%$ ). This is because the para- substituted EWG inductive influence on the leaving group is greater than the meta substituted EWG.

The mono-BQD was less reactive than the DCBQ because BQD both EWGs on DCBQ contribute to and thus increases the inductive effect over the mono-chloro BQD. The other reason why DCBQs are apparently more reactive than mono-BQD is because of the DCBQs bind at a 1:2 ratio with protein thiols versus the 1:1 protein thiol binding of mono-BQD. ${ }^{95}$

As pointed out by Roberts and Aptula (2008), ${ }^{100}$ if $k_{p}$ and $k_{r}$ are the rate constants for penetration and reaction with carrier protein respectively, and $(D)$ is the concentration of sensitizer applied at the skin surface, then the extent of carrier protein binding PB after time $(t)$ is given by:

$$
P B=D\left\{1+\left[k_{r} \exp \left(-k_{p} t\right)-k_{p} \exp \left(-k_{r} t\right)\right] /\left(k_{p}-k_{r}\right)\right\}
$$

Since both penetration rates and reaction rates for sensitizers can range over several orders of magnitude, in the vast majority of cases either $k_{p} » k_{r}$ or $k_{p} \ll k_{r}$ will apply. 
Where penetration is faster than protein reactivity, i.e. $k_{p} \gg k_{r}$, the expression is simplified to:

$$
\left.P B=D\left\{1+\exp \left(-k_{p} t\right)\right]\right\}
$$

i.e. the extent of protein binding is dependent on the reaction rate but not on the penetration rate. $^{98}$ The weakest allergen in this study 2,5-DMBQ has an EC3 of $0.181 \%$ which could be considered an extreme sensitizer and would fall in the situation where $k_{p}$ $\gg k_{r}$. The reported order of reactivity of chlorine substituted BQs to NBT matched the chemical potency in LLNA and partition coefficient $(\log P)$, i.e. BQ $(\log P=0.497)$, CBQ $(\log P=0.980), 2,6-\mathrm{DCBQ}(\log P=1.338)$ and then $2,5-\mathrm{DCBQ}(\log P=1.341)$. For the situation where the reaction is faster than penetration, i.e. $k_{p} \ll k_{r}$, the expression is simplified to:

$$
\left.P B=D\left\{1-\exp \left(-k_{p} t\right)\right]\right\}
$$

i.e. the extent of protein binding in the skin has greater dependence on the penetration rate than the reaction rate. ${ }^{100} \mathrm{We}$ also observed the following trend in electron magnetic resonance signal, $\mathrm{BQ}<\mathrm{CBQ}<2,6-\mathrm{DCBQ}<2,5-\mathrm{DCBQ}$, and this is the same trend that LLNA EC3 values a following. We concluded that BQ radical may be playing a minor role in haptenation of protens. ${ }^{101}$ This agrees well with what was previously suggested by Christensson et al. (2006), ${ }^{74}$ that semiquinone radicals may act as a hapten.

From the predicted pEC3 values listed in Table 5.2, equation 5.1 over estimates the chemical potency of the BQ and EWG BQD by 30 to 2000 fold. Potential reasons for the limited accuracy of equation 5.1 in predicting EC3 values include a potential error 
introduced by inclusion of multiple mechanistic domains, the influence multiple intermediate species, and chemicals with multiple electrophilic moieties. The published predictive equation also covered a wider range of chemical solubility's, reactivities and allergenic potencies. It must also be noted that BQ was the most reactive allergen in the data set reported by Chipinda $e t . a l .^{71}$ and the predicted values for the chlorobenzoquinones were extrapolated beyond the tested data set. This assumed log-log linearity of pEC3 vs. $\log \mathrm{Ka}$ at the fastest reaction rates and this assumption may not have been correct.

Figure 5.4 and equation 5.1 shows that LLNA of these benzoquinone derivatives are dependent on reactivity alone, and no hydrophobicity parameter is needed to model the data. This has been previously observed that the same applies for the Michael acceptor domain: LLNA is dependent on reactivity but not on hydrophobicity. ${ }^{102}$ The low value on $\log k$ coefficients suggests that the biological nucleophiles are 6 times less selective than NBT which was used in this model. Another possibility is that the relevant in vivo nucleophile is based on the selenocysteine, which is known to be present in the skin protein subunit. ${ }^{103}$ The ionized SeH functional group is even softer nucleophile than ionized SH group. ${ }^{92}$ The good correlation $\left(\mathrm{R}^{2}=0.74\right)$ of equation 5.1 to the in vivo data shows that it is not to use nucleophiles designed to closely resemble the in vivo nucleophiles for models.

The influence of the activating groups was modeled by the sum of their $(\sigma-)$ values, $\left(\sum \sigma_{-}\right)$. The calculated sum of the Hammett constants $\left(\sum \sigma-\right)$, predicted that the order of influence of the substituents on BQ will follow the order, 2,5-DCBQ > 2,6- 
$\mathrm{DCBQ}>2-\mathrm{CBQ}>2-\mathrm{MBQ}>2,5-\mathrm{DMBQ}$ and this agrees well the order of reactivity constants listed in Table 3.2. When pEC3 (LLNA) were plotted against Hammett constants $\left(\sum \sigma-\right)$, equation 5.5 was observed whose $\mathrm{R}^{2}=0.76$, and this is close the $\mathrm{R}^{2}$ (0.74) obtained in equation 5.1. These correlation coefficients were lower than what we obtained from equation 5.4 (Taft constants) because Taft constants treats 2,5-DCBQ and 2,6-DCBQ as if have the same reactivity and yet LLNA EC3 values and reaction rate constants suggests that they are have different reactivities. The good correlation between reactivity predictions using Hammett constants, NBT reactivity rate constants and EC3 estimates suggests that Hammett constants, where available, may provide good estimates of chemicals' relative skin sensitization potency.

\subsection{CONCLUSION}

It is generally accepted that chemical allergens must first bind to a protein to be allergenic. The high correlation between chemical reactivity as demonstrated empirically using the NBT assay, or through modeling using Hammett constants and the LLNA threshold EC3 estimates of the BQ and BQD series suggest that the rate of chemical-toprotein binding is a major determinant of skin sensitization potency. Influence of other factors physical-chemical factors such as $\log \mathrm{P}$, mechanistic domain, and haptenated protein stability on a chemical's skin sensitization potency remains to be determined and may vary between chemical classes. Skin sensitization to chemicals present in consumer products and the workplace continues to be a major concern. The accuracy of the prediction model proposed exceeded that of the LLNA for set of substances tested. EC3 
measurements are reproducible in both intra- and inter-laboratory evaluations and are stable over time which make reactivity model reliable for to determine relative potency, so that potential skin sensitizers may be ranked and to provide a key input for skin sensitization risk assessment. These models are very promising results point to a possible future replacement of animal testing while maintaining the same degree of accuracy and predictivity for human skin sensitizers. ${ }^{104}$ 


\section{REFERENCE LIST}

1. Nielsen, N. H.; Linneberg, A.; Menne, T.; Madsen, F.; Frolund, L.; Dirksen, A.; Jorgensen, T. Allergic contact sensitization in an adult Danish population: Two cross-sectional surveys eight years apart (The Copenhagen Allergy Study). Acta Dermato-Venereologica 2001, 81 (1), 31-34.

2. Andersen, K. E. Occupational issues of allergic contact dermatitis. International Archives of Occupational and Environmental Health 2003, 76 (5), 347350.

3. Jost, B. C. Allergic Contact Dermatitis. In The Washington Manual Allergy, Asthma, and Immunology, 1 ed.; Jost, B. C., Abdel-Hamid, M. K., Friedman, E., Jani, A., Eds.; Lippincott Williams and Wilkins: Missouri, 2003; pp 74-76.

4. Kimber, I.; Maurer, T. Toxicology of Contact hypersensitivity; First ed.; Taylor \& Francis: London, 1996.

5. Karlberg, A. T.; Bergstrom, M. A.; Borge, A.; Luthman, K.; Nilsson, J. L. G. Allergic Contact Dermatitis—Formation, Structural Requirements, and Reactivity of Skin Sensitizers. 21 1, 53-69. Chemical research in Toxicology. 2008. 
6. Mathias, C. G.; Morrison, J. H. Occupational skin diseases, United States. Results from the Bureau of Labor Statistics Annual Survey of Occupational Injuries and Illnesses, 1973 through 1984. Arch. Dermatol. 1988, 124 (10), $1519-1524$.

7. Al-Tamrah, S. A. Colorimeteric Determination of p-Benzoquinone, Hydroquinone and Paracetamol. Arab Gulf J. Scient Res., Math, Phys, Sci 1988, $A 6$ (3), 363-375.

8. Cenas, N. K.; Pocius, A. K.; Kulys, J. J. Bioelectrocatalytic Conversion of Substances on Polymer-Modified Electrodes. Bioelectrochemistry and Bioenergetics 1984, 12 (5-6), 583-591.

9. Samsonova, L. V.; Nikiforov, G. A. Direct and Sensitized Photolysis of 1,4Benzoquinone Diazides in Organic-Solvents. Bulletin of the Academy of Sciences of the Ussr Division of Chemical Science 1984, 33 (5), 943-947.

10. Kim, S. B.; Cai, C.; Faust, M. D.; Trenkle, W. C.; Sweigart, D. A. A Water-Stable Organometallic Rhodium Quinone Catalyst and Its Recyclability. Organometallics 2009, 28 (8), 2625-2628.

11. Wester, R. C.; Melendres, J.; Hui, X. Y.; Cox, R.; Serranzana, S.; Zhai, H. B.; Quan, D. Y.; Maibach, H. I. Human in vivo and in vitro hydroquinone topical bioavailability, metabolism, and disposition. Journal of Toxicology and Environmental Health-Part A 1998, 54 (4), 301-317. 
12. De Capitani, E. M.; Vieira, R. J.; Bucaretchi, F.; Fernandes, L. C. R.; Toledo, A. S.; Camargo, A. C. Human accidents involving Rhinocricus spp., a common millipede genus observed in urban areas of Brazil. Clinical Toxicology 2011, 49 (3), 187-190.

13. Zhang, X. C.; Zwanziger, J. W. Design and applications of an in situ electrochemical NMR cell. Journal of Magnetic Resonance 2011, 208 (1), 136-147.

14. Katritzky, A. R.; Odens, H. H.; Voronkov, M. V. Rubber chemicals derived from conjugate addition. II. Synthesis of a novel class of benzoquinone diimines. Rubber Chemistry and Technology 2001, 74 (5), 927-945.

15. Li, L.; Lee, L. J. Effects of inhibitors and retarders on low temperature free radical crosslinking polymerization between styrene and vinyl ester resin. Polymer Engineering and Science 2001, 41 (1), 53-65.

16. Neeraja, V.; Nadh, R. V.; Sundar, B. S.; Radhakrishnamurti, P. S. Kinetic studies of thiocyanate and iodide oxidation with 2,6-dichloroquinone-4-chloroimide. A novel and a new oxidizing agent. Oxidation Communications 1998, 21 (3), 369-375.

17. Reszka, K.; Hartley, J. A.; Lown, J. W. Photosensitization by Selected Anticancer Agents. Biophysical Chemistry 1990, 35 (2-3), 313-323. 
18. Nguyen, B.; Gutierrez, P. L. Free-Radicals in Quinone-Containing Antitumor Agents - Enzymatic Redox Reactions of Mitoxantrone. Abstracts of Papers of the American Chemical Society 1989, 198, 15-MEDI.

19. Kwiek, J. J.; Haystead, T. A. J.; Rudolph, J. Kinetic mechanism of quinone oxidoreductase 2 and its inhibition by the antimalarial quinolines. Biochemistry 2004, 43 (15), 4538-4547.

20. Hansen, H. S.; Johansen, J. D.; Thyssen, J. P.; Linneberg, A.; Sosted, H. Personal use of Hair Dyes and Temporary Black Tattoos in Copenhagen Hairdressers. Annals of Occupational Hygiene 2010, 54 (4), 453-458.

21. Kneilling, M.; Caroli, U.; Grimmel, C.; Fischer, J.; Eichner, M.; Wieder, T.; Maier, F. C.; Rocken, M.; Biedermann, T. Para-phenylenediamine-specific lymphocyte activation test: a sensitive in vitro assay to detect paraphenylenediamine sensitization in patients with severe allergic reactions. Experimental Dermatology 2010, 19 (5), 435-441.

22. Gibbs; E.Don. Benzoquinone and hydroquinone derivatives for use as insect feeding deterrents. 5780515, Jul 1, 1998.

23. Abraham, I.; Joshi, R.; Pardasani, P.; Pardasani, R. T. Recent Advances in 1,4Benzoquinone Chemistry. Journal of the Brazilian Chemical Society 2011, $22(3), 385-421$. 
24. Basketter, D. A.; Blaikie, L.; Dearman, R. J.; Kimber, I.; Ryan, C. A.; Gerberick, G. F.; Harvey, P.; Evans, P.; White, I. R.; Rycroft, R. J. G. Use of the local lymph node assay for the estimation of relative contact allergenic potency. Contact Dermatitis 2000, 42 (6), 344-348.

25. Holmdahl, M.; Ahlfors, S. R.; Holmdahl, R.; Hansson, C. Structure-immune response relationships of hapten-modified collagen II peptides in a T-cell model of allergic contact dermatitis. Chemical Research in Toxicology 2008, 21 (8), 1514-1523.

26. Field, S.; O'Sullivan, C.; Bourke, J. F. Allergic Contact Dermatitis from N,NMethylenebismorpholine in a Cutting Oil. Dermatitis 2010, 21 (5), 292293.

27. Cruz, M. T.; Neves, B. M.; Goncalo, M.; Figueiredo, A.; Duarte, C. B.; Lopes, C. Effect of skin sensitizers on inducible nitric oxide synthase expression and nitric oxide production in skin dendritic cells: Role of different immunosuppressive drugs. Immunopharmacology and Immunotoxicology 2007, 29 (2), 225-241.

28. Fan, W.; Guo, L.; Tang, A.; Wan, Y. The pathogenesis role of Th1 and Th2 in ACD mouse models induced by DNFB and FITC. Journal of Investigative Dermatology 2005, 124 (4), A7. 
29. Riis, J. L.; Johansen, C.; Vestergaard, C.; Bech, R.; Kragballe, K.; Iversen, L. Kinetics and differential expression of the skin-related chemokines CCL27 and CCL17 in psoriasis, atopic dermatitis and allergic contact dermatitis. Experimental Dermatology 2011, 20 (10), 789-794.

30. Gad, S. C. The mouse ear swelling test (MEST) in the 1990s. Toxicology 1994, 93 (1), 33-46.

31. Magnusson, B.; Kligman, A. M. The identification of contact allergens by animal assay. The guinea pig maximization test. The Journal of investigative dermatology 1969, 52 (3), 268-276.

32. About the Interagency Coordinating Committee on the Validation of Alternative Methods (ICCVAM). http://iccvam. niehs. nih. gov/about/about_ICCVAM. htm 2011.

33. About ECVAM. http://ecvam. jrc. it/ 2011.

34. Worth, A. P.; Bassan, A.; De, B. J.; Gallegos, S. A.; Netzeva, T.; Patlewicz, G.; Pavan, M.; Tsakovska, I.; Eisenreich, S. The role of the European Chemicals Bureau in promoting the regulatory use of (Q)SAR methods. SAR QSAR Environ Res 2007, 18 (1-2), 111-125.

35. Herouet, C.; Cottin, M.; LeClaire, J.; Enk, A.; Rousset, F. Contact sensitizers specifically increase MHC class II expression on murine immature dendritic cells. In Vitr. Mol Toxicol 2000, 13 (2), 113-123. 
36. Ashikaga, T.; Hoya, M.; Itagaki, H.; Katsumura, Y.; Aiba, S. Evaluation of CD86 expression and MHC class II molecule internalization in THP-1 human monocyte cells as predictive endpoints for contact sensitizers. Toxicol In Vitro 2002, 16 (6), 711-716.

37. Vandebriel, R. J.; Van Och, F. M.; van, L. H. In vitro assessment of sensitizing activity of low molecular weight compounds. Toxicol Appl Pharmacol. 2005, 207 (2 Suppl), 142-148.

38. Gerberick, G. F.; Vassallo, J. D.; Bailey, R. E.; Chaney, J. G.; Morrall, S. W.; Lepoittevin, J. P. Development of a peptide reactivity assay for screening contact allergens. Toxicol. Sci. 2004, 81 (2), 332-343.

39. Maxwell, G.; Aeby, P.; Ashikaga, T.; Bessou-Touya, S.; Diembeck, W.; Gerberick, F.; Kern, P.; Marrec-Fairley, M.; Ovigne, J. M.; Sakaguchi, H.; Schroeder, K.; Tailhardat, M.; Teissier, S.; Winkler, P. Skin sensitisation: the Colipa strategy for developing and evaluating non-animal test methods for risk assessment. ALTEX. 2011, 28 (1), 50-55.

40. Aptula, A. O.; Roberts, D. W. Mechanistic applicability domains for nonanimalbased prediction of toxicological end points: general principles and application to reactive toxicity. Chem. Res. Toxicol. 2006, 19 (8), 10971105. 
41. Schultz, T. W.; Yarbrough, J. W.; Johnson, E. L. Structure-activity relationships for reactivity of carbonyl-containing compounds with glutathione. SAR QSAR Environ. Res. 2005, 16 (4), 313-322.

42. Schultz, T. W.; Carlson, R. E.; Cronin, M. T.; Hermens, J. L.; Johnson, R.; O'Brien, P. J.; Roberts, D. W.; Siraki, A.; Wallace, K. B.; Veith, G. D. A conceptual framework for predicting the toxicity of reactive chemicals: modeling soft electrophilicity. SAR QSAR Environ. Res. 2006, 17 (4), 413428.

43. Schwobel, J. A. H.; Koleva, Y. K.; Enoch, S. J.; Bajot, F.; Hewitt, M.; Madden, J. C.; Roberts, D. W.; Schutz, T. W.; Cronin, M. T. D. Measurement and Estimation of Electrophilic Reactivity for Predictive Toxicology. Chemical Reviews 2011, 111 (4), 2562-2596.

44. Divkovic, M.; Pease, C. K.; Gerberick, G. F.; Basketter, D. A. Hapten-protein binding: from theory to practical application in the in vitro prediction of skin sensitization. Contact Dermatitis 2005, 53 (4), 189-200.

45. Roberts, D. W.; Patlewicz, G.; Kern, P. S.; Gerberick, F.; Kimber, I.; Dearman, R. J.; Ryan, C. A.; Basketter, D. A.; Aptula, A. O. Mechanistic applicability domain classification of a local lymph node assay dataset for skin sensitization. Chem. Res. Toxicol. 2007, 20 (7), 1019-1030. 
46. Finley, K. T. Quinones. In Kirk-Othmer Encyclopedia of Chemical Technology, 4 th ed.; Kroschwitz, J. I., Ed.; John Wiley \& Sons: New York, 1996; Vol. 20, pp 799-830.

47. Kutyrev, A. A. Nucleophilic Reactions of Quinones. Tetrahedron 1991, 47 (38), 8043-8065.

48. Bolton, J. L.; Trush, M. A.; Penning, T. M.; Dryhurst, G.; Monks, T. J. Role of quinones in toxicology. Chemical Research in Toxicology 2000, 13 (3), 135-160.

49. Schultz, T. W.; Yarbrough, J. W.; Hunter, R. S.; Aptula, A. O. Verification of the structural alerts for Michael acceptors. Chemical Research in Toxicology 2007, 20 (9), 1359-1363.

50. Davies, K. J. A.; Pryor, W. A. The evolution of Free radical biology \& medicine: A 20-year history. Free Radical Biology and Medicine 2005, 39 (10), $1263-1264$.

51. Talupula, B. K. Cytotoxicity of PBN spin trap on A204 cells. Journal of Advanced Pharmaceutical Research 2011, 2 (1), 9-17.

52. Fukuzumi, S.; Nakanishi, I.; Maruta, J.; Yorisue, T.; Suenobu, T.; Itoh, S.; Arakawa, R.; Kadish, K. M. Formation of radical anions in the reaction of p-benzoquinone and C-60 with alkoxide ions. Journal of the American Chemical Society 1998, 120 (27), 6673-6680. 
53. Joshi, R.; Ghanty, T. K.; Mukherjee, T. Formation of semiquinone radical in the reaction of embelin (2,5-dihydroxy-3-undecyl-1,4-benzoquinone) with reductants as well as oxidants. Characterization by pulse radiolysis and structure investigation by quantum chemical study. Journal of Molecular Structure 2009, 928 (1-3), 46-53.

54. Mcconnell, H. M. Indirect Hyperfine Interactions in the Paramagnetic Resonance Spectra of Aromatic Free Radicals. Journal of Chemical Physics 1956, 24 (4), 764-766.

55. Rozeboom, M. D.; Tegmolarsson, I. M.; Houk, K. N. Frontier Molecular-Orbital Theory of Substituent Effects on Regioselectivities of Nucleophilic Additions and Cyclo-Additions to Benzoquinones and Naphthoquinones. Journal of Organic Chemistry 1981, 46 (11), 2338-2345.

56. Roberts, D. W.; Aptula, A. O.; Patlewicz, G. Electrophilic chemistry related to skin sensitization. Reaction mechanistic applicability domain classification for a published data set of 106 chemicals tested in the mouse local lymph node assay. Chem. Res. Toxicol. 2007, 20 (1), 44-60.

57. Chipinda, I.; Ajibola, R. O.; Morakinyo, M. K.; Ruwona, T. B.; Simoyi, R. H.; Siegel, P. D. Rapid and Simple Kinetics Screening Assay for Electrophilic Dermal Sensitizers Using Nitrobenzenethiol. Chem. Res. Toxicol. 2010, 23 (5), 918-925. 
58. Hi-Tech Scientific Operator's Manual for the SF-61 DX2 Double-Mixing Stopped-Flow Spectroflourimeter. 1997. Salisbury, UK, Hi-Tech Limited.

59. Mclauchlan, K. A. A Handbook of Nuclear Magnetic-Resonance - Freeman,R. Nature 1988, 331 (6153), 221.

60. Mills, N. S.; Shanklin, M. Access to NMR Spectroscopy for Two-Year College Students: The NMR Site at Trinity University. Journal of Chemical Education 2011, 88 (6), 835-839.

61. Gottlieb, H. E.; Kotlyar, V.; Nudelman, A. NMR chemical shifts of common laboratory solvents as trace impurities. Journal of Organic Chemistry 1997, 62 (21), 7512-7515.

62. Kleschyov, A. L.; Wenzel, P.; Munzel, T.; Analysis of the Electron paramagnetic resonance (EPR) spin trapping of biological nitric oxide. Journal of Chromatography B 2007, 851 (1-2), 12-20.

63. Banerjee, S.; Mazumdar, S. Electrospray Ionization Mass Spectrometry: A Technique to Access the Information beyond the Molecular Weight of the Analyte. International Journal of Analytical Chemistry 2011, 2012, 1-40.

64. Ho, C. S.; Lam, C. W.; Chan, M. H.; Cheung, R. C.; Law, L. K.; Lit, L. C.; Ng, K. F.; Suen, M. W.; Tai, H. L. Electrospray ionisation mass spectrometry: 
principles and clinical applications. The Clinical biochemist. Reviews / Australian Association of Clinical Biochemists 2003, 24 (1), 3-12.

65. Cronin, M. T.; Bajot, F.; Enoch, S. J.; Madden, J. C.; Roberts, D. W.; Schwobel, $\mathrm{J}$. The in chemico-in silico interface: challenges for integrating experimental and computational chemistry to identify toxicity. Altern. Lab Anim 2009, 37 (5), 513-521.

66. Schultz, T. W.; Rogers, K.; Aptula, A. O. Read-across to rank skin sensitization potential: subcategories for the Michael acceptor domain. Contact Dermatitis 2009, 60 (1), 21-31.

67. Perrin, D. D.; Dempsey, B.; Serjent.E.P. pKa Prediction for Organic Acids and Bases; First Edition ed.; Chapman and Hall, London and New York, 1981.

68. Haneke, K. E.; Tice, R. R.; Carson, B. L.; Margolin, B. H.; Stokes, W. S. ICCVAM evaluation of the murine local lymph node assay. Data analyses completed by the National Toxicology Program Interagency Center for the Evaluation of Alternative Toxicological Methods. Regul. Toxicol Pharmacol. 2001, 34 (3), 274-286.

69. Basketter, D. A.; Balikie, L.; Dearman, R. J.; Kimber, I.; Ryan, C. A.; Gerberick, G. F.; Harvey, P.; Evans, P.; White, I. R.; Rycroft, R. J. Use of the local lymph node assay for the estimation of relative contact allergenic potency. Contact Dermatitis 2000, 42 (6), 344-348. 
70. Kimber, I.; Dearman, R. J.; Basketter, D. A.; Ryan, C. A.; Gerberick, G. F. The local lymph node assay: past, present and future. Contact Dermatitis 2002, $47(6), 315-328$.

71. Basketter, D. A.; Lea, L. J.; Dickens, A.; Briggs, D.; Pate, I.; Dearman, R. J.; Kimber, I. A comparison of statistical approaches to the derivation of EC3 values from local lymph node assay dose responses. J. Appl. Toxicol. 1999, $19(4), 261-266$.

72. Dearden, J. C. In silico prediction of ADMET properties How far have we come? Expert Opinion on Drug Metabolism \& Toxicology 2007, 3 (5), 635-639.

73. Gurevitch, J. Sigma-Plot - Scientific Graphing Software. Quarterly Review of Biology 1991, 66 (1), 115-116.

74. Christensson, J. B.; Matura, M.; Backtorp, C.; Borje, A.; Nilsson, J. L. G.; Karlberg, A. T. Hydroperoxides form specific antigens in contact allergy. Contact Dermatitis 2006, 55 (4), 230-237.

75. Spasojevic, I. Electron Paramagnetic Resonance - A Powerful Tool of Medical Biochemistry in Discovering Mechanisms of Disease and Treatment Prospects. Journal of Medical Biochemistry 2010, 29 (3), 175-188.

76. Chipinda, I.; Ajibola, R. O.; Morakinyo, M. K.; Ruwona, T. B.; Simoyi, R. H.; Siegel, P. D. Rapid and Simple Kinetics Screening Assay for Electrophilic 
Dermal Sensitizers Using Nitrobenzenethiol. Chemical Research in Toxicology 2010, 23 (5), 918-925.

77. Davies, K. J. A. The evolution of Free Radical Biology \& Medicine Still radical after a quarter of a century. Free Radical Biology and Medicine 2010, 49 (12), 1825-1833.

78. Valgimigli, L.; Amorati, R.; Fumo, M. G.; DiLabio, G. A.; Pedulli, G. F.; Ingold, K. U.; Pratt, D. A. The unusual reaction of semiquinone radicals with molecular oxygen. Journal of Organic Chemistry 2008, 73 (5), 18301841.

79. Shinde, S. S.; Hay, M. P.; Patterson, A. V.; Denny, W. A.; Anderson, R. F. Spin Trapping of Radicals Other Than the (center dot)OH Radical upon Reduction of the Anticancer Agent Tirapazamine by Cytochrome P(450) Reductase. Journal of the American Chemical Society 2009, 131 (40), $14220-+$

80. Roberts, D. W.; Patlewicz, G.; Kern, P. S.; Gerberick, F.; Kimber, I.; Dearman, R. J.; Ryan, C. A.; Basketter, D. A.; Aptula, A. O. Mechanistic applicability domain classification of a local lymph node assay dataset for skin sensitization. Chemical Research in Toxicology 2007, 20 (7), 1019-1030.

81. Yu, P.; Strug, I.; Cafarella, T. R.; Seaton, B. A.; Krantz, A. Site-specific crosslinking of annexin proteins by 1,4-benzoquinone: a novel crosslinker 
for the formation of protein dimers and diverse protein conjugates. Org. Biomol. Chem. 2012, 10 (23), 4500-4504.

82. Chan, K.; Jensen, N.; O'Brien, P. J. Structure-activity relationships for thiol reactivity and rat or human hepatocyte toxicity induced by substituted pbenzoquinone compounds. J. Appl. Toxicol. 2008, 28 (5), 608-620.

83. Smith, P. A.; Bowerbank, C. R.; Savage, P. B.; Drown, D. B.; Lee, M. L.; Alexander, W.; Jederberg, W. W.; Still, K. Conjugation of 7oxodehydroabietic acid to lysine, a haptenation mechanism for an oxidized resin acid with dermal sensitizing properties. Applied Occupational and Environmental Hygiene 1999, 3, 171-176.

84. Gerberick, G. F.; Vassallo, J. D.; Foertsch, L. M.; Price, B. B.; Chaney, J. G.; Lepoittevin, J. P. Quantification of chemical peptide reactivity for screening contact allergens: A classification tree lmodel approach. Toxicological Sciences 2007, 97 (2), 417-427.

85. Enoch, S. J.; Cronin, M. T. D.; Schultz, T. W.; Madden, J. C. Quantitative and mechanistic read across for predicting the skin sensitization potential of alkenes acting via Michael addition. Chemical research in toxicology 2008, 21 (2), 513-520. 
86. Karlberg, A. T.; Bergstrom, M. A.; Borje, A.; Luthman, K.; Nilsson, J. L. G. Allergic contact dermatitis-formation, structural requirements, and reactivity of skin sensitizers. Chem. Res. Toxicol. 2008, 21 (1), 53-69.

87. Song, Y.; Buettner, G. R.; Parkin, S.; Wagner, B. A.; Robertson, L. W.; Lehmler, H. J. Chlorination Increases the Persistence of Semiquinone Free Radicals Derived from Polychlorinated Biphenyl Hydroquinones and Quinones. Journal of Organic Chemistry 2008, 73 (21), 8296-8304.

88. Landsteiner, K.; Jacobs, J. STUDIES ON THE SENSITIZATION OF ANIMALS WITH SIMPLE CHEMICAL COMPOUNDS. II. J. Exp. Med. 1936, 64 (4), 625-639.

89. Basketter, D. A.; Balikie, L.; Dearman, R. J.; Kimber, I.; Ryan, C. A.; Gerberick, G. F.; Harvey, P.; Evans, P.; White, I. R.; Rycroft, R. J. Use of the local lymph node assay for the estimation of relative contact allergenic potency. Contact Dermatitis 2000, 42 (6), 344-348.

90. Standard Practice for Testing Guinea Pigs for Contact Allergens: Guinea Pig Maximization Test. F 720 - 81. 2002. West Conshohocken, American Society for Testing and Materials.

91. Roberts, D. W.; Aptula, A. O.; Patlewicz, G. Electrophilic chemistry related to skin sensitization. Reaction mechanistic applicability domain classification for a published data set of 106 chemicals tested in the mouse local lymph node assay. Chem. Res. Toxicol. 2007, 20 (1), 44-60. 
92. Roberts, D. W.; Aptula, A. O.; Patlewicz, G. Y. Chemistry-Based Risk Assessment for Skin Sensitization: Quantitative Mechanistic Modeling for the SNAr Domain. Chem. Res. Toxicol. 2011, 24 (7), 1003-1011.

93. Roberts, D. W.; Aptula, A. O. Does the extreme skin sensitization potency of benzoquinone result from special chemistry? Contact Dermatitis 2009, 61 (6), 332-336.

94. ECETOC . Contact sensitisation: classification according to potency: a commentary. Document No. 43. 2003. Brussels, Belgium, European Centre for Ecotoxicology and Toxicology of Chemicals.

95. Mbiya, W.; Chipinda, I.; Siegel, P. D.; Mhike, M.; Simoyi, R. H. Substituent Effects on the Reactivity of Benzoquinone Derivatives with Thiols. Chem. Res. Toxicol. 2012, 26 (1), 112-123.

96. Perrin, D. D.; Dempsey, B.; Serjent.E.P. pKa Prediction for Organic Acids and Bases; First Edition ed.; Chapman and Hall, London and New York, 1981.

97. Roberts, D. W.; Aptula, A. O.; Patlewicz, G. Y. Chemistry-Based Risk Assessment for Skin Sensitization: Quantitative Mechanistic Modeling for the SNAr Domain. Chemical Research in Toxicology 2011, 24 (7), 10031011.

98. Aptula, A. O.; Roberts, D. W. Mechanistic applicability domains for nonanimalbased prediction of toxicological end points: General principles and 
application to reactive toxicity. Chem. Res. Toxicol. 2006, 19 (8), 10971105.

99. Roberts, D. W. Linear Free-Energy Relationships for Reactions of Electrophilic Halobenzenes and Pseudohalobenzenes, and Their Application in Prediction of Skin Sensitization Potential for Snar Electrophiles. Chem. Res. Toxicol. 1995, 8 (4), 545-551.

100. Roberts, D. W.; Aptula, A. O. Determinants of skin sensitisation potential. Journal of Applied Toxicology 2008, 28 (3), 377-387.

101. Kapungu, G. P.; Rukweza, G.; Tran, T.; Mbiya, W.; Adigun, R.; Ndungu, P.; Martincigh, B.; Simoyi, R. H. OxyhalogenGÇôSulfur Chemistry: Kinetics and Mechanism of Oxidation of Captopril by Acidified Bromate and Aqueous Bromine. J. Phys. Chem. A 2013.

102. Roberts, D. W.; Natsch, A. High Throughput Kinetic Profiling Approach for Covalent Binding to Peptides: Application to Skin Sensitization Potency of Michael Acceptor Electrophiles. Chem. Res. Toxicol. 2009, 22 (3), $592-$ 603.

103. Lee, B. J.; Park, S. I.; Park, J. M.; Chittum, H. S.; Hatfield, D. L. Molecular biology of selenium and its role in human health. Molecules and Cells 1996, 6 (5), 509-520. 
104. Bauch, C.; Kolle, S. N.; Ramirez, T.; Eltze, T.; Fabian, E.; Mehling, A.; Teubner, W.; van Ravenzwaay, B.; Landsiedel, R. Putting the parts together: Combining in vitro methods to test for skin sensitizing potentials. Regulatory Toxicology and Pharmacology 2012, 63 (3), 489-504. 